Portland State University

PDXScholar

\title{
The Importance of Online Peer Relationships During the Transition to Motherhood: Do They Decrease Stress, Alleviate Depression and Increase Parenting Competence?
}

Bobbie Sue Arias

Portland State University

Follow this and additional works at: https://pdxscholar.library.pdx.edu/open_access_etds

Part of the Social Media Commons, and the Social Work Commons Let us know how access to this document benefits you.

\section{Recommended Citation}

Arias, Bobbie Sue, "The Importance of Online Peer Relationships During the Transition to Motherhood: Do They Decrease Stress, Alleviate Depression and Increase Parenting Competence?" (2016). Dissertations and Theses. Paper 2946.

https://doi.org/10.15760/etd.2941

This Dissertation is brought to you for free and open access. It has been accepted for inclusion in Dissertations and Theses by an authorized administrator of PDXScholar. Please contact us if we can make this document more accessible: pdxscholar@pdx.edu. 
The Importance of Online Peer Relationships During the Transition to Motherhood: Do They Decrease Stress, Alleviate Depression and Increase Parenting Competence?

by

Bobbie Sue Arias

A dissertation submitted in partial fulfillment of the requirements for the degree of

\author{
Doctor of Philosophy \\ in \\ Social Work and Social Research
}

\author{
Dissertation Committee: \\ Eileen Brennan, Chair \\ Joan Shireman \\ Thomas Keller \\ Sherwin Davidson
}

Portland State University

2016 
(C) 2016 Bobbie Sue Arias 


\begin{abstract}
This research addressed the challenges faced by women in today's society during the transition to motherhood, and explored the possible benefits of an online natural helping network of blogging peers. Given the content of the literature describing the transition to motherhood and the many hardships that pose possible obstacles for an ideal transition, this research attempted to uncover the reasons why mothers blog and what benefit, if any, they experience as a result of blogging. This study explored the following questions: Why do women blog during the transition to motherhood? What is the relationship among the seven identified variables: blogging intensity, authentic selfdisclosure, perceived general social support, perceived social support from blogging, current depression, stress, and parenting competence?
\end{abstract}

This dissertation employed a cross-sectional research design using a web-based survey. The data were trimmed to limit the participants to residents/citizens of the United States and mothers of preschool aged (0-5) children who lived with them four or more days per week. The data were further limited to include only those participants $(N=501)$ who completed the survey in its entirety. New mothers experienced benefits as a result of their authentic participation in blogging and reported key reasons that they participated including: to share their experiences with others, to preserve their memories, to interact with a like-minded audience, and to feel understood. There were significant positive correlations between authentic self-disclosure and perceived social support, and sense of parenting competency, and a negative relationship between authentic self-disclosure and 
maternal depression and perceived stress. Multiple regression analysis indicated that social support was the strongest predictor of current depression. Social support was also a predictor of stress and of perceived parenting competence. Additionally, social support significantly predicted authentic self-disclosure. With a growing reliance on technology and social media, social work has an obligation to identify and utilize the beneficial aspects of this medium. 


\section{Dedication}

To my beloved family. A special thank you to my husband, Charlie, for supporting me in this endeavor. To my dearest Andrew, Sofia and Joseph: you have been my abiding joy and constant distraction. Being your mother has made me a better person. And to the elder women in my life: Bonnie and Cledia, my mother and mother-in-law. Were it not for your willingness to help with dishes, laundry, childcare, dinners and transportation, I would have never been able to complete my degree. Bonnie, you have been a champion cheerleader. Your unwavering belief in me compels me to soar higher, try harder and achieve more. You are a wonderful mother. 


\section{Acknowledgments}

I would like to acknowledge and thank my Dissertation Committee members: Dr. Eileen Brennan-Chair, Dr. Joan Shireman, Dr. Sherwin Davidson, and Dr. Thomas Keller. I will always remember and appreciate your patience and willingness to remain involved in this process with me, in spite of setbacks and many years of delays. I would especially like to express my deep gratitude to Dr. Eileen Brennan for her continued support, enthusiasm for my research and patient guidance. She gently prodded me forward with a perfect blend of kindness and pragmatic goal setting. She inspired me, motivated me and sometimes, necessarily, put the fear of God in me. I would also like to acknowledge Dr. Joan Shireman for her warmth and generosity as my Advisor. She provided me the first words of encouragement in this process and has continued to cheer me on, even into her retirement. To Dr. Thomas Keller for his patience and expertise in helping me conceptualize the analysis and continued commitment to this project. And to Dr. Sherwin Davidson for her eagerness to participate in my committee and her willingness to see this process through to completion.

This research would not have been possible without the blogging community, of which I accidentally, but happily, found myself a part. Particular thanks to those bloggers who agreed to publicize my research link: your beautiful writing, large audience and enthusiastic participation in the blogosphere was invaluable to the collection of this data. Also to those parent bloggers who took time out of their busy lives to complete my survey: thank you. You were some of the first to contribute to what will likely be a growing body of research and knowledge about participation in the virtual world. 
Table of Contents

Page

$\begin{array}{lr}\text { Abstract } & \text { i } \\ \text { Dedication } & \text { iii } \\ \text { Acknowledgments } & \text { iv } \\ \text { List of Tables } & \text { viii } \\ \text { List of Figures } & \text { ix }\end{array}$

Chapter One: Introduction 1

Chapter Two: Literature Review 5

Theoretical Framework: Self-in-Relation Model 5

Changes in Society and the Transition to Motherhood 8

Social Support and Relationships $\quad 11$

$\begin{array}{ll}\text { Partner Support } & 11\end{array}$

$\begin{array}{ll}\text { Peer Support } & 12\end{array}$

Mother-Mentor Support $\quad 13$

$\begin{array}{lr}\text { Stress } & 18\end{array}$

$\begin{array}{ll}\text { Transition to Motherhood } & 18\end{array}$

Work and Family 20

How Women Handle Stress 24

$\begin{array}{ll}\text { Women and Depression } & 28\end{array}$

Perceived Parenting Competence $\quad 37$

$\begin{array}{ll}\text { Literature Summary } & 40\end{array}$

Chapter Three: The Virtual Natural Helping Network 42

The Online Journal: Weblog 43

Narrating a Life $\quad 46$

Network of Mothers: Building a Peer Support Network 50

Chapter Four: Research Questions 53

Major Concepts $\quad 53$

Research Questions $\quad 57$

Question One: Why Do Women Blog During the Transition to 58 Motherhood?

Question Two: What is the Relationship Among the Seven 59 Identified Variables?

Question Three: What are the Strongest Predictors of Stress 59

Level, Current Depression, and Perceived Parenting

Competence? 
Chapter Five: Methodology $\quad 61$

$\begin{array}{ll}\text { Procedure } & 61\end{array}$

Pilot Testing $\quad 62$

\begin{tabular}{ll} 
Participants & 63 \\
\hline
\end{tabular}

$\begin{array}{ll}\text { Measurement } & 67\end{array}$

Participant and Household Characteristics $\quad 67$

Blogging Motivation $\quad 68$

Blogging Intensity $\quad 69$

Authenticity in Self-disclosure $\quad 69$

$\begin{array}{ll}\text { Perceived Social Support } & 70\end{array}$

Stress $\quad 71$

$\begin{array}{ll}\text { Current Depression } & 71\end{array}$

Perceived Parenting Competence $\quad 72$

Chapter Six: Results $\quad 73$

Blogging Behavior $\quad 75$

Question One: Why Do Women Blog During the Transition to 79

Motherhood?

Question Two: What is the Relationship Among the Seven 83

Identified Variables?

Question Three: What are the Strongest Predictors of Stress 87

Level, Current Depression, and Perceived Parenting Competence?

Chapter Seven: Discussion $\quad 90$

Summary of Findings: Implications by Research Question \& Variable $\quad 90$

Why Do Women Blog During the Transition to Motherhood? 90

What is the Relationship Among the Seven Identified

Variables? $\quad 91$

Blogging Intensity 92

Authenticity in Self-Disclosure $\quad 94$

Social Support $\quad 94$

Stress $\quad 96$

Depression 96

Perceived Parenting Competence 97

Implications for Social Work Practice 98

Implications for Policy $\quad 99$

Implications for Future Research 99

Limitations $\quad 100$

$\begin{array}{ll}\text { Conclusion } & 101\end{array}$

$\begin{array}{ll}\text { References } & 103\end{array}$ 


\section{Appendices}

Appendix A: Introduction Letter

Appendix B: Informed Consent

Appendix C: Blog Relationships Survey 


\section{List of Tables}

Table

Page

$1 \quad$ Participant Characteristics $\quad 64$

2 Mothers' Report Proportion of Household Chores and Childcare 66 Responsibility

3 Preschooler Child Descriptors-Age 66

$4 \quad$ Preschooler Child Descriptors-Relationship to Mother 67

$5 \quad$ Psychometric Properties for Major Research Variables 74

$\begin{array}{lll}6 & \text { Blogging Behavior } & 76\end{array}$

$\begin{array}{lll}7 & \text { Blogging Social Behavior } & 78\end{array}$

$8 \quad$ Frequency of Writing and Reading Blogs 79

$9 \quad$ Hours Spent Writing and Reading Blogs 80

10 Rank Order and Mean Score of Blog Motivation: Why Do You Blog? 81

11 Correlation Matrix of Blogging Intensity Index Variables 84

12 Correlation Matrix of Research Variables 85

13 Summary of Multiple Regression Analysis for Variables Predicting 87 Stress

14 Summary of Multiple Regression Analysis for Variables Predicting $\quad 88$ Depression

15 Summary of Multiple Regression Analysis for Variables Predicting 89 Perceived Parenting Competence 


\section{List of Figures}

Figure

1 Variable Flow Chart
Page

58 


\section{Chapter One: Introduction}

This research was born of the author's interest and participation in the blogging community over the course of several years, beginning in 2006. With three preschool children, blogging became a way to connect with other mothers in a way that a busy professional and family life did not allow in real life. It began with an internet search about potty-training and the subsequent visit to a then-popular blog, written by a mother of young children, who provided insight, humor and honesty about the trials of motherhood.

Over a short time, this author developed relationships with several bloggers through blog comments and follow-up emails. Soon, this author was officially introduced by one of the bloggers. This entailed a warm, welcoming, introductory blog post by another mommy blogger with a hyper link and invitation to her readers to visit this author's blog. Over the course of three years, this author participated in an active online community of mothers. During that time, there was an upsurge in interest by advertising agencies to harness the popularity and influential power of several bloggers. This author participated in a parent bloggers network that was among that very first to test emerging social media sites such as Twitter and Facebook. Participation in blogging, and what would eventually be called "social media," sparked an interest in the potential benefits of this modern community of women.

Beyond personal experience with the topic, interest in the benefits of blogging was squarely rooted in this author's many years of crisis-oriented work with families in a small, rural town. Most of this work was with single, impoverished, isolated mothers who 
were clinically depressed and at the end of their rope. Many were suicidal. It follows that the sum of personal and professional experiences influenced, and arguably biased, this research.

Technology has become an ever-increasing presence in mainstream society as we are well into the 21 st century. Technological advances ushered in the age of the World Wide Web and the Internet. At the time of this research, it was estimated (Horrigan, 2001) that up to $75 \%$ of U.S. residents had access to the Internet and were considered "connected." Access and utilization of the Internet has steadily increased and is currently estimated to include $85 \%$ of American women, with some groups (e.g., young adults, 97\%) at near saturation (Perrin \& Duggan, 2015).

Those who are connected have access to vast amounts of information, are capable of easily communicating with people (even on the other side of the world), and can meet someone online to play computer games, share ideas, exchange information, and engage in a relationship. Those millions of people who are connected on the Internet have become accustomed to using it for just about everything; it is part of their lives (Fallows, 2004; S. Fox \& Rainie, 2014; Horrigan \& Rainie, 2002; Perrin \& Duggan, 2015). Additionally, $65 \%$ of adults now use social networking sites, a nearly ten-fold increase over the past decade (Perrin, 2015).

Because so many people are connected, many business and organizations have incorporated the use of websites in order to have a presence on the Web. In fact, individuals can do their banking, buy their groceries, order their prescriptions, and shop for clothes ... without ever leaving their home. 
Just as people are accessing the Internet for goods and services, they are also turning to the Web seeking help in times of emotional pain and personal suffering. Accordingly, the need for helping professionals to be available and maintain a presence on the Internet is becoming more crucial. The field of psychology has begun to incorporate such things as e-therapy into practice (Mantovani, Castelnuovo, Gaggioli, \& Riva, 2003), and the medical field has incorporated the use of online support groups for patients with cancer (Lieberman \& Goldstein, 2006) and other illnesses (Coulson, 2005). Clinical social work, counseling, and psychotherapy utilize online interventions in a variety of ways. Sessions are conducted using a web-cam, email, or chat programs. Some modalities are less conducive to the format (behavioral therapy) and some presenting problems are less responsive to online treatment (weight loss) but, overall, cyber therapy demonstrated nearly equivalent success rates as face-to-face therapeutic interventions (Barak, Hen, Boniel-Nissim, \& Shapira, 2008; Knaevelsrud \& Maercker, 2007). Recognizing the need for technology to meet the needs of underserved populations, social workers embraced the use of such things as email, information websites, online advocacy, and online support groups for serving client populations. This dissertation investigates yet another way in which social work could have a meaningful presence online among an underserved population, women who are transitioning into motherhood.

This research focuses on the possible challenges faced by women who are transitioning into motherhood. First, the theoretical framework of self-in-relation is introduced, followed by a description of changes in society, and the transition to 
motherhood. Next, social support and relationships are examined, followed by a discussion of stress, depression, and perceived parenting competence during the transition to motherhood.

In light of this study's examination of the importance of social support during the transition to motherhood, a great deal of attention is paid to a natural helping network, the online community of mothers who are recording the happenings of their lives in virtual diaries (otherwise known as blogs) while nurturing relationships with other mothers. This online community, or blogosphere, is further described as a potentially beneficial resource for first-time mothers. The aim of this research is to explore the social support that may be experienced through blogging and whether that social support is related to levels of depression, stress, and perceived parenting competence. Next, a description of the research questions and methodology is followed by presentation of the study results. Finally, a discussion of the implications of the study for the field of Social Work is provided. 


\section{Chapter Two: Literature Review}

\section{Theoretical Framework: Self-in Relation Model}

The transition to parenthood is a developmental milestone that most adults will achieve. For the most part, parenthood is looked forward to with great joy and anticipation. Both men and women hold expectations of what the passage into parenthood will entail. For many, thoughts of bouncing the newborn baby on their lap, hugging a child close, and anticipating their child's laughter is the one thing they look forward to above all others. Certainly women, as a function of our biology and socialization, are prone to idealized and romanticized images of what motherhood will hold. Among other things, joy and fulfillment are recognized as two of the most anticipated outcomes of becoming a mother (Higgins, 1989; Wolf, 2003).

However, just as transitioning into adolescence or adulthood holds unique challenges and difficulties, transitioning into parenthood is a complicated evolution fraught with life-altering changes (Cavanaugh \& Blanchard-Fields, 2002). While both men and women experience difficulties during the transition to parenthood, this transition may be particularly challenging for women, for myriad reasons (Arendell, 2000;

Goldstein, Diener, \& Mangelsdorf, 1996; Nordenmark, 2004).

From the Self-in-Relation Model of development for women, women are recognized as having a more interdependent and relationship-dependent orientation compared with men (Carr, Gilroy, \& Sherman, 1996; Miller, 1976). One of the strongest predictors for women's depression is the lack of a supportive and understanding 
relationship. Women who do not have a supportive intimate relationship are much more likely to experience depression (Carr et al., 1996).

A woman's intimate connections organize and sustain her sense of self. When intimate relationships fail or are not reciprocal, a woman feels a sense of failure and loss of self. Societal standards for being a "good mother" and a "good wife" require a great deal of emotional investment. These ideals of the feminine mystique (Friedan, 1963) are unattainable and arguably mythical in nature. While a woman may give everything she has in order to attain these standards, she will always fall short. When a woman gives everything she has to her partner and children and then finds those relationships unsupportive or one-sided, she may feel like a failure as a woman. She quiets her feelings of anger and despair to put on the face society wants to see. The depressed woman who is not validated in her intimate relationships may feel disconnected, helpless, and hopeless (Carr et al., 1996).

The Self-in Relation Model essentially asserts that a woman is the sum of her relationships. Women have been described as having a great need for affiliation and developing their psychological attributes as a consequence of their social connections (Miller, 1976). Research suggests that relationships are extremely important to a woman; some would argue that while both men and women are relational beings, relationships are more crucial to a woman's sense of self and identity formation than they are to men (Coy \& Kovacs-Long, 2005).

Self-in Relation with its emphasis on social connection and affiliation has been used as a model by which to explain the primary importance of a woman's relationship to 
her own mother in terms of gender role identification and as the leading influence on her ultimate values, beliefs, and opinions (Andersen, Chen, \& Miranda, 2002; Chodorow, 1978; G. Fox, 1980; Miller, 1976; Surrey, 1985). Intimate relationships with friends and mentors and strong community associations are also important connections that help to shape a woman's sense of self (Liang et al., 2002).

A woman uses her relationships much like a mirror. She shapes her opinion of herself based upon how others respond to her or make her feel. She also shapes how she behaves and interacts in her relationships based to some degree on how she expects her partner to respond (Murray \& Holmes, 1999; Surrey, 1983). Positive outcomes are associated with the degree to which her important, mutually supportive relationships make her feel empowered (Alvarez \& Lazzari, 2016) and foster a sense of engagement and comfort in authentic disclosure (Liang et al., 2002). Moreover, women may base their moral reasoning (during times of conflict) on caring for and preserving their relationships rather than winning (Gilligan, 1982). A woman is not just a solitary individual; in many ways, she is a tapestry comprised of her interactions and relationships with others (Chodorow, 2011).

Major transitions in a woman's development may demand a greater need for, or reliance upon, significant relationships. She may be more likely to accept social support from her network of relationships, if she understands the supporter to be similar to herself in terms of values and circumstances. In addition to more readily accepting "peer" support, her self-concept is associated with the degree to which she feels empowered, 
engaged, and willing to use authentic self-disclosure in her relationships (Liang et al., 2002).

It is within the framework of Self-in-Relation that each of the variables in this research is discussed. The underlying assumption of women's desire for relationship, connection and affiliation in forming identity as well as easing major developmental transitions forms the foundation for this exploratory inquiry.

\section{Changes in Society and the Transition to Motherhood}

The American family has undergone tremendous changes over the past few decades. These changes have been affected by changes in social climate, economic climate, and societal values. According to current household data (Child Trends Databank, 2015) for American children (aged 18 and younger) fully 64.7\% live with two married parents. Another $23.1 \%$ live with their mothers only, while $6.7 \%$ live with grandparents, and 3.7\% live in father-only households. In households of married parents, both parents tend to be college-educated with either some college (men $=24.0 \%$; women $=26.1 \%)$ or a bachelor's degree or higher $(\mathrm{men}=40.3 \%$; women $=44.0 \%)$. Additionally, in married households both parents are generally employed (60.2\%) with an annual household income, specified individually by gender, of $\$ 30,000-74,999$ (men $=42.8 \%$; women $=30.1 \%)$ or above $\$ 75,000($ men $=31.4 \%$; women $=9.8 \%)$.

Americans have more formal education, work longer hours, and marry and start families later than in previous decades. Women work more outside of the home and achieve higher levels of education while using more outside childcare for their children. 
Fathers are also more valued for their input in child rearing and maintaining the home (Bianchi, 2011; Bianchi \& Casper, 2000).

The American family, particularly the roles that men and women play, is steeped in tradition. Gender is a social context in which men and women occupy different roles. Femininity is considered a female trait that denotes nurturing, caring, childbearing, and rearing. The male trait of masculinity promotes the notion that men are strong, protective providers for their dependent wives and children. The traditional family is composed of a supportive wife who cares for and nurtures her children at home while the husband blazes a successful trail in the working world. This traditional family was socially constructed to promote successful child rearing and to ensure survival of the species. In the modern world, the reality of the composition of a family has changed dramatically, but the idealized roles of men and women remain very much the same (Coontz, 1992; HareMustin, 1988).

Although many of a woman's desires, ambitions, and career expectations have changed, society's expectation of her role as wife and mother has not (Cha, 2014; Douglas \& Michaels, 2004; Stevens, Kiger, \& Riley, 2001). During the transition to motherhood, a woman may find that her workload increases sharply in comparison to that of her male partner (Yavorsky, Kamp Dush, \& Schoppe-Sullivan, 2015). Which may cause her to feel a sense of unfairness or increased stress (Offer \& Schneider, 2011; Yavorsky et al., 2015).

In spite of the social definitions of gender roles, women have made huge strides over the past decades by breaking into the professions and careers previously held 
exclusively by men. This has been and continues to be a struggle for women. Many of the careers women occupy give little to no accommodation for women who want to become mothers. Women, who have come to love their careers and success, more often than not, must choose: family or career (Arendell, 2000; Crittenden, 2001; Kotila, SchoppeSullivan, \& Kamp Dush, 2013; Williams \& Cooper, 2004; Yavorsky et al., 2015).

Given the fact that women enjoy many more career opportunities and individual freedoms than in times past, choosing motherhood can be a difficult transition. In the past, a woman may have grown up expecting to ultimately devote herself to the raising of children and keeping her house. Today, the transition to motherhood may be more difficult for women whose modern expectations include a vigorous career and upward mobility. If a woman chooses to continue her career, she may find many obstacles to balancing work and home (Arendell, 2000; Crittenden, 2001; Douglas \& Michaels, 2004; Maushart, 1999; Williams \& Cooper, 2004; Wolf, 2003).

Well-being is an indicator of how people evaluate their lives. People tend to evaluate their lives in terms of life satisfaction, marital satisfaction, the experience of pleasant emotion (such as joy), and the lack of unpleasant emotions (such as those associated with depression). In the simplest of terms, well-being refers to happiness (Diener, 1984; Diener, Suh, \& Oishi, 1997). For a woman in particular, her sense of wellbeing is dependent upon the quality of her relationships. Social support and her marital partnership may be of particular importance during the transition to motherhood (McDaniel, Coyne, \& Holmes, 2012). 


\section{Social Support and Relationships}

Partner support. There is another often unspoken accommodation a woman must make during the transition to first-time parenthood. Whatever her expectations, a woman may learn that the underlying cultural definitions of gender roles come to the forefront in her own marital partnership. She, more often than not, discovers that she is responsible for the majority of the tasks and chores associated with motherhood (Arendell, 2000; Crittenden, 2001; Douglas \& Michaels, 2004; Maushart, 1999; Wolf, 2003; Young, Wallace, \& Polachek, 2013).

Women who work outside the home remain responsible for housework and childrearing. Most household chores are delegated to the woman, regardless of how many hours she has spent in the workforce. She may work an hour or more per day than her husband and up to three more weeks per year (Arendell, 2000; Hare-Mustin, 1988; Offer \& Schneider, 2011; Strazdins, Galligan, \& Scannell, 1997; Williams \& Cooper, 2004; Yavorsky et al., 2015).

While we have experienced significant changes in our society, much of our ideology in raising a family has stayed the same. Although we have shifted our focus on child-rearing to include the necessity of a father's practical and emotional input, women still shoulder a great deal of the child-rearing responsibilities (Arendell, 2000; Goldberg \& Perry-Jenkins, 2004; Raley, Bianchi, \& Wang, 2012).

Feeling support in parenting efforts is significantly correlated with marital satisfaction. Being acknowledged and praised by one's spouse for parenting efforts increases relationship and marital satisfaction. Women tend to be forgiving of the 
inequality of shared parenting when their husbands participate in family-oriented activities, are willing to help out when necessary, and are explicitly supportive of their efforts as wives, mothers, and workers (Ehrenberg, Gearing-Small, Hunter, \& Small, 2001; McDaniel et al., 2012).

Undeniably filled with moments of intense joy, the demands of raising young, dependent children take their toll on mothers. While having adult children increases levels of subjective well-being for women, having young, dependent children living in the home negatively affects their levels of subjective well-being; the opposite of which is true for fathers (Shields \& Wooden, 2003). Mothers experience high levels of demands from their children, particularly young children, but report similar levels of quality of child relationship to those of fathers. Mothers experience a decrease in the demands children make on them as the children age. For both parents, the quality of their relationship with their children has a positive impact on their well-being. Furthermore, the demands made by children do not detract from this increase in the overall well-being (Shields \& Wooden, 2003). Although mothers commonly experience a dip in subjective well-being while raising young children, the quality of their relationship with their children and partner appear to be a buffer against lowered levels of subjective well-being (Nelson, Kushlev, \& Lyubomirsky, 2014; Umberson, 1989).

Peer support. Mothering is hard work. In many cultures the concept of mothering as a community undertaking is well established. Many hands, particularly the hands of other mothers, make for a lighter work load. From the time of giving birth through the rearing of children, women who feel the support of other women fare better. Mothering 
was not meant to take place in the isolation of our separate homes, but in the company of our family members and other helpers. Women who are mothers need both emotional and practical support in their endeavors to rear children (Coontz, 1992: Short, Goldscheider, \& Torr, 2006). In the U.S. women have made efforts to create this sanctuary of support through developing mommy-groups and other support groups, particularly when the help of their extended family is unavailable or when they feel isolated. A mother needs other women who provide her strong, quality support, particularly when she is the mother of young children (Wolf, 2003).

When mothers have strong social support, they raise children who are more likely to be securely attached, especially when their children have a difficult temperament (Karen, 1994). Women who have strong identity development in mid-life are more likely to have a sense of well-being (Martire, Stephens, \& Townsend, 2000). The quality of their roles rather than the number of roles correlates with levels of well-being (Vandewater, Ostrove, \& Stewart, 1997). The significant predictor of life satisfaction in middle-aged adults is the presence of loving relationships in their lives. This may suggest that it is developmentally appropriate to value relationships at this stage in life, while men and women are likely building families and raising children (Isaacowitz, Vaillant, \& Seligman, 2003). Based on the research of the benefits of social support for women, it appears overwhelmingly evident that a mother's level of well-being is inextricably linked to the quality of her relationships (Alvarez \& Lazzari, 2016).

Mother-mentor support. Traditionally, or perhaps ideally, a new mother has her own mother to rely on during her postpartum days. Grandma lovingly watches over the 
baby while new mom catches up on her sleep. Grandma cleans the house, makes dinner, and teaches her daughter how to change the baby's diaper, care for diaper rash, mend her bruised nipples, and puts warm wash cloths on her daughter's breasts to bring down the milk. Grandma is the quiet, understanding wisdom to ease the transition (Mitchell \& Green, 2002; Oakley, 1979, 1992).

However, in today's fast-paced society, most new moms live a great distance from their own mothers (McGlone, Park, \& Roberts, 1999), have tormented relationships with their mothers, or may believe that they ought to be able to do it all (Sepa, Frodi, \& Ludvigsson, 2004; Silver, Heneghan, Bauman, \& Stein, 2006). In today’s society a new mother may feel shame for asking for help and may be hesitant to reach out to those around her, even her own mother. Rather than easing into the role of mother, with the gentle guidance of a mentor, she may feel thrust into the role of mother (O'Connor \& Madge, 2004).

The mentoring relationship is generally an intentional partnership between two individuals, wherein the mentor has advanced knowledge of some thing or some skill that is important to the mentee. A mentoring relationship can encourage development, socialization, and help in mastering important skills (Devos, 2004). The mentoring relationship usually assumes that the mentor has something valuable to pass on to the mentee. The relationship can be quite formal or can also be very friendly. The literature on mentoring relationships between women is almost exclusively within the realm of corporate business, although there is some amount of research describing the beneficial exchange among women in terms of academic mentoring (Gibb, 2003) and in the nursing 
literature (Greggs-McQuilkin, 2004). The focus of the research on mentoring relationships between women is generally on helping women to succeed in primarily male dominated careers. Mentoring is seen as a beneficial partnership in which the mentee learns how to propel herself forward in her career without suffering some of the pitfalls that the women before her may have endured.

In theory, the mentoring relationship seems to be well suited for women during their transition into motherhood (Weis \& Ryan, 2012). Historically, women have learned how to mother by observing the women around them. For many women, their primary role model, and mentor is their own mother (Fischer, 1981; Goldstein et al., 1996).

It has long been tradition among many cultures around the world that a woman's mother is with her during the birth of her children and then remains with her daughter to show her the ropes of motherhood, to lend a helping hand after the arrival of the baby, or to simply offer comfort to her daughter during the first weeks of new motherhood (Amato, Rezac, \& Booth, 1995; Fischer, 1981; Schwarz, Trommsdorff, Albert, \& Mayer, 2005; Troll, 1987). In fact, in some cultures the process of giving birth and becoming a mother involves being surrounded by and taken care of by many women. The notion that "it takes a village" to raise a child is steeped in tradition for most cultures.

As we have become more dispersed geographically, many women find themselves a great distance from their mothers during the transition to motherhood. While some women can afford to travel great distances to be with their daughters, more often than not, women are left to make the transition without having the necessary support of a mentor (Fischer, 1981). 
The research that seems to address the need for and the benefits derived from mother mentors emerges in studies that address infant sleep patterns and also perceived parenting competence across the transition to motherhood (Goldstein et al., 1996). Those mothers who are taught how to encourage their babies to sleep better as well as those mothers who are taught techniques and skills that directly increase their feelings of competency are less likely to experience postpartum depression (Dennis \& Ross, 2005). It is also those mothers who have a realistic expectation of motherhood that fare better, suggesting that they may have received more accurate information rather than a romanticized description of the trials of motherhood (Levy-Shiff, Dimitrosky, Shulman, \& Har-Even, 1998).

In fact, it is nearly impossible to come to consensus about which skills a woman should be taught in order to decrease her risk of postpartum depression because each woman's experience is so different. For some women, a lactation specialist is the mentor they need because their feelings of incompetence surface as they struggle with milk supply or cracked and bleeding nipples (Kruske, Schmied, Sutton, \& O’Hare, 2006). For other mothers, learning how to soothe a colicky baby or how to use a breast pump so that late-night feeding responsibilities can be shared with their partners, increases competency thereby decreasing their risk for postnatal depression (Maxted et al., 2005).

E. Cohen and Canan (2006) researched a Parent Partner mentoring program in the child welfare system in California. Research participants were parents who were involved in the child welfare system and facing the possibility of losing their child(ren). The 
parents felt empowered, understood and better able to navigate the system to successfully reunite their families.

Therefore, it seems to follow that if a woman has a mother mentor with her at all times during the early transition to motherhood, whatever her unique difficulty or challenge, she has an experienced mother to teach her the necessary skills to navigate the difficulty. Although many women do not have their mother with them during the transition to motherhood, it does not appear the need for someone to mentor them disappears.

While this might be described as simply "support" for mothers, it is arguably a very specific kind of support. It even goes beyond physical support or emotional support. It is mentoring at its very core. This "being taken under the wing" of a wise crone is a different kind of support than that which is normally addressed in the literature.

Furthermore, the mother mentor who has been traditionally depended upon and necessary for many, many generations is decidedly absent more often than not. The increasing utilization of doulas, birthing coaches, and midwives may be a natural expression of the need to fill this void (Dennis, 2004b).

Increasing a mother's sense of competency during the transition to motherhood is not only related to decreasing her risk of postpartum depression, it significantly decreases her level of stress (H. Sharp \& Bramwell, 2004). As her perceived competency increases, the mother's sense of threat (stress) decreases. She can more quickly relax into the role of mother rather than battle her fear of incompetence. 


\section{Stress}

Transition to motherhood. The transition to parenthood is a developmental milestone that most adults will achieve. Just as transitioning into adolescence or adulthood holds unique challenges and difficulties, transitioning into parenthood is a complicated evolution fraught with life-altering changes (Cavanaugh \& BlanchardFields, 2002). While both men and women experience difficulties during the transition to parenthood, this transition may be particularly challenging for women, for myriad reasons (Arendell, 2000; Nordenmark, 2004). Some of the factors that contribute to the difficulty of the transition to motherhood are explored in this section and include: societal myths about perfection and motherhood, violated expectations of motherhood, insufficient social support, stress, and depression (Bianchi \& Casper, 2000; D. D. Johnston \& Swanson, 2006; Rapoport, Bailyn, Fletcher, \& Pruitt, 2002).

American society has embraced a romanticized idealization of mothers. This iconic mother is loving, nurturing, and expertly responds to the needs of her family. Upon entering the role of mother, a woman not only has an impossible standard, she has a society waiting to stand in judgment of her once she fails. Unless she has a different model after which to form her own mother identity, she will likely internalize her failed efforts to live up to the impossible standard (Chodorow, 2000).

In reality, motherhood is extremely complex in its duality of experiences and feelings (Oberman \& Josselson, 1996):

... the experience of mothering is one of dialectic tensions. A change in selfconcept may incur a simultaneous sense of loss and self-expansion; mothering can confer both maternal power and an immense burden of responsibility; the life- 
giving aspects of mothering may be undermined by the rage and aggression it inevitably elicits; the isolation it may impose on a woman can coexist with her initiation into a maternal community. (p. 344)

The transition to first-time motherhood and parenthood is extremely difficult most of the time. There is an existing body of research that focuses on this developmental stage of transitioning to first-time parenthood (Fillo, Simpson, Rholes, \& Kohn, 2015; Schoppe-Sullivan \& Mangelsdorf, 2013). There are many indicators of the difficulty of this transition. Parents and primary caretakers must deal with several disruptions to life and routine.

Many first-time parents experience a difficult transition into parenting. The first year of parenting is a demanding time and involves many changes to accommodate the addition of a child. One of the immediate difficulties after bringing home a baby is the lack and constant interruption of sleep for parents. Continued problematic child sleep patterns are pervasive and have been indicated as contributors to maternal depression and behavior management difficulties (Wolfson, Lacks, \& Futterman, 1992).

Expectations about parenting contribute significantly to creating the reality for first-time parents. New mothers who anticipate that parenting will be stressful are more distressed, less involved in caregiving, and ultimately less effective with their infants (Levy-Schiff et al., 1998). Mothers who expect parenting will be challenging (with positive implications for growth or gain) have higher levels of well-being and more maternal affective behaviors toward their infants. Expectation and appraisal of parenting as challenging and self-controllable allows mothers an easier transition into the parenting role. Mothers who believe they have some control over their situations are better adjusted 
and provide more nurturing and stimulating environments for their infants (Levy-Schiff et al., 1998).

The experience of competency during the transition to parenthood is linked to better outcomes for both parent and child. Maternal competency can be impeded by feelings of anxiety, depression, and a lack of maternal satisfaction during this critical transitional period. In research conducted by Porter and Hsu (2003) a mother's perception of her child's temperament was related to her sense of competency. Women experienced a steady climb in their sense of competency over the first three months of parenthood and also perceived their infants' temperament as significantly less negative during this same period (Porter \& Hsu, 2003).

Women whose goals during pregnancy and early motherhood are focused primarily on the outcome of the birth or the care of their family respectively, demonstrate fewer depressive symptoms while women who are focused on personal goals experience more depressive symptoms. If a woman experiences depression she is more likely to be concerned with personal goals and not focused on child-bearing or family goals during the corresponding transitional phases of early motherhood (Salmela-Aro, Nurmi, Saisto, \& Halmesmaki, 2001).

Work and family. Most mothers of young children scale back on working hours, at least for a time. However, during the transition to motherhood, hours of unpaid work increase. The household and childcare duties increase for both parents, but for mothers in particular (Bianchi, 2011; Bianchi \& Casper, 2000). Regardless of working outside the home, women complete up to three times more of the household work than men, which 
increases after having a child. Although the gender gap is lessening, women continue to spend up to three weeks more per year engaged in household and childcare chores (Young et al., 2013). And while women work harder in the home, less than one third view their circumstances as unfair. For those women who perceive their domestic load as unfair, they are less satisfied with their marriage and experience more unhappiness. Women who experience a discrepancy between their expectations of motherhood and the reality of their experience may be more prone to depression than women who experience what they expect. Women who return to work part-time after childbirth are significantly more depressed than women who return full-time. This may be due in part to feeling not quite competent in either role (Goldberg \& Perry-Jenkins, 2004; Stevens et al., 2001).

Although women, particularly mothers, are estimated to have a 1-5 hour longer work day than their husbands (Raley et al., 2012; Stevens et al., 2001; Yavorsky et al., 2015), many view their situation as fair or expected. It is only in the situations where the woman views her responsibilities as unfair that she experiences lower levels of satisfaction and well-being. Whether she understands her situation to be unfair does not detract from the reality that she is overworked and exhausted (Hare-Mustin, 1988). The only real difference for mothers will occur when society recognizes their contributions and applauds their efforts (Goldberg \& Perry-Jenkins, 2004; Hare-Mustin, 1988).

The work required of women is often underestimated and undervalued by both men and women, particularly in terms of household work. Women tend to categorize their household work in terms of child-rearing and menial tasks and often underestimate the amount of time spent in specific tasks and occupations (Erlandsson \& Eklund, 2003). 
Women identified hassles and uplifts in their everyday occupations and revealed that most hassling on a daily basis were children and spouses; including such things as disobedient children, children not going to bed, quarrelling with spouse, and division of labor. They also reported hassles in the work environment which included lack of respect from superiors at work, or work conflicts with colleagues (Erlandsson \& Eklund, 2003).

Other hassles included feeling time-pressure (not enough, no control over, no flexibility) and having to complete household chores (cleaning, planning, shopping, cooking, laundry, organizing). Interruption or an unexpected occupation (car breaking down, phone always ringing, schedule disrupted) was most hassling in all areas for women. Things that women found most uplifting included having the time to complete household chores, taking time for self, playing with their children, exercising, taking classes, and hobbies. They also felt uplifted at receiving affection, support, and appreciation from their spouses, parents, and others. Women also expressed feeling uplifted by spending time alone in silence or at rest, and sharing happy time with family. This study indicates that a woman is occupied by a vast array of tasks and events throughout her day (Erlandsson \& Eklund, 2003).

The mental, emotional, and physical exhaustion associated with motherhood is at the very least underestimated and at most overlooked. Mothers experience day-to-day strains and drains on their psyche, find themselves with multiple roles to fill and little support by partners and society in meeting the tremendous demands (Arendell, 2000; Hochschild \& Machung, 2012). 
In an important qualitative study by Noor (2003), women reported a rich discourse on how family and household demands offer significant stressors in balancing home and work. They gave examples of days filled with a multitude of tasks and responsibilities. They also provided examples of how their lives are filled with satisfaction and joy. The women described how their needs are met through a successful work life and enjoyment of their families. The very things that cause them the most distress proved to be the most fulfilling and enjoyable aspects of their life. "Combining family life, paid work and voluntary work will, for me, always involve compromise and stress ... My work is enjoyable, fulfilling and demanding, as is my family” (p. 315).

Work and career can be fulfilling and rewarding for mothers, however it is difficult to balance work and family. While working mothers are still held to the "ideal worker norm" whereby they are expected to complete their education, enter the workforce and continue working hard and long until retirement age, they are also expected to meet the social expectations for raising and caring for a family (Drago, 2001). This suggests that a working mother's day is longer and can be more exhausting than her partner's. When comparing working mothers and women workers who are not mothers, the amount of time that they spend on childcare or other family responsibilities decreased the amount of time they were able to commit to work. Although working mothers still worked more than contracted hours (the study focused on teachers), they had to "borrow" the extra time needed for family care from somewhere, and this ultimately led to fewer hours spent on work demands (Drago, 2001). 
Combining work and family is a constant struggle for mothers. They are often guilt-ridden for being less than the idealized mother when they send their children to childcare (Arendell, 2000). When they choose to combine work and family, they often find it necessary to cut back to part-time work, in which they experience a pay cut, reduced benefits, and a stigmatized job role. Mothers who continue to work full-time often find work environments unfriendly to accommodating their role as mother. They experience time conflicts and inflexibility in their work hours (Williams \& Cooper, 2004).

Not surprisingly, women who experience concerns about the division of labor in their home and the balancing act around work and family are more likely to be depressed. When women feel that the division of labor is unfair they are likely to experience marital dissatisfaction or dissatisfaction in relationships revolving around their work outside the home (Hammen, 2003), which may lead to depression.

How women handle stress. Whether stress makes us more vulnerable to disease and illness or is a direct cause, it has become increasingly evident that in today's society stress is largely to blame for the most prominent health problems in the United States. Stress is not only indicated in physical health problems, it is also indicated as a primary cause of mental illness, represented most clearly in mood disorders (Blonna, 2004; Olpin \& Hesson, 2007).

Our fast-paced lives and the ever-increasing demands placed upon our time and resources have led to an epidemic of chronic stress. The effects of chronic stress can devastate us physically, emotionally, and spiritually. The human body, after years 
without relief, can be compromised and vulnerable to disease and illness (Olpin \& Hesson, 2007).

Although it is becoming clear that stress is harmful, some amount of stress is necessary. Without any stress, human beings lack any motivation for movement and change, are not inclined to reach goals, and would likely have died off long ago. Eustress is a kind of stress that is beneficial in that it propels us forward. This kind of stress is likely the reason behind why human beings have accomplished as much as they have (Blonna, 2004; Olpin \& Hesson, 2007)

Acute stress, on the other hand, is a temporary state during which our bodies respond to a sense of threat. Our bodies experience what has been equated to fear or anger. This emotional response, coupled with the physical reaction, motivates us to selfpreserve. Acute stress has been quite useful to human beings over the course of our evolution (Rosal, King, Ma, \& Reed, 2004).

Early research suggested that the general human response to acute stress, anger, or fear, was for the express purpose of self-preservation. The resulting theory reflected that general response and was deftly named "fight or flight." This theory focused upon the physical surge of adrenaline and the hormones released in the body that cause the desire for self-preservation through increased strength, heightened awareness and the resultant desire to fight or take flight (Cannon, 1932).

However accurate the stress research seemed to be, the bulk of the research, prior to the late 90 's was conducted primarily with college men. For many years, this theory was generally accepted to describe the human reaction to stress. It was not until the late 
90's, when two women colleagues at UCLA noticed that, during a time of high stress in their department, the women responded very differently than the men. Intrigued by this, they set out to research the difference and subsequently developed a new theory. It turned out that women responded to stress differently than men (Taylor \& Klein, 2000).

The UCLA study discovered that women respond with more of a "grouppreservation" mentality during times of heightened stress. This is likely a result of the flood of oxytocin that takes place in a woman's body, which suppresses cortisol and drives her need for maternal behavior. A woman responds to stress with an intense biological desire to "tend and befriend." This biological response to stress is also evident in female animals. Females show their tendency toward group preservation by huddling together in groups and caring for the young. This tend-and-befriend response, while coming from the same evolutionary motivation and serving the same end as the fight-orflight response, plays out differently in women than it does in men. Women herd together to protect the young, share the duties of protection, and seem to lean toward survival of the species through community involvement and collective strength rather than the warrior mentality of duking it out or the individual escape impulse of men (Steinbeis, Engert, Linz, \& Singer, 2015; Taylor \& Klein, 2000).

This tend-and-befriend response to stress that women generally experience is likely the reason behind their strong desire for social support, particularly during times of distress (Cardoso, Ellenbogen, Serravalle, \& Linnen, 2013; C. Pedersen \& Boccia, 2002). This behavior, as pointed out by Taylor and Klein (2000) serves not only as a biological and evolutionary protection of the species, it serves to decrease the stress hormones in 
women and bring them back to baseline. Seeking out social support offers women a way to relieve stress (Israel-Cohen \& Kaplan, 2015).

The body's natural progression through the reaction to stress, whether achieved through fight-or-flight or tend-and-befriend, is to ultimately reach a resolution to the stress. After the surge of hormones, the body comes back to baseline, usually exhausted from the adrenaline rush. From the perspective of evolution, one either escapes the threat or is lost to it. Having escaped, the body can re-regulate and return to base functioning, no longer requiring the surge of strength and heightened state of awareness needed while fighting to stay alive or huddling together to protect the species. The let-down leaves a person physically exhausted. The body, mind, and spirit are wasted in their efforts to evade doom (C. Pedersen \& Boccia, 2002).

The body is not meant to stay in such a state for very long and requires a period of recovery to return to normal functioning. In modern society, however, there are circumstances in which the threat is never fully alleviated. In such cases, chronic stress is a result. Chronic stress is a state in which the body is under constant threat and must remain in the heightened state of hypervigilance for a prolonged period of time. While postpartum depression is more recognized during the transition to motherhood, it may very well be that all types of postnatal depression are a direct result of the chronic stress that is commonly experienced by women during the transition to motherhood (Blonna, 2004; Goldstein et al., 1996; Olpin \& Hesson, 2007).

Research that has studied postpartum stress has focused upon traumatic birthing experiences and the resultant Post Traumatic Stress that occurs among mothers who have 
a particularly harrowing experience during the birth of their baby. While some of the experiences are most certainly more horrific than others, it is difficult to describe birthing a baby as anything less than traumatic (Östberg, 1998). Even if the birth itself does not leave lasting physical or emotional scars, the fact that one leaves the hospital with another life for whom she is responsible is a daunting experience and should not be discounted as a significant source of stress (Dennis \& Ross, 2005; Östberg, 1998).

It is not out of the question to suggest that the stress associated with the transition to motherhood is perhaps the most significant and consequently most pervasive experience shared by large numbers of women (Andersson \& Hildingsson, 2015). One study suggests that the impact of postnatal stress is such that occupational therapy may be required to ease the transition (Slootjes, McKinstry, \& Kenny, 2015). Mitigating maternal stressors during the transition to motherhood through coaching (e.g. breastfeeding mastery) can be a protective factor and may increase parenting efficacy, competence, and child well-being (Rowe, Barnes, \& Sutherns, 2013).

\section{Women and Depression}

The distress that women face as they juggle the multiple tasks of motherhood in addition to challenges they experience maneuvering the new roles associated with this developmental milestone, can create obstacles in their transition (Strazdins et al., 1997). Among other challenges, a woman may be at her highest level of risk for depression during the transition to motherhood. This heightened risk for depression generally spans the course of what might be several years, suggesting that the milestone is not only abrupt in its beginnings, but the effects and repercussions for women can be long-lasting 
(Turner, 2006). Research indicates that a woman who has three or more pre-school children is at the highest level of risk for severe depression. After the birth of her second child, her risk of depression increases with each additional child, particularly when the children are born in close succession (McAuley, Knapp, Beecham, McCurry, \& Sleed, 2004; Mulvaney \& Kendrick, 2005).

Studies also indicate that a woman's level of depression tends to decrease with the decreasing demands of dependent children. As her children gain independence, a woman's level of depression continues to decrease (Barnett \& Hyde, 2001). The milestone associated with the decrease in a mother's level of depression is her child's entry into school, which marks a new developmental phase for both mother and child.

Generally, women are 1.7 times more likely to experience major depression during their lifetime compared to men. This can be explained by the different ways in which a woman's hormones affect brain function in regards to mood stabilization. A woman also experiences more distress than men under extreme stress. Women tend to ruminate more and to be more concerned with measuring up or receiving outward approval and validation. The combination of these variables may leave women more vulnerable to depression (National Women's Health Resource Center, 2003).

Approximately $13 \%$ of U.S. women will experience depression during their lifetimes. For mothers, $12 \%$ to $47 \%$ will experience postpartum depression (Zimmer \& Minkovitz, 2003, p. 537). Risk factors include: sociodemographic characteristics (young age, low income and education, single-parent, multiple children), stress (history of abuse, 
domestic violence, marital discord), and health status (health of parent, health of child and history of depression).

Women experience depression for many of the same reasons as men, but are especially vulnerable to depression during childbearing years. Women who are depressed have some common characteristics and life circumstances. They have lower levels of marital satisfaction and are more likely to suffer divorce. Depressed women are more likely to have children with depressive and non-depressive disorders. Depressed mothers are also more likely to experience negative parent-child relationships. They experience more stressful life events than non-depressed women. There is evidence to suggest that there is a cycle of depression spurred on by stressful life events and poor relationships (Hammen, 2003).

Postpartum depression is experienced by women within three months following childbirth and can last from two weeks to two years. It is an affective disorder ranging from "baby blues" to psychosis. Women who experience Postpartum depression are likely to experience symptoms such as: "dysphoria, emotional lability, insomnia, confusion, anxiety, guilt, and suicidal ideation” (Dennis, 2004a, p. 467). Postpartum depression can have major health consequences for the mother including making her "twice as likely to experience future episodes of depression over a 5-year period" (Dennis, 2004b, p. 526). While Postpartum depression can be devastating to women, children and families also suffer the consequences (Dennis, 2004a, 2004b).

Adoptive mothers are also subject to postpartum depression. Adoptive mothers' rates of depression are affected by lack of sleep, infant colic, and constant screaming or 
crying by the infant. This may suggest that postpartum depression is affected by other factors than perinatal hormones and supports the notion that transition to motherhood is extremely difficult and can be distressing, even when the baby is not her biological child (Gair, 1999).

Maternal depression is more likely to occur in women who receive or perceive little support from relationships. Social support and the marital relationship play important parts in preventing maternal depression. Marital conflict or unsupportive spouses are directly linked to postpartum depression. Women who experience anxiety about their spousal relationship prior to giving birth to their first child are more likely to experience postpartum depression than women who do not experience prenatal relationship anxiety (Feeney, Alexander, Noller, \& Hohaus, 2003).

The most common treatment of postpartum depression, if it is diagnosed, is psychopharmacological. Women who are prescribed antidepressants often find relief from the symptoms of postpartum depression. But there is less frequently any attempt to provide a thorough psychosocial assessment for the woman in order to address the ongoing parenting problems she may encounter. Women are also required to stop breastfeeding in order to take medication, and many opt out of a medication regimen based upon their desire to breast-feed their baby (MacQueen \& Chokka, 2004).

There are a number of preventive and treatment approaches that have been researched in terms of postpartum depression. A two-part review (Dennis, 2004a, 2004b) examining the outcomes for preventive techniques targeting postpartum depression suggested that there is no specific approach that can be endorsed. This was due primarily 
to methodological limitations in the research designs. Dennis (2004a, 2004b) examined the outcomes for both biological (pharmacological, hormonal, fatty acid, and mineral supplementation) and nonbiological interventions (psychological, psychosocial, quality improvement, educational, and relaxation). Although none of the interventions could be universally recommended, some approaches showed more promise than others. Dennis found that not one of the biological treatments could be recommended and very few of the nonbiological treatments rated "good" (vs. fair or poor) in terms of recommendation for use with postpartum women. The nonbiological interventions that rated a good status for recommendation included: psychological (psychological debriefing), psychosocial (supportive interactions), and quality of care (continuity of care and flexible postpartum care). Interestingly, all of the good nonbiological intervention strategies included a support component (Dennis, 2004b).

Parenting groups can offer the emotional support needed by first-time mothers (Hanna, Edgecombe, Jackson, \& Newman, 2002). Several parenting group research interventions were examined and were found to be helpful in decreasing postpartum depression, increasing feelings of support, and increasing feelings of competence. Parenting groups that are cohesive, not too diverse, do not focus on didactic input, and remain fairly small are likely to decrease levels of postpartum depression and increase a mother's support network (Hanna et al., 2002).

Other group interventions have also been shown to be effective with first-time mothers. Although the content of the group did not overtly focus on building support networks, ultimately social support may have been either the confounding variable or 
most important component as any group-based intervention format lent itself to the formation of natural support networks. Depressed women in rural Australia who participated in a group intervention around the topic of problem-solving, experienced significantly lowered levels of depression over time. The group dynamics and the resultant social support may likely have accounted for some of the positive outcomes (Day, Kane, \& Roberts, 2003).

In terms of interventions to treat postpartum depression, the most successful interventions have a distinct support element or include a subtle support element by way of group interaction (Dennis, 2004b). And while there appears to be no one treatment that can be universally recommended, it seems abundantly evident that the social support element (sometimes as a confounding variable by way of any "group intervention") is the most promising aspect of the interventions described. Regardless of the intervention, social support in all of its forms seems to have the most concrete impact on women who are transitioning into motherhood (Dennis, 2004a, 2004b).

Women's depression needs to be considered in terms of their environment. Rural black women were found to experience depression associated with socioeconomic conditions that were exacerbated by the lack of support of their spouse. In times of less economic stress, spousal support did not affect the women's depression (Brown, Brody, $\&$ Stoneman, 2000). Child conduct was highly associated with maternal depression and marital discord. It was not determined whether the mother's depression initiated negative child conduct or if child conduct preceded mother's depression. Black mothers' level of 
depression was also affected by conflict with a co-caregiver for their child (usually the grandmother of the child) more so than by marital conflict (Brown et al., 2000).

Maternal depression affects families; it has an impact on the mothers, their partners and their children (Zimmer \& Minkovitz, 2003). Children of depressed mothers experience attachment difficulties, behavioral problems, and more occurrences of peer difficulty and psychiatric problems. Mothers who are depressed are more likely to engage in behavior with risk for their children. They are more likely to smoke, neglect child vitamins, and use improper car restraints. Women often state that they would welcome intervention (Zimmer \& Minkovitz, 2003).

A significant correlate to maternal sense of self and depression is that of early peer rejection and also of parental rejection (Hock \& Lutz, 2001; Lutz \& Hock, 1998). It seems that early peer experiences help to determine a woman's propensity for depression. Early peer rejection may enshroud a woman's sense of self in unworthiness and feelings of being unloved. The early peer rejection is mediated through a mother's depression, and then translates into her toddler exhibiting behavior problems. The early experience of the mother may become reality for her toddler. By far the strongest correlation was that between maternal representation of self and child behavior. It may be that depressed mothers simply perceive their children as more problematic (since the mothers were the ones to rate their children's behavior), or that in fact, a mother's representation of self is predictive of child misbehavior (Hock \& Lutz, 2001).

The cyclical relationship between maternal depression and child temperament includes the component of sleeping patterns. Lack of sleep in mothers can resemble 
depression. There is a strong relationship between infant sleep patterns and maternal depression. Women who report higher levels of depression are more likely to experience disturbed sleep themselves and to report problematic sleep patterns in their infants. However, among women who report problematic sleep patterns in their infants, women who rated their own sleep as good are less likely to experience maternal depression (Hiscock \& Wake, 2001).

Mothers of young children experience depression more frequently than mothers of older children or women who are not mothers. Levels of depression among mothers of young children are correlated with maternal separation anxiety, marital dissatisfaction, parental overprotection, and parental rejection. The mother's relationship with her child is the most substantial correlate to her depression, particularly when she experiences high anxiety when separating from her child (Hock, Schirtzinger, \& Lutz, 1992; Sockol, Epperson, \& Barber, 2014). Low marital satisfaction is also correlated with maternal depression (Dew \& Wilcox, 2011).

Some personality traits have been associated with postpartum depression. Mothers with postpartum depression demonstrate higher levels of irrationality (need for achievement, need for approval, need for comfort, demands for fairness, criticism of self and others) than non-depressed mothers. Mothers with postpartum depression use mature defenses (sublimation, humor, anticipation, and suppression) significantly less than immature defenses (projection, passive-aggression, acting-out, isolation, devaluation, autistic fantasy, denial, splitting, rationalization, and somatization (Milgrom \& Beatrice, 2003). 
Married mothers were less distressed than other mothers. Mothers with higher levels of education experienced more work-family conflict resulting in lower levels of well-being. Mothers with high neuroticism scores and low extraversion scores reported family interfering with work more frequently than their counterparts. Higher levels of neuroticism increased levels of distress and work-family conflict resulting in lower levels of well-being. Personality variables have an impact on multiple roles and well-being, however complex (Noor, 2003).

A woman's relationship with society and employers plays a role in postpartum depression. Even new mothers must conform to the notion of the "ideal worker norm" (Drago, 2001). Pressured to re-enter the workforce quickly, many women take very little respite during the postpartum period. While the U.S. government requires that a woman receive 12 weeks maternity leave, this is available only after having worked for one year fulltime with the employer and is unpaid (Gilbert \& Van Voorhis, 2003; Williams \& Cooper, 2004). Women who return to work after only six weeks of maternity leave are more depressed and angry than women who take longer maternity leaves, when mediated by concerns about their marriage (Hyde, Klein, Essex, \& Clark, 1995). Shorter maternity leaves create a risk factor for mothers by increasing work over-load (Hyde, Essex, Clark, \& Klein, 2001). While women tend to utilize the federal standard maternity leave, they believe the time is insufficient, particularly with subsequent children (Barnes, 2013).

Women who report their role of mother as highly central to their life are less likely to experience depression as a result of the stress associated with mothering. Women who report being a wife as a central role are more likely to feel depressed as a 
result of the stress related to being a wife. Centrality of the employee role also exacerbates feelings of stress and depression (Martire et al., 2000).

When women have supportive relationships, they are usually spared from postpartum depression. This support can come from their spouses/partners, mothers or mothers-in-law, or friends who are mothers (Almeida, Wenthington, \& Chandler, 1999; Ehrenberg et al., 2001; Karen, 1994). Women benefit from support and flexibility from supervisors at work, as well as support and understanding from peers and coworkers, leading to more satisfaction and less distress related to combining work and family life (Griggs, Casper, \& Eby, 2013; Spitzmueller et al., 2015). It is not only a mother's relationship with others, but also her development of self-confidence and competence, which are needed to avoid postpartum depression. However, without relationships that are empathetic, understanding and empowering, she may not have either (Mauthner, 1999; Simonds, 2001).

Postpartum depression is extremely complex and individual, albeit a common experience for mothers. Overwhelmingly, the most consistent predictors of postpartum depression center on a mother's relationships: with her partner, with her children, with her family, with her friends, with her colleagues, and with her society.

\section{Perceived Parenting Competence}

Most women, feeling a bit like a fish out of water, do not feel confident in their parenting skills during the first few weeks of motherhood. The lack of competence that a woman experiences during the transition to motherhood can be rather jarring, particularly for women who may have been fairly accomplished in their professional lives. Going 
from feeling confident with one's life and career to feeling completely lost can be one of the most stress-inducing circumstances of motherhood. Feeling lost, inexperienced, nonexpert is a difficult experience when the life of one's baby is at stake (Sepa et al., 2004).

The women who feel most competent soon after the birth of their baby, have someone who has taught them, or teaches them, the ropes when they bring baby home (Wolfson et al., 1992). Becoming a mother is a process of learning and the women for whom this fact is not a surprise, fare better emotionally immediately following the birth of their baby. Either they expect to encounter difficulties in terms of figuring things out as a new mother and are not daunted by such expectations (Ruble, Fleming, Hackel, \& Stangor, 1988), or they have a trusted person present to help ease them into motherhood (Mitchell \& Green, 2002).

In studies focused on enhancing parent sleep after their first baby, parents who were provided with group training sessions on helping their infant transition into longer sleep patterns demonstrated higher levels of perceived parental competence than control group parents, who did not receive the training. Again, the content of the group may likely have been secondary to the fact that parents built relationships with other first-time parents, affording them the precious opportunity to build and maintain social support (Wolfson et al., 1992).

Although issues of perceived competency repeatedly surface in research on postpartum depression, and have also been addressed to some degree in some of the previously addressed concepts in this paper, the complexity of its experience warrants a closer look. Motherhood, particularly first-time motherhood, is a unique experience for 
women. While many women may have had many successes in their life, in school, in their career, and in romantic relationships, motherhood is a different ballgame. The tasks of first-time motherhood are such that everyday life is rarely a practice field for success. In today's society it is less common for a woman to be mentored closely by her mother in the fine details of home life and childcare duties. Whereas in the past a young woman may have stood beside her mother most of her days into young adulthood, learning how to season the stew to perfection, knit a cap, sew a quilt, darn a sock, or powder a baby's bottom, today's women are much more likely to measure their success outside of household duties (Porter \& Hsu, 2003; Salmela-Aro et al., 2001).

Women who experience social support that provides functional (informational, instrumental, emotional, appraisal) and structural (formal and informal) support have increased levels of maternal self-efficacy and lower levels of postpartum depression (Leahy-Warren, McCarthy, \& Corcoran, 2011). This suggests that the link between stress, parenting competence, and postpartum depression may be mitigated through social support that includes information, empathy, and a helping hand. Increasingly, the role of functional social support can be met online, with evidence to suggest that blogging and social networking may be an effective protective factor for postpartum depression (McDaniel et al., 2012).

However much a woman's desires, ambitions, and career expectations have changed, society's expectation of her prowess on the home-front has not (Stevens et al., 2001). Most modern women are afforded practice and learning opportunities, and even mentoring in their academic or working lives but have little (or at least less) experience 
or instruction on childcare basics. Women's changing lifestyles and personal aspirations, combined with the stress, likely sleep deprivation, and lack of mentoring during the transition to motherhood may lead directly to feelings of incompetence. It should come as no surprise that lack of parenting competence is associated with postpartum depression (Sepa et al., 2004; H. Sharp \& Bramwell, 2004).

\section{Literature Summary}

The complex interaction of several different but unmistakably interconnected variables during the transition to motherhood, make it very difficult to identify one definitive cause of postpartum distress, or even to identify the most important issues to focus on to ease the transition. Were it not for that enduring desire to snuggle a newborn, the difficulties of the transition might seem insurmountable. But, in fact, women successfully navigate the waters of first-time motherhood quite routinely. They also routinely experience distress, the contributors to which include a complex interaction of several different but unmistakably interconnected variables. What results is a kind of delicate play in a game with many players. The biggest, most documented contributors to a first-time mother's psychological distress, as described above, include: stress, depression, and perceived lack of parenting competence. These variables are intricately related and dependent upon the degree to which each is experienced or perceived as difficult, by each individual woman, in terms of defining her transition into motherhood. Each woman will respond differently to the combination of life-changing circumstances she will face upon leaving the hospital with her new infant in arms. Rarely will the transition be easy (Cunningham \& Zayas, 2002; Maxted et al., 2005). 
In the next chapter interventions are more closely examined, particularly related to social support and the Internet. The concepts and risk factors that were explored in the current chapter lay the foundation for the types of interventions explored and the anticipated benefits for women transitioning into motherhood. 


\section{Chapter Three: The Virtual Natural Helping Network}

Intervention and prevention strategies for maternal depression have been somewhat successful, usually when there is an element of social support (Dennis, 2004a, 2004b; McNaughton, 2000). The studies that seem to show the most promising results are those that assign mentors to new mothers. There have been very few studies utilizing mentors for mothers, but those that are available seem to suggest that the exchange of information and support of peer mothers is more beneficial to the mother than turning to professionals (E. Cohen \& Canan, 2006; Kruske et al., 2006). Having a peer mentor seems to equalize the power differential and allows the mother room for personal growth and learning rather than simply depending on an expert (Liang et al., 2002).

Mothers of young children are many times confined to their homes, and taking the initiative to join intervention programs or support groups can be difficult. Whether it be lack of transportation, trying to work around nap schedules and breastfeeding, or simply the stress of packing up one or more children and all of their necessary gear, leaving the house for a support group or other intervention can be an enormous hassle in and of itself (Saris \& Johnston-Robledo, 2000). If a mother works outside of the home, she is even less likely to show a committed interest in such services (Ames, Brosi, \& DamianoTeixeira, 2006).

What this means for mothers of young children is that, even though they are risk for high rates of depression and distress, there is a lack of appropriate resources and services that can be easily accessed. Mothers may feel at a disadvantage with societal 
expectations, a desire to be a good mother, with few viable resources (Ames et al., 2006; Rollins, Saris, \& Johnston-Robledo, 2001).

Mothers of young children represent an at-risk population that may require more creative intervention and prevention strategies than those the field of social work has historically employed. It is the argument of this paper that Social Work, by employing its historical grassroots methods of connecting with clients "where they are," may be able to tap into and utilize an existing natural helping network (Collins \& Pancoast, 1976;

Libertoff, 1980) in their virtual communities.

It is also important to note that, as with every intervention, individuals must not only have access to the intervention, they must actually participate in order to receive any benefit. This is, of course, true of social support. One cannot experience any positive social support without actually participating in a social support network. Although this is can be an assumption in service-based fields such as Social Work, the necessity of participation is an important consideration in this research.

\section{The Online Journal: Weblog}

Many mothers regularly use a system on the World Wide Web for communication, documentation, and community. The Weblog is a fairly recent phenomenon. Its very earliest beginnings can be traced back to 1994, although its current form can perhaps be traced back to between 1996 and 1999. While it started out as a literal "log of the Web," Weblogs have morphed into something quite different than what they were originally (Blood, 2002). 
Weblogs originally cropped up on the World Wide Web as a way for "Web junkies" and other such technical gurus to keep track of their peers online. It was a way to keep track of what was being reported online in terms of current events, new discoveries, and technological advances that were not available through the mainstream media. It was mostly technological information that was being disseminated as quickly as it was being born. It was an exciting time for those who were involved in the cutting edge beginnings of the World Wide Web (Schmidt, 2007).

Because of the technical nature of the early Internet, most of the early Weblogs were written by men and all were written by those who were well versed in computer programming. As the knowledge of Weblogs steadily grew, so did the number of Weblogs. In its early stages, part of the expected nature of a Weblog included the outside linking to other Weblogs and linking to news sources that were being written about and discussed online. The act of outside linking or hyperlinks created a kind of community, in which most of the Webloggers were connected to one another. Anyone who read a Weblog was automatically able to follow the hyperlinks in the Weblog and immediately entered the "virtual community" of Webloggers (Blood, 2002).

As the popularity of Weblogs and building virtual communities grew, a few early companies like Blogger and Xanga created Weblog templates that allowed even novice Internet users to develop their own Weblog. Without the required expertise in computer programming, the user-friendly Weblog templates created an explosion of Weblogs. The once technology-centered topic of most Weblogs changed dramatically with the availability of Weblog templates (Blood, 2002). Rather quickly, the availability of easy 
templates created an upsurge in use and popularity. Weblogs of yore became "blogs" and started to resemble journals or personal diaries as blog authors used the new forum to express their opinion on topics ranging from politics and science to how wasted they had been at their most recent weekend kegger party (McNeil, 2003; Schmidt, 2007).

The year that marked the most remarkable increase in the number of blogs was 2001, during which the number of blogs increased from 3,000 to 250,000 (Lenhart \& Fox, 2006; Rainie, 2005). It is difficult to estimate the number of blogs currently active, with several blog platforms services, some of which do not report user statistics. Tumblr (tumblr.com/about) reports 293.1 million hosted blogs and Wordpress (wordpress.com/activity) reports more than 409 million readers visit more than 25.1 billion pages every month. Blogger, which is reportedly the most popular blog platform, does not publish user statistics.

As many as $84 \%$ of women who have access to the Internet, have used it to research medical conditions, symptoms, or follow up on a recent doctor's visit (Duggan, Lenhart, Lampe, \& Ellison, 2015). Women use the Internet primarily as a means of gaining knowledge and answering questions concerning such things as medical issues and retail product information. If they have a pain in their side or if their child has some mysterious sore, they are increasingly turning to the Internet to find answers (Lenhart, Fox, Spooner, Rainie, \& Horrigan, 2000; O’Connor \& Madge, 2004).

Not only are they researching medical issues, they are searching for answers to their questions about motherhood (Drentea \& Moren-Cross, 2005, 2011), and by the hundreds of thousands, they are starting blogs. Mothers are so remarkably represented in 
the world of blogging that their blogs are considered a genre, adeptly entitled: Mommy Blogs. With the sudden surge of Mommy Blogs and not an apparent end in sight to the increasing number of women routinely utilizing the Internet, researchers started studying the meaning behind blogging and virtual communities for women (Herring, Kouper, Scheidt, \& Wright, 2004; Herring, Scheidt, Bonus, \& Wright, 2004).

Since the onset of this research, blogging has become a fixture of the Internet, with the inclusion of micro-blogging sites like Twitter and Facebook. The virtual community for mothers has continued to expand (Drentea \& Moren-Cross, 2011; Ley, 2011). Research has begun the process of defining why women blog and exploring the benefits to women during the transition to motherhood (Friedman \& Calixte, 2009; Gattoni, 2013; McDaniel et al., 2012).

\section{Narrating a Life}

For many hundreds, perhaps thousands of years, men and women have documented their lives through keeping journals or diaries. Emerging in recent decades as a field of research and literature is the study of the motivation for keeping a journal or diary and gaining an understanding of the ways in which writing about our lives may be of some benefit.

The benefits of journaling are most specific to the transition to motherhood in the studies focused upon levels of self-disclosure, particularly the research based upon the work of Pennebaker (Pennebaker, 1997, 2012; Pennebaker \& Segal, 1999). In the research indicating a correlation between journaling and a decrease in negative mood states, the mediating variable is the level of self-disclosure that is employed by the 
author. It seems that the more one honestly pours out one's heart on paper (or on a screen), the more therapeutically beneficial the act of journaling. In fact, particularly in times of distress, trauma, or depression, journaling about the events or circumstances with a high degree of self-disclosure produce significant positive benefits (Pennebaker \& Segal, 1999).

Journaling might be particularly relevant to women who are transitioning into motherhood as they would be able to use such a medium at any time and could lament their situation without suffering the public guilt and shame that is unmistakably present when a mother points out the particular hardships of motherhood. Not only that, but journaling, and more currently journaling using the computer, lends itself quite naturally to circumstances under which one is all alone, thereby making it useful during times of isolation (O’Connor \& Madge, 2004).

The act of narrating one's own experience can also lend itself to the possibility of re-storying the events (Lenhart \& Fox, 2006). The act of writing new endings and retelling one's story with more hope and possibility is in and of itself therapeutically beneficial in terms of positive outcomes for the story-teller. The act of telling one's own story may allow a sense of control as narrator that may not have existed as the passive participant. The act of owning the role of narrator and changing the story as one sees fit can be a very powerful experience for writers who feel they are without control in their lives (Pennebaker, 1990).

Whether self-disclosure or powerful narration, the act of writing about one's experience can be liberating and healing. When emotive expression through writing or 
personal narrative is combined with the deeply beneficial presence of social support, in theory at least, it seems to address most of the deeply difficult aspects that a woman can face during the transition to motherhood. This becomes particularly important in the consideration of blogging for mothers of young children (Berman, 2003; O'Connor \& Madge, 2004).

Mommy Blogs are considered a genre of blogging because blogs written and maintained by mothers are very similar in structure and content. For the most part, a Mommy Blogger writes several times each week, publicly posting her thoughts and narrative online, usually detailing some aspect of motherhood including funny quips about her children, describing a particularly frustrating aspect of her day, relating her most frequent discussion or argument with her spouse, or reminiscing about the precious moments shared with friends and family. Mommy Bloggers also commonly post pictures to their blogs of their children, their partners, and of important family events or celebrations (Herring et al., 2004; Duggan et al., 2015).

Mommy Bloggers may start their blogs with the common goal of preserving their story and the documenting the details of the important moments they share with their children in order to revisit the written account in their later years. Many Mommy Bloggers may start their blogs with the intention that one day their blog will be a kind of heirloom or special gift for their children. They want to pass on their memories to their children (Lenhart \& Fox, 2006; Lenhart et al., 2000).

While some Mommy Bloggers may start out with the intention of preserving memories, they may find that they are able to use their blogs for other reasons as well. 
Blogs can provide a platform for mothers to express their conflicted feelings of rage and joy about the tasks and responsibilities of motherhood. They are able to express things in their blogs that they might be publicly punished for if they were to stand on their neighborhood street corner and yell such things for everyone to hear. Blogs can provide a sense of safety and freedom to discuss publicly the things that the author has silently struggled with in the real world (Drentea \& Moren-Cross, 2005, 2011; Kitzman, 2003). In a similar vein, mothers may use their blog as a way of exploring their honest feelings or practicing the expression of their uncertainties. In many ways, Mommy bloggers could use their blogs to take control of their lives, or at the very least, the experiences that they have. Many might become the active and even powerful narrator that they have never been in authoring their lives, through blogging. Still others protect themselves by remaining completely anonymous, allowing them the perceived freedom to explore even the most taboo of subjects from their real life (Friedman \& Calixte, 2009; Sorapure, 2003).

Still others may blog with the intention of being real and utilizing deep selfdisclosure that is profoundly meaningful and healing to them. And yet others might adopt a persona that is, for example, the raunchy or irreverent side that they do not feel safe enough to express in their proper real life. And there are, of course, those who live out devilish fantasies or purposely deceive and mislead others through outlandish and sympathy-inducing tales (Geitgey, 2002). For a brief period, and for precious few, Mommy Bloggers could use their blog as a money-making venture, leading to blog posts that were paid for by advertisers and seen as less than genuine by readers (Khazan, 2015). 


\section{Network of Mothers: Building a Peer Support Network}

Generally, however, Mommy Bloggers routinely write about things that are deeply meaningful and can be most specifically appreciated by other mothers. The fact that they are online, may actually facilitate their comfort level with expressing their "true self" and may relate deeply poignant stories of motherhood as a result (Bargh, McKenna, \& Fitzsimons, 2002; Duggan et al., 2015). It may be for this reason that Mommy Bloggers read other Mommy Blogs, and frequently use hyperlinks to reference the writing of other Mommy Bloggers, ultimately creating a virtual community of likeminded women.

This building of virtual community leads to the other important benefit of blogging. A blog is designed not just as a journal or diary, wherein writers can document the experiences of their life. A blog is also interactive. At the end of each entry, or blog post, the author can choose to allow comments from her readers. Inviting others to comment about personal thoughts, feelings, and experiences opens up the opportunity for communication with like-minded mothers. Comments often become dialogue, opening up the possibility of feeling validated, engaging in an exchange of ideas and knowledge, and ultimately providing an avenue through which even the most isolated mother can develop meaningful relationships with other mothers. Building relationships with other mothers can provide a sense of comradery, validation, and connectedness for women who may otherwise feel marginalized by their society, overlooked in their communities, and taken for granted in their own homes. 
The commenting aspect of blogs also invites the exchange of knowledge between mothers that may very well act as a kind of peer mentoring. Many women use their blogs to occasionally request input from other mothers on such topics as how to address bedwetting, how to get the binky away from their 4-year-old, or how to get their child to sleep through the night. Usually, without experiencing shame or guilt for not knowing, mothers can solicit suggestions or ideas, and call upon the expertise of mothers who have "been there, done that." This aspect of blogging seems to be very valuable and appreciated by mothers. When women receive valuable suggestions void of judgment, they are perhaps more willing and able to share their own wisdom when given the opportunity. Such exchanges may have something to do with the surge in numbers of Mommy blogs (Drentea \& Moren-Cross, 2011; Lenhart \& Fox, 2006; Ley, 2011).

The relationships that women develop through blogging do not fit traditional definitions of friendship, or even social support. Fellow bloggers may never meet in person, and may never even know what each other looks like. They may never attend social gatherings together, visit over coffee, or carry on a complete conversation. But, nonetheless the relationships may be meaningful and akin to mentoring (Drentea \& Moren-Cross, 2011; McDaniel et al., 2012; McKenna, Green, \& Gleason, 2002).

Blogging and the resultant self-disclosure may very well have a hand in changing the culture of motherhood for future generations. The platform of blogging has helped to build a network of mothers and as such may help to strip away the guilt associated with imperfect mothering and once again encourage women to open themselves up to allowing the help of the virtual village in tackling the sometimes daunting task of raising children. 
In the next chapters the research concepts are defined and described. The research questions incorporate the concepts presented and attempt to describe the benefits of blogging for women as they transition into motherhood. 


\section{Chapter Four: Research Questions}

This chapter defines the major concepts that are of importance in this study. Following this chapter on conceptualization, operationalization is addressed by examination of the research methods, particularly the instruments that were utilized to measure the concepts described below. In this section, the following concepts are defined: transition to motherhood, blogging intensity, authenticity of self-disclosure, social support, empowerment, stress, depression, and perceived competence. The consideration of concepts is followed by a statement of the research questions.

\section{Major Concepts}

The transition to motherhood is, for the purposes of this study, defined as the time after which a woman brings home her first baby (whether biological or adopted) and lasting until which time that child turns 5 years old. It is during this transitional period, wherein an enormous shift in identity requiring major adjustments occurs (Oberman \& Josselson, 1996), that a woman's resultant challenges were examined. As her children enter the school system and become less dependent, a woman enters a new phase of her life and as such has transitioned through her adjustment to motherhood and may have found a new or different definition of herself as a woman, mother, and person (Gilligan, 1982, 1995).

The concept of authenticity of self-disclosure is defined as the degree to which a mother feels confident and comfortable to express her honest feelings and opinions. A willingness to express honest feelings and opinions regardless of whether or not those feelings and opinions are shared by peers, particularly if there is no fear about being 
rejected for those disclosures, indicates a level of trust in the people to whom the disclosures are being made. As blogs generally involve a process of writing about life's experiences, the level to which a person is authentic in her self-disclosure is thought to be related to the level of emotional benefit she receives from the very act of writing about their experiences (D. Pedersen \& Higber, 1969; Schoutrop, Lange, Hanewald, Duurland, \& Bermond, 1997; Simpson \& Stoh, 2004).

Blogging intensity is defined as the actual participation of a person in blogging, with the assumption that one must participate in order to receive any benefit from that activity. Blogging intensity was additionally defined as the degree to which a person is invested in blogging. This was identified through the frequency, total amount of time spent blogging, and the importance that it plays in everyday life. The time investment included writing on their own blogs, responding to comments made at their blogs, visiting other blogs and commenting at other blogs. The importance of blogging was measured by such questions as: "How important is blogging to you?" (Lenhart \& Fox, 2006).

For the purposes of this study, the concept of social support encompasses the biological tendency to seek support and community during times of heightened stress (Taylor \& Klein, 2000), as well as the Self-in-Relation theoretical explanation of a woman's development and identity formation as inextricably linked to the quality of her significant relationships (Chodorow, 1978; G. Fox, 1980; Gilligan, 1982, 1995; Miller, 1976). 
According to Miller (1984), through interaction with its caretaker even as an infant, she/he

begins to develop an internal representation of her/himself as a 'being-inrelationship.' This is the beginning of a sense of 'self' which reflects what is happening between people ... pick[ing] up the feelings of the other person .... The child experiences a sense of comfort only as the other is also comfortable ... attended to by the other; and who begins to attend to the emotions of the other ... a self inseparable from dynamic interaction. (pp. 3-4)

The concept of social support includes both real life support and the support of the blogging community. This research makes a distinction between emotional, informational, and functional support as it is provided within the context of real life or the virtual community. It is assumed that functional social support (childcare, help with the dishes, sharing a few diapers when needed) is offered only in real life, while emotional and informational support can be found both in real life and in the virtual community (Drentea \& Moren-Cross, 2011).

During the transition to motherhood, affiliation and connection help to shape a woman's self-definition. If she is successful in her relationships and receives support, she will feel understood, encouraged, and validated thereby increasing her sense of self-worth and easing her transition into motherhood. In this study, particular attention is paid to significant relationships in terms of whether or not they offer empowerment, are engaging, and allow for authentic self-disclosure (Liang et al., 2002).

Stress is defined as the reaction to the events and circumstances present in one's life that are perceived as impeding their optimal experience. The number of events and circumstances may increase the possibility of experiencing stress, but one's perception of those events is what indicates levels of stress for this study. Stress was measured by the 
degree to which one feels out of control of the things that are happening in her life, particularly when those events are perceived as affecting her life in a negative way (S. Cohen, Kamarck, \& Mermelstein, 1983; Östberg, 1998).

The concept of current depression addresses several aspects associated with the experience. Depression is characterized by disruptions in normal thinking patterns that result in such things as the degree to which a person experiences: distractibility, lack of motivation, restlessness, and hopelessness. Depression is also defined by disruptions in normal mood including the prevalence of such things as: irritability, fear, sadness, crying, and feeling lonely (Cox, Holden, \& Sagovsky, 1987).

Perceived parenting competence is specific to one's experience of fulfilling the needs of her child or children. This included a parent's perception that she provided appropriate and satisfactory love, care, safety, and discipline. The ability to respond appropriately and satisfactorily to the needs of her child as well as the degree to which she is confident and assertive in addressing the needs of her child or children was measured (C. Johnston \& Mash, 1989).

The concepts described in this section and explored in the literature, provide a backdrop for the transition to motherhood. These concepts and variables drove the purpose of this research and are intended to help the formulation of research questions and hypotheses. The following section describes the questions and hypotheses that were developed to describe, and attempted to explain, the possible benefits of blogging for women during the transition to motherhood. 


\section{Research Questions}

There seem to be common reasons for why people ultimately choose to blog (Lenhart \& Fox, 2006). Given the content of the literature describing the transition to motherhood and the many hardships that pose possible obstacles for an ideal transition, this research attempted to uncover the reasons why mothers blog and what benefit, if any, they experience as a result of blogging. The study focuses on three research questions (see Figure 1). It was the ultimate goal of this research to explore the following:

1. Why do women blog during the transition to motherhood?

2. What is the relationship among the seven identified variables?

a. Is greater intensity of blogging associated greater perceived social support (online and general) and/or with reduced stress and current depression and greater self-confidence?

b. Is greater authenticity in self-disclosure associated with greater perceived social support (online and general) and/or reduced stress and current depression and greater self-confidence?

c. Is greater perceived social support (online and general) associated with reduced stress and current depression and greater self-confidence?

3. What are the strongest predictors of stress level, current depression, and perceived parenting competence? 


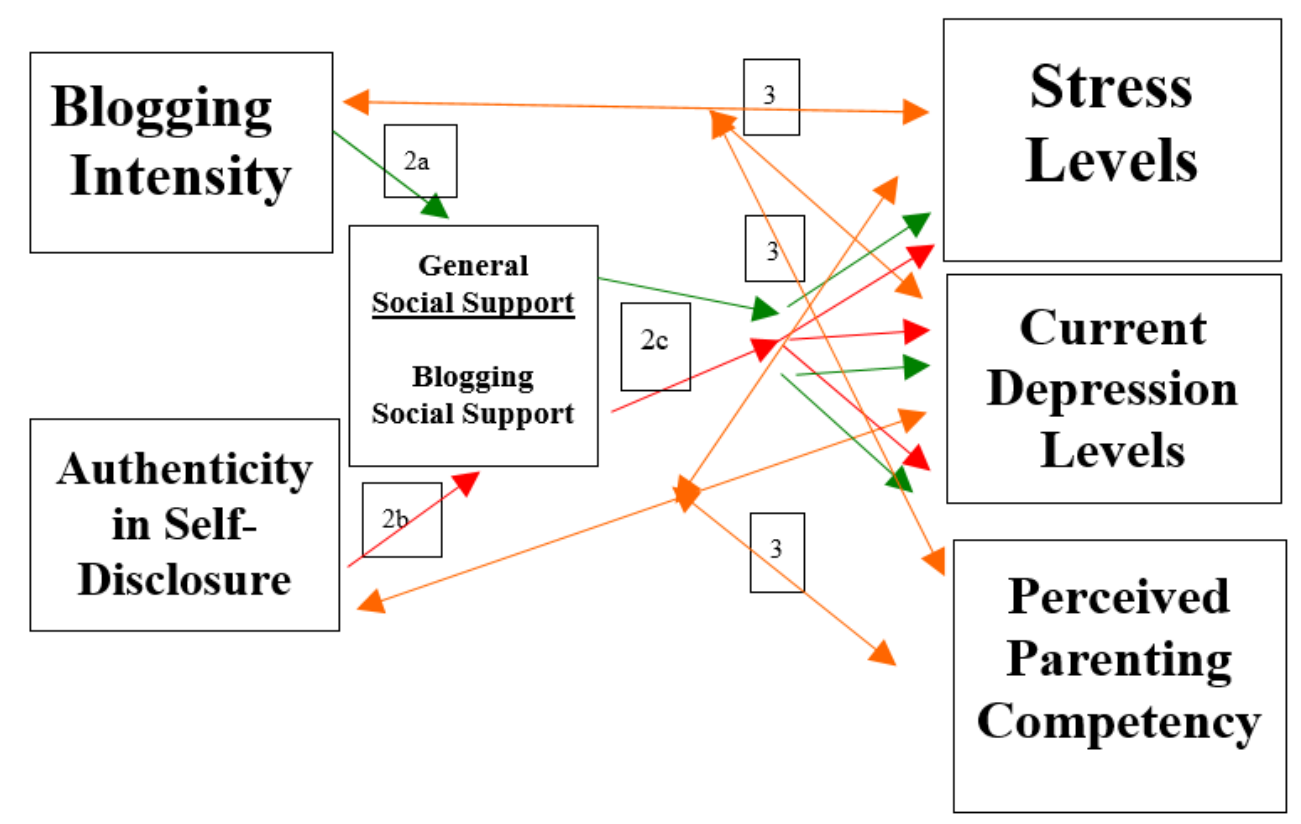

Question 1: Why do women blog during the transition to motherhood?

Question 2: What is the relationship among the seven identified variables?

a. Is greater intensity of blogging associated with greater perceived social support (online and general) and/or with reduced stress and current depression and greater parenting competence?

b. Is greater authenticity in self-disclosure associated with greater perceived social support (online and general) and/or reduced stress and current depression and greater parenting competence?

c. Is greater perceived social support (online and general) associated with reduced stress and current depression and greater parenting competence?

Question 3: What are the strongest predictors of stress level, current depression, and perceived parenting competence?

Figure 1. Variable flow chart.

Question one: Why do women blog during the transition to motherhood? The

literature seems to indicate that the number of women who blog is increasing rapidly.

This growth rate encompasses those women who are mothers. It follows that there might

be a common reason behind why so many women are drawn to the medium. This

question was addressed by examining a large number of possible motivation factors. 


\section{Question two: What is the relationship among the seven identified variables?}

As this was largely an exploratory study, associations among the various variables were examined with the assumption that each variable played an important role, but that the associations of the variables may not be linear. (a) Is greater intensity of blogging associated with greater perceived social support (online and general) and/or or reduced stress and current depression and greater perceived parenting competence? (b) Is greater authenticity in self-disclosure associated with greater perceived social support (online and general) and/or reduced stress and current depression and greater perceived parenting competence? (c) Is greater perceived social support (online and general) associated with reduced stress and current depression and greater perceived parenting competence?

\section{Question three: What are the strongest predictors of stress level, current} depression, and perceived parenting competence? This question sought to clarify the relationship among the identified variables by examining the strength of predictors for the variables: stress, current depression, and perceived parenting competence. Possible predictors were identified as the remaining major research variables: blogging intensity, authentic self-disclosure, and social support (online and general). Investigating the strength of combined identified predictors allows for a better understanding of possible relationships among variables and identification of variables that independently predict stress level, current depression, and perceived parenting competence.

This research attempted to unpack the complex relationships indicated by the research questions above. In so doing, it was anticipated that a great deal more will be 
known about the reasons why mothers blog, and whether or not they experience benefits as a result of blogging. 


\section{Chapter Five: Methodology}

This dissertation employed a cross-sectional research design using a Web-based survey, designed to reach as many appropriate participants as possible. Given the fact that the research questions and hypotheses specifically measured blogging, which is only available via accessing the Internet, the data were collected entirely online.

As technology continues to infiltrate our lives and becomes more accessible and less expensive, more and more people have reliable access to smart phones, computers, and the Internet. Whether it is through home, work or school, approximately $75 \%$ of adults reportedly had access to the Internet in the United States at the time these data were collected (Lenhart \& Fox, 2006), further supporting the use of a Web-based survey. The number of Americans with access to the Internet has increased nearly $10 \%$ since the time of the study in 2008, with disparities of usage by age, education, socioeconomic status, and racial identify quickly narrowing (Perrin \& Duggar, 2015).

\section{Procedure}

Participants were recruited for the study through several popular "Mommy Bloggers" who hosted the live survey link on their website/blog for at least a one-week timeframe. The survey link was active over the course of one month from February 25March 24, 2008. An introductory email was sent to the authors of popular and frequently visited "Mommy Blogs" or to administrators of popular websites geared toward mothers or parents of young children (see Appendix A). Upon consenting to host the survey link, a follow-up email with a statement describing the research was sent to the host bloggers. The follow-up email included a hyperlinked web-button leading to the research survey website with instructions for hosting the link (see Appendix B). Some of the host bloggers left the survey link on their blog for one week, while others permanently left the 
link on their blog or blog post. However long the link was hosted by the participating bloggers, the survey was no longer accessible after March 24, 2008.

Upon following the link to the research website, participants encountered a statement of informed consent that required them to click a button reading "I agree to participate" in order to connect with the research survey. There was no way to count those who decided not to participate after reading the informed consent. Participants completed 43 questions in approximately 25-35 minutes, depending on internet connection speeds, environmental factors, and answer lengths. Completed surveys were anonymously submitted through Survey Monkey, eliminating any possible identifying information available to the researcher. No IP addresses, names or locations of the participants were collected. The data were entered and stored on this researcher's password-protected computer network account, which is only accessible by the researcher. The account is secured and is protected by a username, password, and PIN.

Pilot testing. In order to ensure the user-friendliness and clarity of the survey, pilot testing was utilized. First, the survey was examined by two other researchers. Each checked for grammatical errors, readability, and formatting. Both accessed the survey through a hyperlink directing them to the survey website. Each was asked to assess the overall experience as well as the content of the survey.

Secondly, mothers who keep blogs tested the survey. Each of the bloggers who agreed to host the link on their personal blog agreed to pilot test the survey. Special effort was made to recruit pilot testers who did not have a college education, so as to check the readability and eliminate any possible jargon that may have been overlooked in the survey. In total, 28 pilot testers provided feedback regarding the survey. A few grammatical changes were made to clarify questions; otherwise feedback was largely 
positive, indicating clarity of the instrument and ease of use. All links to the survey functioned properly with high-speed and low-speed internet connections.

\section{Participants}

Participants accessed this research survey by clicking on the link at a blog they visited and, presumably, read. Everyone who participated in this study read a mommy blog at least one time. Out of the original 1,034 surveys collected online, 753 surveys were identified as meeting criteria for inclusion in data analysis. The data were trimmed to limit the participants to residents/citizens of the United States and mothers of preschool aged (0-5) children who lived with them 4 or more days per week. Participants could have no child who was older than 5 years of age living in their home. Of those who answered a question on their current age $(N=748)$, the mean age was $31.95(S D=4.75$, range 21-50). The participant group was fairly racially homogenous with $93.9 \%$ $(N=705)$ indicating Caucasian as her primary racial affiliation, $2.7 \%(N=20)$ Latina, and $3.47 \%(N=49)$ other. Participants could choose as many answers as applied. Please see Table 1.

The largest number of participants reported living in suburban communities $(N=515,68.7 \%)$ with smaller numbers of urban $(N=125,16.7 \%)$ and rural residents $(N=110,14.7 \%)$. The average time of current residence $(N=752)$ was reported as 3.54 years (range 0-22 years, $S D=2.94$ ) and the average number of household residents was $4.26(N=750, S D=1.20$, range $2-12)$. In $95.6 \%$ of homes there were 2 or more adults (see Table 1). 


\section{Table 1}

Participant Characteristics

\begin{tabular}{|c|c|c|}
\hline Variable & $N$ & $\%$ \\
\hline \multicolumn{3}{|l|}{ Race/Ethnicity } \\
\hline Caucasian & 705 & 93.87 \\
\hline Latina or Hispanic American & 20 & 2.66 \\
\hline Other & 23 & 2.81 \\
\hline American Indian & 10 & 1.33 \\
\hline African American & 9 & 1.20 \\
\hline Asian American & 7 & .93 \\
\hline \multicolumn{3}{|l|}{ Residence } \\
\hline Suburban & 515 & 68.67 \\
\hline Urban & 125 & 16.67 \\
\hline Rural & 110 & 14.67 \\
\hline \multicolumn{3}{|l|}{ Adults living in home } \\
\hline 1 & 34 & 4.5 \\
\hline 2 & 683 & 90.7 \\
\hline $3+$ & 36 & 4.8 \\
\hline \multicolumn{3}{|l|}{ Annual household income } \\
\hline$\$ 24,999$ or less & 28 & 3.7 \\
\hline$\$ 25,000$ through $\$ 34,999$ & 39 & 5.2 \\
\hline$\$ 35,000$ through $\$ 49,999$ & 71 & 9.4 \\
\hline$\$ 50,000$ through $\$ 74,999$ & 140 & 18.6 \\
\hline$\$ 75,000$ through $\$ 99,999$ & 100 & 13.3 \\
\hline$\$ 100,000$ or more & 152 & 20.5 \\
\hline Prefer not to answer & $\begin{array}{r}152 \\
33\end{array}$ & $\begin{array}{r}20.2 \\
4.4\end{array}$ \\
\hline \multicolumn{3}{|l|}{ Education level } \\
\hline Some high school & 1 & .1 \\
\hline High school graduate & 12 & 1.6 \\
\hline Some college & 141 & 18.7 \\
\hline College graduate & 263 & 34.9 \\
\hline Graduate/Professional school & 143 & 19.0 \\
\hline Other & 1 & .1 \\
\hline \multicolumn{3}{|l|}{ Work/Employment } \\
\hline Working full time outside the home & 113 & 20.1 \\
\hline Working part-time outside the home & 72 & 12.8 \\
\hline Working full time at home & 33 & 5.9 \\
\hline Working part-time at home & 97 & 17.2 \\
\hline Managing a household and/or raising children full time & 407 & 72.2 \\
\hline Unemployed or laid off & 9 & 1.6 \\
\hline
\end{tabular}

Note. $N=753$ respondents. 
Participants were generally well-educated with $18.7 \%(N=141)$ attending some college, $34.9 \%(N=263)$ college graduates, and $19.0 \%(N=143)$ indicating a graduate school education. Additionally, 20.2\% $(N=152)$ of participants reported annual household incomes more than $\$ 100,000,13.3 \%(N=100)$ made $\$ 75,000-99,999$, and $18.6 \%(N=140)$ had incomes ranging from $\$ 50,000-74,999$.

The majority of participants were married or partnered $(N=551,97.9 \%)$ and worked (part-time or full-time) from home $(N=130,23.1 \%)$ or identified themselves as managing the household and raising children full-time $(N=407,72.2 \%)$, while $32.8 \%$ of participants $(N=185)$ worked outside the home $(N=113,20.0 \%$ full-time $)$. Please refer to Table 1 for more details. Participants took care of the majority of household chores and childcare duties (see Table 2).

Households of the participants included an average of 4.26 occupants $(N=750$, $S D=1.20$, range 2-12). A total of 360 participants (47.8\%) reported having one preschool child, $319(42.4 \%)$ had two preschool children, $64(8.5 \%)$ had three preschool children, and 10 participants (1.3\%) indicated 4-6 preschool children (see Table 3 for ages). Greater than $95 \%$ of the participants indicated that their children were biological and had lived with them since birth (see Table 4). 
Table 2

Mothers' Reported Proportion of Household Chores and Childcare Responsibility

\begin{tabular}{lrrrr}
\hline Percentage & \multicolumn{2}{c}{ Household Chores } & \multicolumn{2}{c}{ Childcare } \\
\cline { 2 - 5 } & \multicolumn{1}{c}{$N$} & $\%$ & \multicolumn{1}{c}{ \% } \\
\cline { 2 - 5 } 0 & 1 & .1 & 1 & .1 \\
20 & 4 & .5 & 6 & .8 \\
30 & 17 & 2.3 & 7 & .9 \\
40 & 11 & 1.5 & 10 & 1.3 \\
50 & 78 & 10.4 & 62 & 8.2 \\
60 & 68 & 9.0 & 51 & 6.8 \\
70 & 130 & 17.3 & 134 & 17.8 \\
80 & 168 & 22.3 & 192 & 25.5 \\
90 & 202 & 26.8 & 199 & 26.4 \\
100 & 73 & 9.7 & 91 & 12.1
\end{tabular}

Note. $N=753$ respondents.

Table 3

Preschool Child Descriptors-Age

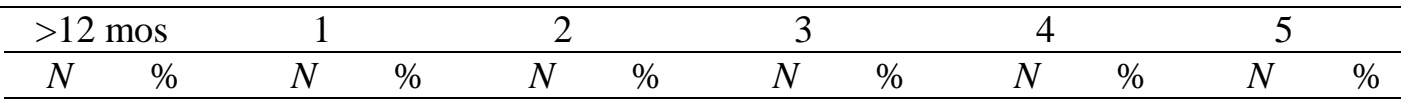

Child

$\begin{array}{rrrrrrrrrrrrr}1 & 83 & 11.0 & 107 & 14.2 & 126 & 16.7 & 139 & 18.5 & 135 & 17.9 & 163 & 21.6 \\ 2 & 66 & 8.8 & 62 & 8.2 & 94 & 12.5 & 91 & 12.1 & 62 & 8.2 & 59 & 7.8 \\ 3 & 31 & 4.1 & 20 & 2.7 & 15 & 2.0 & 15 & 2.0 & 7 & .9 & 32 & 4.2 \\ 4 & 10 & 1.3 & 6 & .8 & 2 & .3 & 3 & .4 & 4 & .5 & 11 & 1.5 \\ 5 & 1 & .1 & 2 & .3 & 0 & & 1 & .1 & 1 & .1 & 2 & .3 \\ 6 & 1 & .1 & 0 & & 2 & .3 & 0 & & 0 & & 0 & \end{array}$

Note. $N=753$ respondents. 
Table 4

Preschool Child Descriptors-Relationship to Mother

\begin{tabular}{|c|c|c|c|c|c|c|c|c|c|c|c|c|}
\hline & \multicolumn{2}{|c|}{ Biological } & \multicolumn{2}{|c|}{ Adopted } & \multicolumn{2}{|c|}{ Stepchild } & \multicolumn{2}{|c|}{ Foster } & \multicolumn{2}{|c|}{ Grandchild } & \multicolumn{2}{|c|}{ Other } \\
\hline & $N$ & $\%$ & $N$ & $\%$ & $N$ & $\%$ & $N$ & $\%$ & $N$ & $\%$ & $N$ & $\%$ \\
\hline & & & & & & & & & & & & \\
\hline 1 & 711 & 94.4 & 24 & 3.2 & 1 & .1 & 2 & .3 & 2 & .3 & 3 & .4 \\
\hline 2 & 413 & 54.8 & 6 & .8 & 6 & .8 & 1 & .1 & 1 & .1 & 1 & .1 \\
\hline 3 & 112 & 14.9 & 3 & .4 & 3 & .4 & 0 & & 0 & & 1 & .1 \\
\hline 4 & 32 & 4.2 & 1 & .1 & 2 & .3 & 0 & & 0 & & 0 & \\
\hline 5 & 7 & .9 & 0 & & 0 & & 0 & & 0 & & 0 & \\
\hline 6 & 3 & .4 & 0 & & 0 & & 0 & & 0 & & 0 & \\
\hline
\end{tabular}

Note. $N=753$.

\section{Measurement}

Survey questions (please refer to Appendix C) included both original questions and standardized instruments. Still other questions were adapted from standardized instruments to more specifically apply to the research topic. In each case, citations and any description of changes to the standardized questions as well as those questions that have been written by this researcher are identified.

Participant and household characteristics. Identifying data were collected in the survey in order to describe the participants. This aided in analysis of data (controlling for confounding variables), informed possible generalization, and offered guidelines for any future replication of this research. Participants were asked to describe themselves in terms of: gender, age, country of residence, race/ethnicity, community type in which they 
resided, and length of time at current residence (survey questions 2-7 respectively). Survey question number 1 (“What is your gender?") and survey question number 6 ("Describe where you live") were drawn directly from the Pew Internet and American Life Project (PIALP) interview schedule (Rainie, 2005). The remaining questions were derived from PIALP, but some of the wording was altered for the purposes of this research. Permission was obtained to both use the questions and alter them as needed.

Next, a series of questions (survey questions 8-11) that obtained information about the participant's household and identified the appropriateness of each person's participation was included in the survey. Question number 8 asked, "How many people live at your residence?" directly followed by questions concerning the participant's parenting status and the number of preschool children living with them " 4 days/wk or more." If they did not have preschool children, or if they had older children, they were redirected to a pop-up window thanking them and releasing them from the survey website.

Household questions were used to describe the children who lived in the house (ages, biological, adopted). In addition, two questions were asked to identify the percentage of: childcare duties (survey question 14) and household duties/chores (survey question 15) participants felt responsible for. Both questions utilized a " $0-100 \%$ " scale, anchored at every $10 \%$. Combined with the descriptive data, these two questions provided a clearer picture of the responsibility load each participant perceived that she carried. Questions indicating annual household income, educational level, and employment provided further descriptive data. Each question measured important components that informed the final analyses and each was authored by the researcher.

Blogging motivation. Respondents were asked several questions that addressed blogging motivation. The questions came primarily from the Blog Motivation subscale embedded in the research survey; most of the items were extracted from a questionnaire 
(Bloggers, PIALP) developed by the Pew Research Center (Lenhart \& Fox, 2006). The subscale identified 20 reasons for blogging and allowed participants to rate the importance of each reason to them personally. In addition, a qualitative question was asked, "In your own words, please describe why you blog." The qualitative question was intended to identify any motivators that were not identified in the quantitative blogging motivation measure.

Blogging intensity. The intensity with which the mothers blogged was measured through the following questions from the research survey: "About how long have you been blogging?; How many blogs do you currently author?; How often do you typically post new material on your blog?; In a typical week, approximately how many hours do you spend working on your blog?; In a typical week, approximately how many hours do you spend reading other people's blogs?; How often do you read other people's blogs?" The answers to these questions were coded and then summed to determine a Blogging Intensity score.

Blogging Intensity was scored by summing raw hours (or number of visits per week) and adding ordinal level coded categories with $5=$ several times per week and $0=$ less often (than once every few weeks). Therefore the summed score for both frequency and number of hours rendered a total score ranging from zero upward. This continuous variable indicated that the higher the score, the higher the levels of frequency and greater total number of hours per week spent blogging.

Authenticity in self-disclosure. The Authenticity Subscale of the Relational Health Indices-Peer (Liang et al., 2002) was used to measure authenticity in selfdisclosure. The subscale measure is a 4-item index $(\alpha=.69)$ embedded in the RHI-Peer index. Participants were asked to answer questions with a "close blog friend" in mind. The subscale used such statements as: "Even when I have difficult things to share, I can 
be honest and real with my friend;" and "I can talk to my friend about our disagreements without feeling judged;" to determine the degree to which a person engaged in authentic self-disclosure. Each was scored on a 5-point Likert-type scale ranging from $1=$ never to $5=$ always. The score was summed and utilized to create an Authenticity score.

Perceived social support. Two measures were utilized. The first measure, the Relational Health Indices (Liang et al., 2002) contributed to the measurement of perceived social support, specifically related to their "blogging community." The Multidimensional Scale of Perceived Social Support (Zimet, Dahlem, Zimet, \& Farley, 1988) was used to assess social support in "face-to-face" relationships.

The Relational Health Indices (RHI; Liang et al., 2002) included index measures of Peer, Mentor, and Community Support. The RHI also included three subscales measuring engagement, authenticity, and empowerment/zest. The community measure is a 14-item index with reports of good internal validity $(\alpha=.90)$ that was developed specifically for women. Construct validity using standardized scales for self-esteem, loneliness, perceived stress, and depression demonstrated levels of significance $(p \leq .05$ and $p \leq .01$ ) for each correlation analysis (Liang et al., 2002).

The statements used in the RHI were evaluated using a 5-point scale with values ranging from $1=$ never to $5=$ always. The indices were then summed, accounting for reverse-scored items, and providing separate perceived support scores for Peer, Mentor and Community with each index containing embedded engagement, authenticity, and empowerment/zest subscales. The higher the score, the higher the levels of perceived social support. Generally, scores ranging from 35-39 and higher indicate a high level of community social support.

The Multidimensional Scale of Perceived Social Support (MSPSS), used to measure general social support, reported good internal and factoral validity (Zimet, 
Powell, Farley, Werkman, \& Berkoff, 1990). The MSPSS is a 12-item scale ( $\alpha=.85$ to .91) without established norms. It is widely used, with suggested scoring categories of 12.9 (low support), 3-5 (moderate support) and 5.1-7 (high social support). It was used to measure sources of social support (friends and family). It was not known whether other sources of social support would affect the outcome variables, which was the purpose of utilizing the MSPSS in addition to the RHI-C. The MSPSS uses such statements as "There is a special person in my life who cares about my feelings;" and "My family is willing to help me make decisions;" and "I get the emotional help and support I need from my family." A 7-point scale was used ranging from 1 = very strongly disagree to 7 = very strongly agree.

Stress. The Perceived Stress Scale (Cohen, Kamarck, \& Mermelstein, 1983) is a brief standardized scale that was used to measure the dependent variable of perceived stress levels. It is a 10-item scale with good levels of validity and reliability $(\alpha=.85)$. The Perceived Stress Scale (PSS) used such items as "In the last month, how often have you felt that you were unable to control the important things in your life?;" and "In the last month, how often have you found that you could not cope with all the things that you had to do?" The PSS uses a 5-point scale ranging from $0=$ never to $4=$ very often. The scale was chosen for its appropriateness, as it has been used and validated in several different languages and countries, and for its brevity (S. Cohen \& Williamson, 1988). Scores above 20 indicate high levels of stress.

Current depression. The Center of Epidemiological Studies-Depression (CESD) scale was used to determine levels of depression among participants (Radloff, 1977). The scale was developed to measure levels of depression in the general population and reports high levels of reliability and validity $(\alpha=.85$ to .90$)$. The measure contains 20 questions that are mildly worded statements (e.g., "During the past week, I was bothered 
by things that usually don't bother me" and "During the past week, I had crying spells") that are evaluated based upon a 4-point scale. The 4-point scale ranges from $1=$ Rarely or none of the time (less than one day)" to $4=$ Most or all of the time (5-7 days). A score of 16 or greater indicates an increased risk for clinical depression.

Perceived parenting competency. The Parenting Sense of Competency Scale (PSOC; C. Johnston \& Mash, 1989) was used to determine levels of parenting competence, the final dependent variable. The 17-item instrument measures parenting self-esteem through satisfaction and efficacy. The scale utilizes statements such as: "I meet my own personal expectations for expertise in caring for my child;" and "Being a parent makes me tense and anxious." Each statement is evaluated using a 6-point scale ranging from $1=$ strongly disagree to $6=$ strongly agree. Negatively worded items are reverse scored. The instrument has obtained reports of internal consistency coefficients of .82 for the satisfaction scale and .70 for the efficacy scale. Depending upon the age of child and gender of parent, scores above 27-30 indicate a high level of perceived competency. 


\section{Chapter Six: Results}

Data analysis revealed that the sample, while answering nearly every question thoroughly at the beginning of the survey, began to drop out over the course of the survey. As such, the sample was eventually trimmed to include only the number of participants who completed the survey in its entirety. Out of 753 eligible participants, 501 completed the survey. The participants who completed the survey ( $N=501$; Completers) were not, in any significant way, different from the Non-Completers $(N=252)$. This was determined through an Independent Samples t-test for continuous variables and through chi-square analysis for categorical variables. There was not a single descriptor or composite score that distinguished Completers from Non-Completers. Therefore, the analysis only includes results from the Completers $(N=501)$, and from this point forward "sample" or "participants" refers only to the participants who completed the survey. In very few cases, individuals skipped or elected not to answer an item. The missing values on specific scale items were replaced by the mean of items on that scale with data for the given case/individual. For example, if an individual skipped one question on the depression scale, that missing value was replaced with the mean value for that scale item. This was an infrequent occurrence and replacing the missing individual value did not change the analysis outcome in any way.

The research sample differs from normal populations in several areas, related to the measures used for this study reported in Table 5. Participant mean scores for current depression (CES-D; $M=33.0, S D=9.11)$ were above normative scores $(M<16$ considered at risk), and would likely identify many as clinically depressed, although the 
instrument is utilized primarily for screening purposes. Participants perceived themselves as relatively competent parents (PSOC; $M=69.59, S D=11.05$ ) compared to non-clinical samples $(M=60.92)$, with high levels of stress (PSS; $M=27.94, S D=6.42)$ compared to normative groups $(M=13.0-13.7)$. The sample reported relatively high levels of both general social support (MSPSS; $M=5.77, S D=1.04$ ) and blogging community support (RHI-C; $M=46.46, S D=9.41)$ compared to normed samples $(M=2.3$ and $M=30$, respectively).

Table 5

Psychometric Properties for Major Research Variables

\begin{tabular}{lrrrrrrr}
\hline Research Variable & $\alpha$ & $M$ & $S D$ & Min & Max & Skewness & Kurtosis \\
\hline 1. BII & .567 & 16.59 & 3.14 & 7.00 & 25.00 & .081 & -.036 \\
2. Auth-P & .900 & 13.73 & 3.61 & 4.00 & 20.00 & -.381 & -.378 \\
3. RHI-C & .875 & 46.46 & 9.41 & 19.00 & 70.00 & -.215 & -.189 \\
4. MSPSS & .936 & 5.77 & 1.04 & 1.42 & 7.00 & -.952 & .703 \\
5. PSS & .888 & 27.94 & 6.42 & 12.00 & 48.00 & .244 & -.164 \\
6. CES-D & .907 & 33.00 & 8.99 & 20.00 & 69.00 & 1.21 & 1.50 \\
7. PSOC & .856 & 69.59 & 11.05 & 40.00 & 98.00 & .034 & -.268
\end{tabular}

Note. $N=501 . \mathrm{BII}=$ Blogging Intensity Index; Auth-P = Relational Health Indices Authenticity Subscale, Peer; RHI-C = Relational Health Indices - Community; MSPSS = Multidimensional Scale of Perceived Social Support; PSS = Perceived Stress Scale; CES-D = Center of Disease Control-Depression; PSOC = Parenting Sense of Competency Scale. 


\section{Blogging Behavior}

As it relates to this research, the following information describes the specific blogging behavior of the remaining participants, reported in Table 6. Participants indicated that they had been blogging an average of 2.45 years $(N=501, S D=1.10)$, with a range of six months or less $(N=114)$ to six or more years $(N=12)$. Most $(N=279$, $55.8 \%)$ indicated that they authored one blog, while some $(N=144,28.8 \%)$ reported authoring two blogs, with the remainder of participants $(N=76,15.2 \%)$ authoring three or more blogs. A majority of participants indicated that they were the only author $(N=466,92.6 \%)$ of their blogs, while others $(N=36,7.2 \%)$ reported they are among multiple authors. Most $(N=327,65.3 \%)$ indicated that they blog under their own name, while the remainder $(N=174,34.7 \%)$ reported using a pseudonym or made-up name (see Table 5).

In terms of access to the internet, participants $(N=432,85.88 \%)$ reported that they usually blogged from home, both home and work equally $(N=41,8.15 \%)$, or from work $(N=30,5.96 \%)$. Participants indicated that their computer at home was connected primarily by cable modem $(N=180,35.79 \%), \operatorname{DSL}(N=151,30.02 \%)$, wireless $(N=146,29.03 \%)$, fiber optic $(N=15,2.98 \%)$, dial-up $(N=6,1.91 \%)$ or other $(N=5$, $1.00 \%)$. 
Table 6

Blogging Behavior

\begin{tabular}{|c|c|c|}
\hline & $N$ & $\%$ \\
\hline \multicolumn{3}{|l|}{ How long have you been blogging? } \\
\hline Six months or less & 114 & 22.62 \\
\hline One year & 135 & 26.79 \\
\hline Two-Three years & 201 & 39.88 \\
\hline Four years & 36 & 7.14 \\
\hline Five years & 6 & 1.19 \\
\hline Six years or more & 12 & 2.38 \\
\hline \multicolumn{3}{|l|}{ How many blogs do you author? } \\
\hline One & 279 & 55.80 \\
\hline Two & 144 & 28.80 \\
\hline Three or more & 76 & 15.20 \\
\hline \multicolumn{3}{|l|}{ Are you the only author on your main blog? } \\
\hline Yes & 466 & 92.64 \\
\hline No & 36 & 7.16 \\
\hline \multicolumn{3}{|l|}{ Do you blog under your own name? } \\
\hline Yes & 327 & 65.27 \\
\hline No & 174 & 34.73 \\
\hline \multicolumn{3}{|l|}{ Where do you usually blog from? } \\
\hline Home & 432 & 85.88 \\
\hline Work & 30 & 5.96 \\
\hline Both home and work equally & 41 & 8.15 \\
\hline \multicolumn{3}{|l|}{ How does your home internet connect? } \\
\hline Dial-up & 6 & 1.19 \\
\hline DSL-enabled phone line & 151 & 30.02 \\
\hline Cable modem & 180 & 35.79 \\
\hline Wireless (land-based or satellite) & 146 & 29.03 \\
\hline $\mathrm{T}-1$ fiber optic & 15 & 2.98 \\
\hline Other & 5 & 1.00 \\
\hline \multicolumn{3}{|l|}{ What does your blog mean to you? } \\
\hline $\begin{array}{l}\text { It is very important to me and is a big part } \\
\text { of my life. }\end{array}$ & 133 & 26.55 \\
\hline $\begin{array}{l}\text { It is like a hobby to me, and I enjoy working } \\
\text { on it when I can. }\end{array}$ & 309 & 61.68 \\
\hline $\begin{array}{l}\text { It is something I do, but not something I } \\
\text { spend a lot of time on. }\end{array}$ & 53 & 10.58 \\
\hline None of these. & 6 & 1.20 \\
\hline
\end{tabular}

Note. $N=501$. 
For those who indicated having a "blog roll" (a list of hyper-linked blogs, usually visible in the margin and visible to visitors) listed on their blog $(N=396,78.73 \%)$, the majority of participants reported having 10-49 links to other blogs $(N=248,52.65 \%)$, with the next largest group $(N=164,34.82 \%)$ listing fewer than 10 blog links, and still fewer participants $(N=38,8.07 \%)$ linking to 50 or more blogs. The remainder $(N=21$, 4.46\%) indicated "don't know" for the number of links in their blog roll (see Table 7).

When asked who reads their blog, participants reported $(N=221,44.11 \%)$ "mostly people I personally know;" some participants $(N=120,23.95 \%)$ indicating "mostly people I have never met;" and many $(N=136,27.15 \%)$ reporting "both equally;" The remainder $(N=24,4.79 \%)$ indicated they did not know who reads their blog.

Participants reported posting new material to their blogs multiple times per week (see Table 8), indicating "3-5 times per week" most frequently $(N=206,40.95 \%)$. In a typical week, participants reported writing on their main blog an average of 5.03 hours (range: $0-21, S D=3.77$ ) and, for those who have more than one blog, writing an additional average of 1.98 hours per week (range: $1-10, S D=1.72$; see Table 8 ). In a typical week, the majority of participants $(N=430,85.60 \%)$ indicated that they read blogs one or more times each day (see Table 8 for detailed data). Additionally, participants indicated spending an average 7.91 hours per week (range: 0-20, SD 4.82) reading blogs. 
Table 7

Blogging Social Behavior

\begin{tabular}{|c|c|c|}
\hline & $N$ & $\%$ \\
\hline \multicolumn{3}{|l|}{ Does your blog include a blog roll? } \\
\hline Yes & 396 & 78.73 \\
\hline No & 106 & 21.28 \\
\hline \multicolumn{3}{|l|}{ How many links on your blog roll? } \\
\hline Fewer than 10 & 164 & 34.82 \\
\hline $10-49$ & 248 & 52.65 \\
\hline $50+$ & 38 & 8.07 \\
\hline Don't know & 21 & 4.46 \\
\hline \multicolumn{3}{|l|}{ Who reads your blog? } \\
\hline Mostly people I personally know & 221 & 44.11 \\
\hline Mostly people I have never met & 120 & 23.95 \\
\hline Both equally & 136 & 27.15 \\
\hline Don't know & 24 & 4.79 \\
\hline \multicolumn{3}{|l|}{ Do you allow comments on your blog? } \\
\hline Yes & 494 & 98.60 \\
\hline No & 7 & 1.40 \\
\hline \multicolumn{3}{|l|}{ Overall, would you say you blog ...? } \\
\hline Mostly for yourself & 184 & 36.73 \\
\hline Mostly for your audience & 40 & 7.98 \\
\hline Both equally & 271 & 54.09 \\
\hline Neither & 1 & .20 \\
\hline Don't know & 5 & 1.00 \\
\hline \multicolumn{3}{|l|}{ Are you able to blog as much as you want? } \\
\hline Yes & 269 & 53.29 \\
\hline No & 224 & 44.71 \\
\hline Don't know & 8 & 1.60 \\
\hline \multicolumn{3}{|c|}{ If you could spend more time blogging, would you? } \\
\hline Yes & 272 & 54.29 \\
\hline No & 163 & 32.53 \\
\hline Don't know & 66 & 13.17 \\
\hline \multicolumn{3}{|l|}{ In a year, will you still be blogging? } \\
\hline Yes & 471 & 94.58 \\
\hline No & 5 & 1.00 \\
\hline Don't know & 21 & 4.22 \\
\hline \multicolumn{3}{|c|}{ In the last 6 months, has the time you spend blogging $\ldots$ ? } \\
\hline Increased & 263 & 52.60 \\
\hline Decreased & 91 & 18.20 \\
\hline Stayed the same & 144 & 28.80 \\
\hline Don't know & 2 & .40 \\
\hline
\end{tabular}

Note. $N=501$. 
Table 8

Frequency of Writing and Reading Blogs

\begin{tabular}{lcccc}
\hline Frequency & Writing & \multicolumn{2}{c}{ Reading } \\
\hline & $N$ & $\%$ & $N$ & $\%$ \\
\cline { 2 - 5 } Several times a day & 10 & 2.0 & 230 & 45.90 \\
About once a day & 99 & 19.68 & 200 & 39.84 \\
$3-5$ times a week & 206 & 40.95 & 51 & 10.16 \\
$1-2$ times a week & 136 & 27.04 & 18 & 3.59 \\
Once every few weeks & 40 & 7.95 & 2 & .40 \\
Less often & 10 & 2.20 & 0 & \\
\hline
\end{tabular}

Note. $N=501$

The remainder of the chapter endeavors to answer each of the research questions.

\section{Question One: Why Do Women Blog During the Transition to Motherhood?}

Participants were asked to endorse the reason why they blog with a Likert-type scale: "Here are some reasons a person might blog. Please indicate how important each reason is to you PERSONALLY.” A mean score was calculated for each item after which the items were rank-ordered to display importance to the participants (see Table 9). Among the reasons available, the four items with the highest mean score, endorsed by participants were: "To document your experiences and share them with others; To express yourself creatively; To document your life in order to pass it down to your children;" and "To stay in touch with family and friends" (see Table 10). 
Table 9

Hours Spent Writing and Reading Blogs

\begin{tabular}{|c|c|c|c|c|c|c|}
\hline \multirow[t]{2}{*}{ Hours } & \multicolumn{2}{|c|}{ Reading Blogs } & \multicolumn{2}{|c|}{ Writing-Main } & \multicolumn{2}{|c|}{$\begin{array}{c}\text { Writing-Other } \\
\text { Blogs }\end{array}$} \\
\hline & $N$ & $\%$ & $N$ & $\%$ & $N$ & $\%$ \\
\hline 0 & 7 & 1.39 & N/A & & 1 & .20 \\
\hline 1 & 104 & 20.68 & 127 & 27.25 & 27 & 5.37 \\
\hline 2 & 104 & 20.68 & 45 & 20.54 & 58 & 11.53 \\
\hline 3 & 85 & 16.90 & 18 & 8.21 & 63 & 12.52 \\
\hline 4 & 43 & 8.55 & 8 & 3.65 & 42 & 8.35 \\
\hline 5 & 64 & 12.72 & 21 & 9.58 & 68 & 13.52 \\
\hline 6 & 17 & 3.38 & & & 22 & 4.37 \\
\hline 7 & 17 & 3.38 & & & 33 & 6.56 \\
\hline 8 & 10 & 1.99 & & & 28 & 5.57 \\
\hline 9 & 4 & .80 & & & 6 & 1.19 \\
\hline $10+$ & 37 & 7.34 & & & 155 & 30.82 \\
\hline Don't know & 10 & 2.19 & & & 5 & .99 \\
\hline
\end{tabular}


Table 10

Rank Order and Mean Score of Blog Motivation: Why Do You Blog?

\begin{tabular}{lll}
\hline Reason & Mean & $S D$ \\
& Score \\
\end{tabular}

1. To document your personal experiences and share them with others.

$4.35 \quad .79$

2. To express yourself creatively.

$3.86 \quad .99$

3. To document your life in order to pass it on to your children. $\quad 3.84 \quad 1.25$

4. To stay in touch with family and friends. $\quad 3.82 \quad 1.33$

5. To feel understood. $\quad 3.34 \quad 1.18$

6. To entertain people. $\begin{array}{ll}3.30 & 1.05\end{array}$

7. To see how others handle the stress of parenting. $\quad 3.12 \quad 1.18$

\begin{tabular}{lll}
8. To vent. & 3.05 & 1.21 \\
\hline
\end{tabular}

Reason Mean SD

Score

9. To see how others feel about parenting. $\quad 3.00 \quad 1.14$

10. To share practical knowledge or skills. $\quad 2.90 \quad 1.14$

11. To store resources or information that is important to you. $\quad 2.89 \quad 1.36$

12. To rant about frustrations. $\quad \begin{array}{ll}2.75 & 1.20\end{array}$

13. To gain knowledge about parenting. $\quad 2.79 \quad 1.09$

14. To feel more confident as a parent. $\quad \begin{array}{ll}1.17\end{array}$

15. To network or meet new people. $\quad 2.66 \quad 1.21$

16. To learn more about parenting tasks (potty training, how to treat $\quad 2.59 \quad 1.10$ chickenpox, etc.)

17. To motivate other people to action. $\quad \begin{array}{ll}2.22 & 1.09\end{array}$

18. To influence the way other people think. $\quad 2.10 \quad 99$

19. To describe or document arguments with your spouse/partner. $\quad 1.26 \quad 63$

20. To make money. $\quad 1.26 \quad 66$

21. To be a different person than "in real life." $\quad 1.22 \quad .62$

22. To "flame" stupid people. $\quad 1.11 \quad .46$

Note. $N=501$. For each item participants could choose a Likert-type scale to endorse the level to which they agreed with the statement: (1) not at all important; (2) slightly important, (3) somewhat important, (4) very important, and (5) extremely important. Each item was summed and a mean score was calculated. Missing items were replaced with a mean item score. 
A qualitative question was asked in order to identify any particular motivating factors for blogging that might not have been specified in the Likert-type scale. Participants were asked, "In your own words, please describe why you blog." Their responses were limited to 200 words. Content analysis revealed three themes related to Blog Motivation: connection with others; journal experiences; creative endeavor. Out of the sample, 72 women answered the qualitative question indicating that they utilize blogging to connect with family, friends, and other mothers with a primary purpose of journaling their parenting experiences, an emotional release, and saving their memories. Additionally, women indicated that they used blogging to express themselves creativity through writing, and sometimes photography. One participant stated, "We moved from our home of 8 years to a new area of the country; I decided to blog to keep in touch/let old friends know what we were up to. Also, to have a creative/writing outlet.” Many participants provided similar descriptions, "We wanted to keep out of town friends and relatives up to date with what was happening with the children. I also wanted a record of my experiences so that I can go back and look at it for reference with the next children, or just for nostalgia." Many echoed the notion that blogging may have started out as one thing, but morphed into something else, "When I first started blogging, I thought of it as an outlet ... But it soon became apparent that getting feedback added so much more to my traditional "journaling." Shared experiences, the freedom of discussing hard subjects semi-anonymously, feedback on one's writing, emotional support, good belly laughs, the list goes on." And nearly every participant who articulated her motivation for blogging, had something positive to say about the activity. In fact, the word "enjoy" was a common 
descriptor, "A-because I enjoy the experience of writing. B-to have a record of my children's early years. C-because I enjoy the interaction with my readers.” Many included every primary theme, "a sort of journaling/archive, a venting ground, a forum, a way to keep in touch with my creative side and the outside world." And another stated, "as a way to connect with other people, to write things down about my children I want to remember, to vent, for entertainment." The words "outlet" and "release" were repeatedly used to describe the kind of writing/journaling that they employed. "An outlet, a sharing experience with others (sic) women in my same space." And, "As a release for myself and a way for friends and family to know about our lives." Women used "connect with other people" and "community" to describe their blog interactions: "As a way to connect with other people. As a social outlet. As a way to express myself and get input from others." Another stated, "To record my experience as a mother and to participate in the online community of parents."

Content analysis revealed support for the Likert-type blog motivation question and appeared to indicate that motivating reasons for blogging were sufficiently covered. The narratives provided richness and humanity to the blog motivation factors.

\section{Question Two: What is the Relationship Among the Seven Identified Variables?}

The seven research variables were primarily measured with standardized instruments that reported good psychometric properties. The participants were a specific group of individuals and normal distribution within the sample was not expected. Please refer to Table 5 for variable distribution within the research sample. 
There was no established index to measure the intensity of blogging, therefore items were built into the research survey to measure this variable. In the proposed research, there was some question about how to configure a Blogging Intensity Index and an assumption that frequency of blogging may not be the same as total number of hours spent writing and reading blogs. A correlation matrix was utilized to assess the significance (Pearson's $r$, 2-tailed) of variable inter-connectedness while building the Index (please see Table 11). Items that were significantly correlated with each other, indicated an "amount of intensity," and were scored similarly were combined to create a Blogging Intensity Index. Each item was scored, then all were summed to establish the index.

Table 11

Correlation Matrix of Blogging Intensity Index Variables

\begin{tabular}{|c|c|c|c|c|c|c|}
\hline Variable & 1 & 2 & 3 & 4 & 5 & 6 \\
\hline $\begin{array}{l}\text { 1. About how long have you been } \\
\text { blogging? }\end{array}$ & 1 & & & & & \\
\hline 2. How many blogs do you have online? & $.229 * *$ & 1 & & & & \\
\hline $\begin{array}{l}\text { 3. How often do you post new material } \\
\text { to your blog? }\end{array}$ & $.102 *$ & $.168 * *$ & 1 & & & \\
\hline $\begin{array}{l}\text { 4. How many hours do you spend } \\
\text { working on your blog? }\end{array}$ & $.103 *$ & $.118 * *$ & $.403 * *$ & 1 & & \\
\hline $\begin{array}{l}\text { 5. How many hours do you spend } \\
\text { reading blogs? }\end{array}$ & $.153 * *$ & $.115^{*}$ & $.183 * *$ & $.403 * *$ & 1 & \\
\hline 6. How frequently do you read blogs? & $.124 * *$ & .056 & $.136 * *$ & $.097 *$ & $.347 * *$ & 1 \\
\hline
\end{tabular}

Note. All items were summed to create Blogging Intensity Index score for the purposes of evaluating research questions. ${ }^{*} p=.05 .{ }^{* *} p=.01$. 
The continuous research variables were then correlated using Pearson's $r$ and 2tailed tests of significance to determine significant relationships (see Table 12). Several significant correlations were revealed among the research variables.

Table 12

Correlation Matrix of Major Research Variables

\begin{tabular}{|c|c|c|c|c|c|c|c|}
\hline Research Variable & 1 & 2 & 3 & 4 & 5 & 6 & 7 \\
\hline 1. BII & 1 & & & & & & \\
\hline 2. Auth-P & $-.166 * *$ & 1 & & & & & \\
\hline 3. RHI-C & $.265^{* *}$ & $.490 * *$ & 1 & & & & \\
\hline 4. MSPSS & -.014 & $.356^{* *}$ & $.163 * *$ & 1 & & & \\
\hline 5. PSS & .054 & $-.161 * *$ & -.050 & $-.397 * *$ & 1 & & \\
\hline 6. CES-D & .045 & $-.189 * *$ & $-.121 * *$ & $-.502 * *$ & $.655 * *$ & 1 & \\
\hline 7. PSOC & -.002 & $.170 * *$ & .050 & $.352 * *$ & $-.616 * *$ & $-.473 * *$ & 1 \\
\hline
\end{tabular}

Note. $N=501$. BII = Blogging Intensity Index; Auth-P = Relational Health Indices Authenticity Subscale, Peer; RHI-C = Relational Health Indices - Community; MSPSS = Multidimensional Scale of Perceived Social Support; PSS = Perceived Stress Scale; CES-D = Center of Disease Control-Depression; PSOC = Parenting Sense of Competency Scale. ${ }^{* *} p=.01$.

Question A: Is greater intensity of blogging associated with greater perceived social support (online and general) and/or with reduced stress and depression and greater parenting competence?

Blogging intensity was correlated with increased levels of perceived support, specific to the blogging community (RHI-C). However, blogging intensity was not significantly correlated with "real life" social support (MSPSS), stress (PSS), or 
perceived parenting competence (PSOC). Blogging intensity was also significantly negatively correlated with authenticity (Auth-P). This negative correlation seems to indicate that as blogging intensity increases, authenticity decreases.

Question B: Is greater authenticity in self-disclosure associated with greater perceived social support (online and general) and/or reduced stress and depression and greater parenting competence?

While blogging intensity was associated with improved scores for only one other research variable (blogging community social support), authentic self-disclosure was significantly correlated with all other variables. As authenticity scores increased: social support scores (RHI-C and MSPSS) increased, stress scores (PSS) decreased, depression (CES-D) scores decreased, and perceived parenting competence (PSOC) increased (see Table 12).

Question C: Is greater perceived social support (online and general) associated with reduced stress and depression and greater parenting competence?

As expected, Perceived Social Support (MSPSS) was significantly correlated with Stress (PSS), Depression (CES-D), Parenting Competence (PSOC) and social support within the blogging community (RHI-C). As social support increased, stress decreased, depression decreased, and parenting competence increased. There was, however, no significant correlation between blogging community social support (RHI-C) and stress or perceived parenting competence, although it was positively correlated to general social support (MSPSS). 


\section{Question 3: What are the Strongest Predictors of Stress Level, Current Depression, and Perceived Parenting Competence?}

A multiple linear regression was calculated (please see Table 13) to predict stress based on Blogging Intensity, Authentic Self-Disclosure, Social Support (Blogging) and Social Support (General). A significant regression equation was found $(F(4,496)=$ $23.731, p<.001)$, with an $R^{2}$ of .161 . The combined theoretical model significantly predicted stress with one variable (General Social Support) independently predicting stress $(B=-2.371 ; p<.001)$.

Table 13

Summary of Multiple Regression Analysis for Variables Predicting Stress

\begin{tabular}{lrrrr}
\hline Variable & $B$ & $S E B$ & $\beta$ & $F$ \\
\hline Blogging Intensity & .087 & .080 & .047 & \\
& & & & \\
Authentic Self-Disclosure & -.297 & .355 & -.042 & \\
Social Support: Blogging Community & .187 & .463 & .020 & \\
(RHI-C) & & & & \\
Social Support: General (MSPSS) & -2.371 & .272 & $-.385^{*}$ & \\
$F(4,496)$ & & & & \\
\end{tabular}

A second multiple linear regression was calculated (Please see Table 14) to predict depression based on Blogging Intensity, Authentic Self-Disclosure, Social Support (Blogging) and Social Support (General). A significant regression equation was found ( $F$ $(4,496)=42.608, p<.000)$, with an $R^{2}$ of .256 . The combined theoretical model 
significantly predicted depression with one variable (General Social Support) independently predicting depression $(\mathrm{B}=-4.262 ; p<.001)$.

Table 14

Summary of Multiple Regression Analysis for Variables Predicting Depression

\begin{tabular}{lrrrr}
\hline Variable & $B$ & $S E B$ & $\beta$ & $F$ \\
\hline Blogging Intensity & .131 & .105 & .051 \\
& & & \\
Authentic Self-Disclosure & .062 & .468 & .006 \\
Social Support: Blogging Community & -.775 & .611 & -.058 \\
$\begin{array}{l}\text { (RHI-C) } \\
\text { Social Support: General (MSPSS) }\end{array}$ & -4.262 & .359 & $-.494^{*}$ \\
$\begin{array}{l}F(4,496) \\
\text { Note. }{ }^{*} p<.001 ; R^{2}=.256 .\end{array}$ & & & & \\
\end{tabular}

Finally, a multiple linear regression was calculated (please see Table 15) to predict perceived parenting competence based on Blogging Intensity, Authentic SelfDisclosure, Social Support (Blogging) and Social Support (General). A significant regression equation was found $(F(4,496)=18.061, p<.001)$, with an $R^{2}$ of .127 . The combined theoretical model significantly predicted parenting competence with one variable (General Social Support) independently predicting perceived parenting competence $(B=3.531 p<.001)$. 
Table 15

Summary of Multiple Regression Analysis for Variables Predicting Perceived Parenting Competence

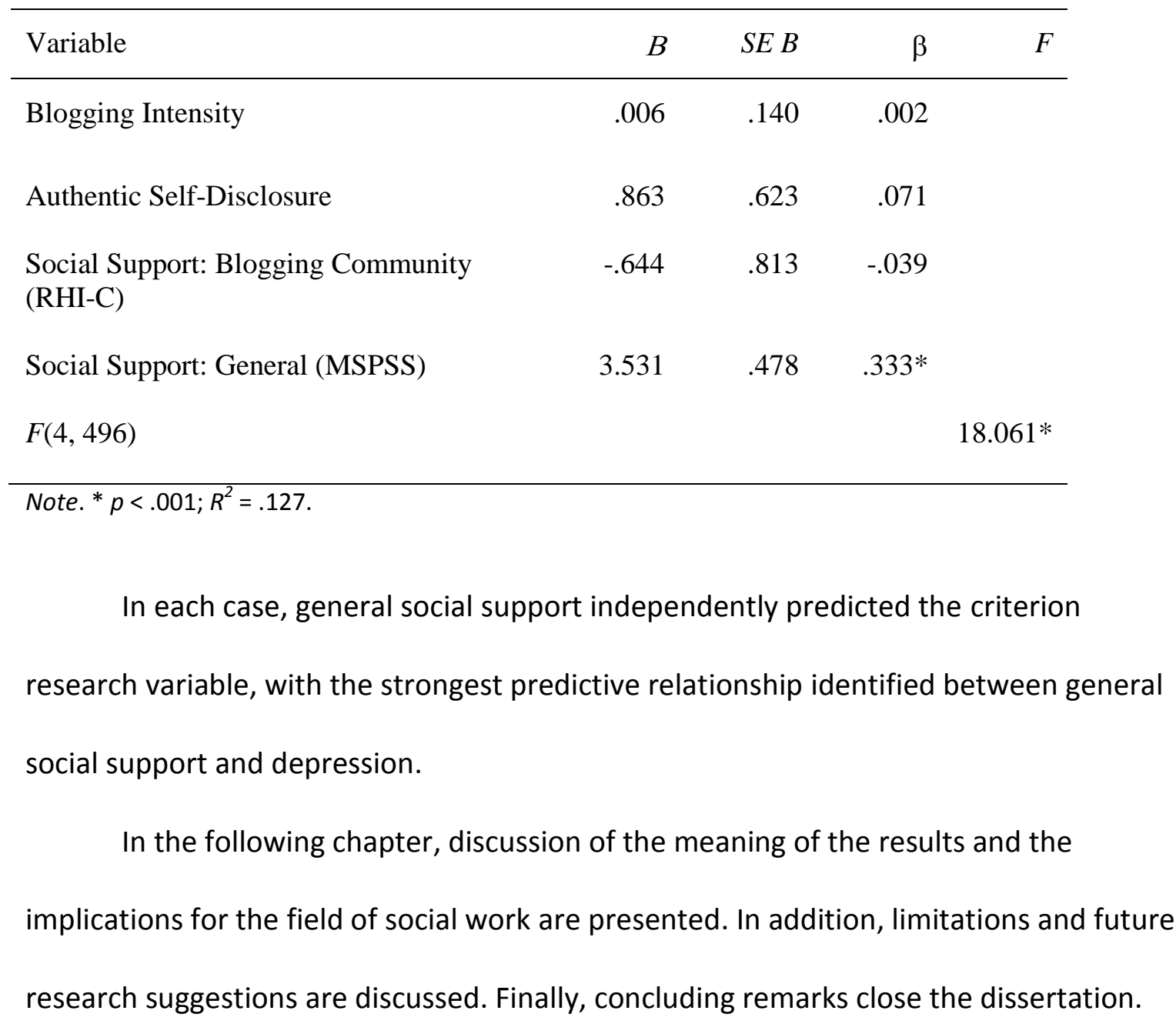




\section{Chapter Seven: Discussion}

This cross-sectional, web-based research provides new information about the benefits of blogging and social networking for women during the transition to motherhood. Discussion in this section first focuses on the outcome summary for each research question, including the seven research variables. Next, implications for social work practice, policy, and future research are considered. This chapter also addresses general suggestions for the use of social media within the context of social work practice. The section concludes with an overview of the limitations of this study and a summary of the implications of key findings.

\section{Summary of Findings: Implications by Research Question and Variable}

Why do women blog during the transition to motherhood? Women reported expected responses to this inquiry. In terms of rank-order, they listed: to keep in touch with friends and family, to record experiences, to foster creativity, and to store resources. These indicators were confirmed in the qualitative question "In your own words, please describe why you blog." Content analysis revealed that connection with others, journaling experiences, and creative endeavor topped the list of qualitative themes. What was interesting about the content of the qualitative data was that it revealed a supporting background story that indicated some women started blogging to stay connected with distant family and friends but discovered an added bonus of finding a community online and an audience. Even in the narratives about connecting, there was an element of "the audience" that seemed to resonate with women. This aspect of blogging seemed to 
provide a kind of validation, in that they were being seen and heard by people who understood the triumphs, joys, and difficulties of their experiences. The narratives liken themselves to Carl Roger's notion of being "deeply heard" and the resultant response, "Thank God, somebody heard me. Someone knows what it's like to be me" (Rogers, 1980, p. 10).

The audience also seemed to provide a kind of reflection that allowed for comparing, contrasting, and understanding the experiences of motherhood in relation to others. Fewer women identified an audience as a particular reason for blogging, but narrative descriptions regarding interaction with readers suggested the experience was made more enjoyable by the interaction, the comments, and commenting, of blogging.

New mothers continue to use blogging, social media (Facebook, Twitter, Instagram) and web forums (website chat sites, open and closed internet groups) to find information about parenting, stay in touch with friends and family, connect with other mothers and journal personal thoughts. Recent studies echo some of the findings of this research, suggesting women enjoy the experience of blogging and social media for the expressive outlet, the interaction, and the camaraderie of other parents (Gibson \& Hanson, 2013; McDaniel et al., 2012; Pettigrew, Archer, \& Harrigan, 2015).

What is the relationship among the seven identified variables? The following research variables are discussed at length: blogging intensity, authentic self-disclosure, social support (blogging and general), stress, depression, and perceived parenting competence. The research outcomes are discussed, followed by implications for social work practice and policy. 
Blogging intensity. It was anticipated that blogging intensity would demonstrate a positive correlation with authenticity, social support, and perceived parenting competence, and a negative correlation with stress and depression. There was a positive correlation between blogging intensity and social support specific to the identified online community (Relational Health Indices-Community [RHI-C]) and an unexpected negative correlation with authenticity. There was no significant correlation with blogging intensity and the MSPSS measure of social support, stress, depression, or perceived parenting competence.

The different findings related to the two measures of social support may indicate that the kind of social support found online may be different than the kind of social support found "in real life." Although blogging intensity was not correlated with the MSPSS measure of social support, the MSPSS was positively correlated to the RHI-C, further suggesting that there was a distinct difference in the kind of social support measured by each scale. The survey specifically asked participants to focus on their blogging community to answer the RHI-C; there were no specifiers for the MSPSS. As such, there may be some kind of relevant difference between the kind of support identified online. The categories of informational and functional social support (LeahyWarren, 2005, 2007; Leahy-Warren \& McCarthy, 2007, Leahy-Warren, McCarthy, \& Corcoran, 2012) may help explain the perceived difference between online and "real life" social support. Perhaps, informational support is provided in online social support and functional support in real life social support. While the social support experienced online 
may be important, having a network of helpful people to lean on for functional support may not be available online.

The negative correlation between blogging intensity and authenticity was not anticipated. The findings appear to indicate that the lower one's level of authentic self disclosure, the higher the level of blogging intensity. This may indicate that the blogging intensity index did not accurately measure what was intended, or it may suggest that women who were less authentic in their self-disclosure spent more time blogging. Interestingly, when the blogging intensity variables were correlated individually with the component research variables making up the index there were differences in the associations related to frequency and number of total hours. Negative correlations were found between frequency posting new material to one's own blog and perceived parenting competence, online social support, and authenticity. These results indicate that the more often mothers posted new material to their main blog, the lower their level of perceived parenting competence, sense of online social support, and level of authenticity. However, positive correlations were found between total number of hours spent working on one's main blog with reported online social support, and authenticity. This finding suggests that frequency of blogging may differ in some way from total number of hours invested in blogging. It paints a kind of picture that suggests the possibility that greater amounts of time invested in writing a post a few times each week may provide more benefit than quickly writing posts every day or multiple times per day. It may be oversimplifying the findings, but high blogging frequency appears to be more frantic and less engaged while high number of hours blogging may be more focused or intentional. 
Authenticity in self-disclosure. Authenticity was significantly correlated with every other research variable. As discussed above, it was unexpectedly, negatively correlated with blogging intensity. Authenticity was also negatively correlated with stress and depression. These findings suggest that the higher the level of authenticity, the lower the levels of stress and depression. This appears to indicate that authenticity, rather than intensity, governs the beneficial impact of blogging. It also seems to suggest that the honest depiction of one's parenting experience and genuine interaction with blogging peers is related to significantly lower levels of stress and depression.

Authenticity was positively correlated with social support, online social support, and perceived parenting competence. This further supports the benefits of authentic selfdisclosure through increased levels of social connection with one's community as well as feeling more competent as a parent. Current literature on emotional disclosure indicates that authentic writing about one's pain, trauma, and struggles can improve well-being and quality of life while lessening physical and emotional pain and depression (Ironson et al., 2013; Whitney \& Smith, 2015; Yazdanfar, Manshaee, Herris, Alipour, \& Noorbala, 2015). Authentic self-disclosure in blogging may provide this same effective outlet for the emotion-laden experiences of parenting.

Social support. As discussed above, the different scales of social support appeared to measure different aspects of social support and were presented in the research survey as specific to online social support (RHI-C) and general social support (MSPSS). General social support was positively correlated to authenticity, online social support, and perceived parenting competence. It was negatively correlated with stress and 
depression. These findings were expected and highlighted the benefit, and possible protective factor, of social support for mothers.

Online social support was positively correlated with authenticity, and general social support, and negatively correlated with depression. No significant correlation was found with stress or perceived parenting competence. Although online social support does not have a direct correlation with stress or perceived parenting competence, there is an indirect connection through general social support. Online social support may increase the protective quality of general social support and may provide some benefit (depression) to those who have limited real life social support.

Similar research (McDaniel et al., 2012) found that new mothers blogged primarily to stay in touch with extended family and friends, with resultant increased levels of social support. It was that increased sense of connection and support that predicted reduced parenting stress which, in turn, predicted levels of lower levels of depression. The study also examined marital satisfaction and marital conflict.

There may be some way that online social support differs from general social support. It is possible that online social support incorporates more of what Leahy-Warren (2005) described as functional social support. The functional social support involves the informational, instrumental, emotional, and appraisal aspects of support. Each was represented in the blogging motivation and qualitative question regarding blogging. Whereas, general social support may have been representative of the additional kinds of support that can be offered in real life. General social support may have included 
structural social support, both formal and informal, that provides additional necessary supports with the daily tasks of mothering (Leahy-Warren et al., 2012).

Stress. Common with the experience of major changes, stress is prevalent among women transitioning into motherhood (Spinelli, Poehlmann, \& Bolt, 2013). Predictably, stress was positively correlated with depression and negatively correlated with authenticity, general social support, and perceived parenting competence. Of particular interest to this study was the role that authentic self-disclosure played in predicting stress. The study findings indicate that the higher the levels of authenticity, the lower the levels of stress. While causation is not indicated, it is important to note that intervention can be attempted with each individual variable, or with multiple variables, and a resultant change can be expected for the other variables. For instance, it is reasonable to assume that if a stress management program for women transitioning to motherhood was initiated with new mothers, we might see decreases in depression levels (George, 2011; Ley, 2011).

Depression. Postpartum depression occurs in about $10-15 \%$ of mothers, can be far-reaching in terms of outcomes, and can impact an affected mother's children (C. Sharp et al., 2014) As expected, the research sample experienced depression at relatively high rates; depression was positively correlated with stress and negatively correlated with authenticity, social support, and parenting competence. Significant to this study was the possibility of a viable intervention for postpartum depression. With authentic participation in blogging there is the possibility of alleviating depression through multiple influencing factors. Authentic blogging could increase social support 
and connection, which may have a significant impact on levels of depression (McDaniel et al., 2012). Additionally, authentic participation in blogging may decrease levels of stress thereby decreasing levels of depression.

Perceived parenting competence. As illustrated above, the inter-relationship of research variables includes that of parenting competence. High levels of social support have been found to increase levels of perceived parenting competence (Gelkopf \& Jabotaro, 2013). As such, it stands to reason that authentic blogging may provide another avenue to increasing parenting competence. That said, there seemed to be an indication in the research outcomes that participating in blogging with high frequency (for both reading and writing) may be associated with a decrease in perceived parenting competence. It may be that the content of what one writes or reads may impact perceived competence. For instance, if a new mother often reads blogs written by highly competent mothers, she may feel her parenting skills pale in comparison. On the other hand, a new mother may often read blogs that describe incompetent parenting techniques that she views as similar to her own.

Women described blogging as a creative and emotional outlet. The act of recounting the highs and lows of motherhood, with depth and honesty, may be therapeutic in the same way as emotive journaling (Pennebaker, 2012). Perhaps, the thoughtfulness involved in recreating a mothering experience and sharing it with readers, allows perspective and evaluation of one's behaviors or responses in the situation. This self-evaluative aspect of writing may have a positive impact on perceived parenting competence. 
Implications for social work practice. Creating a presence online is an expectation for organizations including social work agencies, and for individual practitioners. Providing comprehensive, evidence-based information for new mothers and parents may increase the responsible dissemination of crucial information to clients. Authentic blogging may also provide some benefit to women as they make the transition into motherhood. However, there may need to be some parameters around the activity. Social Workers can lead the charge in communicating the benefits to clients, while also providing directives about how often to engage in authentic blogging for maximum benefit. The distinction between frequency and total time spent becomes more poignant in light of ubiquitous smartphones with near constant access to the Internet. In light of the emerging issues of internet addiction (Block, 2008; Winkler, Dörsing, Rief, Shen, \& Glombiewski, 2013), it would benefit the field of social work to continue to engage in the examination of blogging and social media usage.

The use of blogging as a therapeutic tool may present some issues related to confidentiality and privacy. While encouraging the use of authentic blogging may benefit the client, sharing the content with the social worker may present obstacles to confidentiality and impact the therapeutic alliance. This may involve site statistics that reveal the IP address of blog visitors, or the issue of comments. The social worker would need to take great care in addressing these issues, and ensure informed consent before utilizing the medium for clinical practice.

A closed web group, or shared private blog, may complement a therapeutic group. Some of the same issues of confidentiality, as well as shared agreement regarding 
conduct should be considered. However, this format may allow for isolated or rural clients to participate in therapeutic groups. Additionally, in addition to web-based options, telehealth may play an increasing role in social work and behavioral health in the near future.

Implications for policy. In addition to the necessary funding options for social work and behavioral health, continued and increased access to the internet should be a primary policy concern for social workers. Although internet access continues to include more and more people, the poor, elderly, rural, and homebound constitute a digital divide (Velaga, Beecroft, Nelson, Corsar, \& Edwards, 2012) that requires continued attention. Social workers are bound to represent marginalized individuals and should actively engage in expanding the Internet's reach and in bridging the digital divide.

Implications for future research. As this was primarily an exploratory study, the opportunity for future research is vast. Since the time of this study, use of Facebook and Twitter has increased dramatically. This social media phenomenon went from novel to common in a few short years (Perrin \& Duggan, 2015). Research should include the newer platforms (Instagram, Pinterest, Snapchat), as well as the emerging apps and other options for social connection (gaming) and explore the potential impact of these forms of social media on the research variables addressed in this study.

In addition to social support and connection during the transition to motherhood, research topics related to parent-child interaction, adolescent relationships, marital relationships, dating, and gaming should be addressed in order to better understand the 
emerging complexities of social connection and interaction. New rules are being written about expectations in communication, accepted online behavior, and interaction etiquette.

Along with changing technology and social connection online, there may be a shift in variables that impact stress, depression, and parenting competence. Continued examination of those shifting values and variables is essential to understand the possible changing expectations of motherhood.

The current data set could be further utilized to explore the vast amount of embedded information. A factor analysis could be conducted to detect any specific factors that exist in the blogging motivation instrument. Additionally, the data could be re-analyzed to assess the subsets of mothers who endorsed specific reasons they were blogging, to see whether they differed from mothers with other reasons for blogging as related to authenticity, social support, and depression. Lastly, the qualitative data collected for this research could be further examined to detect themes regarding the research variables.

Limitations. The sample was specific to mothers of preschool aged children living in the United States. As such, generalizability is limited to the specific group that was studied. Additionally, while the sample size was relatively large, the length of the survey itself may have prevented complete participation by many. Time constraints, as well as parenting tasks, may have contributed to the number of participants who did not complete the entire survey.

Standardized instruments were used as much as possible, but issues related to validity were raised with the differing scores for the social support measures (MSPSS \& 
RHI-C) as well as the construction of the Blogging Intensity Index. Social support and blogging intensity may not have adequately or fully measured what was intended.

Because the data were restricted to mothers of preschoolers, living in the United States the homogeneity of the sample prevented a broader understanding of blogging among mothers. There is very little information about lower-income mothers, or single parents. Furthermore, the sample was not diverse in racial/ethnic makeup, education, or income brackets. This restricts the value of the data. Additionally, although this study focused on the experience of mothers, without the voice of fathers, the data lacks comparative information.

Finally, the Internet and social media have changed since this research was conducted. In many ways, other forms of social media or micro-blogging have taken the place of blogging for women transitioning into motherhood. This research was limited to the experience of blogging and how that kind of writing and interacting informed online social support.

Conclusion. This research attempted to uncover the reasons why mothers blog and what benefit, if any, they experience as a result of blogging. New mothers experienced benefits as a result of their authentic participation in blogging and reported key reasons that they participated including: to share their experiences with others, preserve their memories, interact with a like-minded audience and to feel understood. There were significant positive correlations between authentic self-disclosure and perceived social support, and sense of parenting competency, and negative relationships between authentic self-disclosure and maternal depression and perceived stress. Multiple 
regression analysis indicated that social support was the strongest predictor of depression. Social support was also a predictor of stress and of perceived parenting competence. Additionally, social support significantly predicted authentic self-disclosure of these mothers who blogged.

Many mothers participated in this research, sharing their experience of blogging and what it means to them. More than 500 mothers, who reported high levels of depression and stress, demonstrated the positive impact blogging, and perhaps social media as a whole, may have during a difficult transition. When given the opportunity to discuss blogging in their own words, more than 70 women, who answered the openended question, described blogging in an overwhelmingly positive way. They described it as empowering and beneficial. It is well worth our time as professionals, and as people living in a digitally-driven world, to better understand how to harness the narrative power and beneficial aspects of online social support. 


\section{References}

Almeida, D., Wenthington, E., \& Chandler, A. (1999). Daily transmission of tensions between marital dyads and parent-child dyads. Journal of Marriage and Family, 61(1), 49-61.

Alvarez, A. R., \& Lazzari, M. M. (2016). Feminist mentoring and relational cultural theory: A case example and Implications. Affilia, 31(1), 41-54.

Amato, P., Rezac, S., \& Booth, A. (1995). Helping between parents and young adult offspring: The role of parental marital quality, divorce, and remarriage. Journal of Marriage and Family, 57(2), 363-374.

Ames, B., Brosi, W., \& Damiano-Teixeira, K. (2006). "I'm just glad my three jobs could be during the day": Women and work in a rural community. Family Relations, 55, 119-131.

Andersen, S., Chen, S., \& Miranda, M. (2002). Significant others and the self. Self and Identity, 1, 159-168.

Andersson, E., \& Hildingsson, I. (2015, December 3). Mother's postnatal stress: An investigation of links to various factors during pregnancy and post-partum. Scandinavian Journal of Caring Sciences. doi:10.1111/scs.12305. [Epub ahead of print]

Arendell, T. (2000). Conceiving and investigating motherhood: The decade's scholarship. Journal of Marriage and Family, 62(4), 1192-1208.

Barak, A., Hen, L., Boniel-Nissim, M., \& Shapira, N. (2008). A comprehensive review and a meta-analysis of the effectiveness of internet-based psychotherapeutic interventions. Journal of Technology in Human Services, 26(2/4), 109-160.

Bargh, J., McKenna, K., \& Fitzsimons, G. (2002). Can you see the real me? Activation and expression of the "true self" on the Internet. Journal of Social Issues, 58(1), $33-48$.

Barnes, M. W. (2013). Having a first versus a second child comparing women's maternity leave choices and concerns. Journal of Family Issues, 34(1), 85-112.

Barnett, R. C., \& Hyde, J. S. (2001). Women, men, work, and family. An expansionist theory. The American Psychologist, 56(10), 781-796.

Berman, J. (2003). The writing cure: How expressive writing promotes health and emotional well-being. Psychoanalytic Psychology, 20(3), 575-578. 
Bianchi, S. M. (2011). Family change and time allocation in American families. The ANNALS of the American Academy of Political and Social Science, 638(1), 21-44.

Bianchi, S., \& Casper, L. (2000). American families. Population Bulletin, 55(4), 3-48.

Block, J. J. (2008). Issues for DSM-V: Internet addiction. American Journal of Psychiatry, 165, 306-307.

Blonna, R. (2004). Coping with stress in a changing world (3rd ed.). Boston, MA: McGraw-Hill.

Blood, R. (2002). Weblogs: A history and perspective. In J. Rodzvilla (Ed.), We've got blog: How Weblogs are changing our culture (pp. 7-16). Cambridge MA: Perseus Publishing.

Brown, A., Brody, G., \& Stoneman, Z. (2000). Rural black women and depression: A contextual analysis. Journal of Marriage and Family, 62(1), 187-198.

Cannon, W. B. (1932). The wisdom of the body. New York, NY: W. W. Norton \& Co.

Cardoso, C., Ellenbogen, M. A., Serravalle, L., \& Linnen, A. M. (2013). Stress-induced negative mood moderates the relation between oxytocin administration and trust: Evidence for the tend-and-befriend response to stress? Psychoneuroendocrinology, 38(11), 2800-2804.

Carr, J., Gilroy, F., \& Sherman, M. (1996). Silencing the self and depression among women: The moderating role of race. Psychology of Women Quarterly, 20, $375-392$.

Cavanaugh, J., \& Blanchard-Fields, F. (2002). Adult development and aging (4th ed.) Belmont, CA: Wadsworth.

Cha, Y. (2014). Job mobility and the great recession: Wage consequences by gender and parenthood. Sociological Science, 1, 159-177. doi:10.15195/v1.a12

Child Trends Databank. (2015). Family structure. Retrieved from http://www. childtrends.org/?indicators=family-structure

Chodorow, N. (1978). The reproduction of mothering. Berkeley, CA: University of California Press.

Chodorow, N. (2000). Reflections on the reproduction of mothering - twenty years later. Studies in Gender and Sexuality, 1(4), 337-348. 
Chodorow, N. (2011). Beyond the dyad: Individual psychology, social world. Journal of the American Psychoanalytic Association, 58(2), 207-230.

Cohen, E., \& Canan, L. (2006). Closer to home: Parent mentors in child welfare. Child Welfare, 85(5), 867-884.

Cohen, S., Kamarck, T., \& Mermelstein, R. (1983). A global measure of perceived stress. Journal of Health and Social Behavior, 24, 385-396.

Cohen, S., \& Williamson, G. (1988). Perceived stress in a probability sample of the United States. In S. Spacapam \& S. Oskamp (Eds.), The social psychology of health: Claremont symposium on applied social psychology (pp. 31-67). Newbury Park, CA: Sage.

Collins, A. H., \& Pancoast, D. L. (1976). Natural helping networks: A strategy for prevention. Oxford, England: National Association of Social Workers.

Coontz, S. (1992). The way we never were: American families and the nostalgia trap. New York, NY: Basic Books.

Coulson, N. S. (2005). Receiving social support online: An analysis of a computermediated support group for individuals living with irritable bowel syndrome. CyberPsychology and Behavior, 8(6), 580-584.

Cox, J. L., Holden, J. M., \& Sagovsky, R. (1987). Detection of postnatal depression: Development of the 10-item Edinburgh Postnatal Depression Scale. British Journal of Psychiatry, 150, 782-876.

Coy, D., \& Kovacs-Long, J. (2005). Maslow and Miller: An exploration of gender and affiliation in the journey to competence. Journal of Counseling and Development, $83,138-145$.

Crittenden, A. (2001). The price of motherhood: Why the most important job in the world is still the least valued. New York, NY: Henry Holt \& Co.

Cunningham, M., \& Zayas, L. H. (2002). Reducing depression in pregnancy: Designing multimodal interventions. Social Work, 47(2), 114-123.

Day, C., Kane, R., \& Roberts, C. (2003). The prevention of depressive symptoms in rural Australian women. Journal of Community and Applied Social Psychology, 13, $1-14$.

Dennis, C. (2004a). Preventing postpartum depression part I: A review of biological interventions. Canadian Journal of Psychiatry, 49(7), 467-475. 
Dennis, C. (2004b). Preventing postpartum depression part II: A critical review of nonbiological interventions. Canadian Journal of Psychiatry, 49(8), 526-538.

Dennis, C., \& Ross, L. (2005). Relationships among infant sleep patterns, maternal fatigue, and development of depressive symptomatology. Birth: Issues in Perinatal Care, 32(3), 187-193.

Devos, A. (2004). The project of self, the project of others: Mentoring, women and the fashioning of the academic subject. Studies in Continuing Education, 26(1), 67-80.

Dew, J., \& Wilcox, W. B. (2011). If momma ain't happy: Explaining declines in marital satisfaction among new mothers. Journal of Marriage and Family, 73(1), 1-12.

Diener, E. (1984). Subjective well-being. Psychological Bulletin, 95, 542-575.

Diener, E., Suh, E., \& Oishi, S. (1997). Recent findings on subjective well-being. Indian Journal of Clinical Psychology, 24, 25-41.

Douglas, S., \& Michaels, M. (2004). The mommy myth: The idealization of motherhood and how it has undermined women. New York, NY: Free Press.

Drago, R. (2001). Time on the job and time with their kids: Cultures of teaching and parenthood in the U.S. Feminist Economics, 7(3), 1-31.

Drentea, P., \& Moren-Cross, J. L. (2005). Social capital and social support on the Web: the case of an Internet mother site. Sociology of Health and Illness, 27(7), 920-943.

Drentea, P., \& Moren-Cross, J. (2011). Online motherhood: A community of mothers revisited. In M. Moravec (Ed.), Motherhood online (pp. 45-59). Newcastle upon Tyne, UK: Cambridge Scholars.

Duggan, M., Lenhart, A., Lampe, C., \& Ellison, N. B. (2015). Parents and social media. Pew Research Center. Retrieved from http://www.pewinternet.org/2015/07/16/ parents-and social-media/

Ehrenberg, M., Gearing-Small, M., Hunter, M., \& Small, B. (2001). Childcare task division and shared parenting attitudes in dual-earner families with young children. Family Relations, 50(2), 143-154.

Erlandsson, L., \& Eklund, M. (2003). Women's experiences of hassles and uplifts in their everyday patterns of occupation. Occupational Therapy International, 10(2), 95-114. 
Fallows, D. (2004, August). The Internet and daily life. Washington, DC: Pew Internet and American Life Project. Retrieved from http://www.pewinternet.org /2004/08/11/ the-internet-and-daily-life/

Feeney, J., Alexander, R., Noller, P., \& Hohaus, L. (2003). Attachment insecurity, depression, and the transition to parenthood. Personal Relationships, 10, 475-493.

Fillo, J., Simpson, J. A., Rholes, W. S., \& Kohn, J. L. (2015). Dads doing diapers: Individual and relational outcomes associated with the division of childcare across the transition to parenthood. Journal of Personality and Social Psychology, 108(2), 298-316.

Fischer, L. (1981). Transitions in the mother-daughter relationship. Journal of Marriage and Family, 43(3), 613-622.

Fox, G. (1980). The mother-adolescent daughter relationship as a sexual social structure: A research review. Family Relations, 29, 21-28.

Fox, S., \& Rainie, L. (2014, February). The Web at 25 (Pew Research Center). Retrieved from http://www.pewinternet.org/2014/02/25/the-web-at-25-in-the-u-s

Friedan, B. (1963). The feminine mystique. London, UK: Penguin.

Friedman, M., \& Calixte, S. L. (Eds.). (2009). Mothering and blogging: The radical act of the mommyblog. Toronto, Canada: Demeter Press.

Gair, S. (1999). Distress and depression in new motherhood: Research with adoptive mothers highlights important contributing factors. Child and Family Social Work, 4, 55-66.

Gattoni, A. L. (2013). Breaking the silence: The role of online community in the transition to motherhood (Doctoral dissertation, University of Wisconsin, Milwaukee, WI). Retrieved from http://dc.uwm.edu/etd/101

Geitgey, A. (2002). The Kaycee Nicole (Swenson) FAQ. In J. Rodzvilla (Ed.), We've got blog: How Weblogs are changing our culture (pp. 89-98). Cambridge MA:

Perseus Publishers.

Gelkopf, M., \& Jabotaro, S. E. (2013). Parenting style, competence, social network and attachment in mothers with mental illness. Child and Family Social Work, 18(4), 496-503.

George, M. (2011). Proposed role for occupational therapy to serve new mothers (Emerging Practice CATs, Paper 10). Retrieved from http://commons. pacificu.edu/emerge/10 
Gibb, S. (2003). What do we talk about when we talk about mentoring? Blooms and thorns. British Journal of Guidance and Counseling, 31(1), 39-49.

Gibson, L., \& Hanson, V. L. (2013, April). Digital motherhood: How does technology help new mothers? In R. Grinter, T. Rodden, P. Aoki, E. Cutrell, R. Jeffries, \& G. Olson (Eds.), Proceedings of the SIGCHI conference on human factors in computing systems (pp. 313-322). New York, NY: ACM.

Gilbert, N., \& Van Voorhis, R. (2003). The paradox of family policy. Society, 40, 51-56.

Gilligan, C. (1982). In a different voice: Psychological theory and women's development. Cambridge, MA: Harvard University Press.

Gilligan, C. (1995). Hearing the difference: Theorizing connection. Hypatia, 10(2), 120-127.

Goldberg, A., \& Perry-Jenkins, M. (2004). Division of labor and working-class women's well-being across the transition to parenthood. Journal of Family Psychology, 18(1), 225-236.

Goldstein, L., Diener, M., \& Mangelsdorf, S. (1996). Maternal characteristics and social support across the transition to motherhood: Associations with maternal behavior. Journal of Family Psychology, 10(1), 60-71.

Greggs-McQuilkin, D. (2004). Mentoring really matters: Motivate and mentor a colleague. MEDSURG Nursing, 13(4), 209-266.

Griggs, T. L., Casper, W. J., \& Eby, L. T. (2013). Work, family and community support as predictors of work-family conflict: A study of low-income workers. Journal of Vocational Behavior, 82(1), 59-68.

Hammen, C. (2003). Social stress and women's risk for recurrent depression. Archives of Women's Mental Health, 6, 9-13.

Hanna, B., Edgecombe, G., Jackson, C., \& Newman, S. (2002). The importance of firsttime parent groups for new parents. Nursing and Health Sciences, 4, 209-214.

Hare-Mustin, R. (1988). Family change and gender differences: Implications for theory and practice. Family Relations, 37, 36-41.

Herring, S., Kouper, I., Scheidt, L., \& Wright, E. (2004). Women and children last: The discursive construction of Weblogs. Retrieved from the University of Minnesota Digital Conservancy, http://hdl.handle.net/11299/172825 
Herring, S., Scheidt, L., Bonus, S., \& Wright, E. (2004). Bridging the gap: A genre analysis of Weblogs. Retrieved from http://www.blogninja.com/index.php

Higgins, E. (1989). Continuities and discontinuities in self-regulatory and self-evaluative processes: A developmental theory relating self and affect. Journal of Personality, 57(2), 407-444.

Hiscock, H., \& Wake, M. (2001). Infant sleep problems and postnatal depression: A community-based study. Pediatrics, 107(6), 1317-1323.

Hochschild, A., \& Machung, A. (2012). The second shift: Working families and the revolution at home. New York, NY: Penguin.

Hock, E., \& Lutz, W. (2001). Peer rejection in childhood: Effects on maternal depression and behavior problems in toddlers. The Journal of Genetic Psychology, 162(2), 167-177.

Hock, E., Schirtzinger, M., \& Lutz, W. (1992). Dimensions of family relationships associated with depressive symptomatology in mothers of young children. Psychology of Women Quarterly, 16, 229-241.

Horrigan, J. (2001). Online communities: Networks that nurture long-distance relationships and local ties. Washington, DC: Pew Internet and American Life Project. Retrieved from http://www.pewinternet.org/pdfs/ PIP_Communities_Report.pdfhttp://www.pewinternet.org/pdfs/http://www.pewin ternet.org/pdfs/

Horrigan, J., \& Rainie, L. (2002). Use of the internet at major life moments. Washington, DC: Pew Internet and American Life Project. Retrieved from http://www.pewinternet.org/pdfs/ PIP_Major_Moments_Report.pdfhttp://www.pewinternet.org/pdfs/PIP_Major_Mome nts_Report.pdf

Hyde, J., Essex, M. J., Clark, R., \& Klein, M. H. (2001). Maternity leave, women's employment, and marital incompatibility. Journal of Family Psychology, 15(3), 476-491.http://www.pewinternet.org/pdfs/PIP_Major_Moments_Report.pdf

Hyde, J., Klein, M., Essex, M., \& Clark, R. (1995). Maternity leave and women's mental health. Psychology of Women Quarterly, 19, 257-285.

Ironson, G., O'Cleirigh, C., Leserman, J., Stuetzle, R., Fordiani, J., Fletcher, M., \& Schneiderman, N. (2013). Gender-specific effects of an augmented written emotional disclosure intervention on posttraumatic, depressive, and HIV-diseaserelated outcomes: a randomized, controlled trial. Journal of Consulting and Clinical psychology, 81(2), 284-298. 
Isaacowitz, D., Vaillant, G., \& Seligman, M. (2003). Strengths and satisfaction across the adult lifespan. International Journal of Aging and Human Development, 57(2), 181-201.

Israel-Cohen, Y., \& Kaplan, O. (2015, August 26). Traumatic stress during populationwide exposure to trauma in Israel: Gender as a moderator of the effects of marital status and social support. Stress and Health. doi:10.1002/smi.2647. [Epub ahead of print]

Johnston, C., \& Mash, E. (1989). A measure of parenting satisfaction and efficacy. Journal of Clinical Child Psychology, 18, 167-175.

Johnston, D. D., \& Swanson, D. H. (2006). Constructing the "good mother": The experience of mothering ideologies by work status. Sex Roles, 54(7-8), 509-519.

Karen, R. (1994). Becoming attached: First relationships and how they shape our capacity to love. New York, NY: Oxford.

Khazan, O. (2015, September 4). Can mommy bloggers still make a living? The Atlantic. Retrieved from http://www.theatlantic.com/business/archive/2015/09/mommybloggers-money/402535/

Kitzman, A. (2003). That different place: Documenting the self within online environments. Biography, 26(1), 48-67.

Knaevelsrud, C., \& Maercker, A. (2007). Internet-based treatment for PTSD reduces distress and facilitates the development of a strong therapeutic alliance: A randomized controlled clinical trial. BMC Psychiatry. Retrieved from http://bmcpsychiatry.biomedcentral.com/articles/10.1186/1471-244X-7-13

Kotila, L. E., Schoppe-Sullivan, S. J., \& Kamp Dush, C. M. (2013). Time in parenting activities in dual-earner families at the transition to parenthood. Family Relations, 62(5), 795-807.

Kruske, S., Schmied, V., Sutton, I., \& O'Hare, J. (2006). Mothers' experiences of facilitated peer support groups and individual child health nursing support: A comparative evaluation. Journal of Perinatal Education, 13(3), 31-38.

Leahy Warren, P. (2005). First-time mothers: Social support and confidence in infant care. Journal of Advanced Nursing, 50(5), 479-488.

Leahy-Warren, P. (2007). Social support for first-time mothers: An Irish study. The American Journal of Maternal/Child Nursing, 32(6), 368-374. 
Leahy-Warren, P., \& McCarthy, G. (2007). Postnatal depression: Prevalence, mothers' perspectives, and treatments. Archives of Psychiatric Nursing, 21(2), 91-100.

Leahy-Warren, P., McCarthy, G., \& Corcoran, P. (2011). Postnatal depression in firsttime mothers: Prevalence and relationships between functional and structural social support at 6 and 12 weeks postpartum. Archives of Psychiatric Nursing, 25(3), 174-184.

Leahy-Warren, P., McCarthy, G., \& Corcoran, P. (2012). First time mothers: Social support, maternal parental self efficacy and postnatal depression. Journal of Clinical Nursing, 21(3-4), 388-397. Retrieved from https://www.researchgate.net/ publication/50849524

Lenhart, A., \& Fox, S. (2006). Bloggers: A portrait of the internet's new storytellers. Washington, DC: Pew Internet \& American Life Project. Retrieved from http://www.pewinternet.org/

pdfs/PIP\%20Bloggers\%20Report\%20July\%2019\%20http://www.pewinternet.org/ pdfs/PIP\%20Bloggers\%20Report\%20July\%2019\%202006.pdf

Lenhart, A., Fox, S., Spooner, T., Rainie, L., \& Horrigan, J. (2000). Tracking online life: How women use the internet to cultivate relationships with family and friends. Washington, DC: Pew Internet and American Life Project. Retrieved from http://www.pewinternet.

org/pdfs/Report1.pdfhttp://www.pewinternet.org/pdfs/Report1.pdfhttp://www.pe winternet.org/pdfs/Report1.pdf

Levy-Shiff, R., Dimitrosky, L., Shulman, S., \& Har-Even, D. (1998). Cognitive appraisals, coping strategies, and support resources as correlates of parenting and infant development. Developmental Psychology, 34(6), 1417-1427.

Ley, B. (2011). Beyond discussion forums: The transmediated support culture of an online pregnancy and mothering group. In M. Moravec (Ed.), Motherhood online (pp. 23-45). Newcastle Upon Tyne, UK: Cambridge Scholars.

Liang, B., Tracy, A., Taylor, C. A., Williams, L. M., Jordan, J. V., \& Miller, J. B. (2002). The relational health indices: A study of women's relationships. Psychology of Women Quarterly, 26(1), 25-35.

Libertoff, K. (1980). Natural helping networks in rural youth and family services. Journal of Rural Community Psychology, 1(1), 4-17.

Lieberman, M. A., \& Goldstein, B. A. (2006). Not all negative emotions are equal: The role of emotional expression in online support groups for women with breast cancer. Psycho-Oncology, 15(2), 160-168. 
Lutz, W., \& Hock, E. (1998). Factors that influence depressive symptoms in mothers of infants: An interpersonal perspective. Psychology of Women Quarterly, 22, 499503.

MacQueen, G., \& Chokka, P. (2004). Special issues in the management of depression in women. Canadian Journal of Psychiatry, 49(Suppl. 1), 27-40.

Mantovani, F., Castelnuovo, G., Gaggioli, A., \& Riva, G. (2003). Virtual reality training for health-care professionals. CyberPsychology and Behavior, 6(4), 389-395.

Martire, L., Stephens, M., \& Townsend, A. (2000). Centrality of women's multiple roles: Beneficial and detrimental consequences for psychological well-being. Psychology and Aging, 15(1), 148-157.

Maushart, S. (1999). The mask of motherhood: How becoming a mother changes our lives and why we never talk about it. New York, NY: Penguin Books.

Mauthner, N. (1999). Feeling low and feeling really bad about feeling low: Women's experiences of motherhood and postpartum depression. Canadian Psychology, 40(2), 143-161.

Maxted, A., Dickstein, S., Miller-Loncar, C., High, P., Spritz, B., Liu, J., \& Lester, B. (2005). Infant colic and maternal depression. Infant Mental Health Journal, 26(1), $56-68$.

McAuley, C., Knapp, M., Beecham, J., McCurry, N., \& Sleed, M. (2004). Young families under stress: Outcomes and costs of home-start support. York, UK: Joseph Rowntree Foundation.

McDaniel, B., Coyne, S., \& Holmes, E. (2012). New mothers and media use: Associations between blogging, social networking, and maternal well-being. Maternal and Child Health Journal, 16, 1509-1517. doi:10.1007/s10995-0110918-2.

McGlone, F., Park, A., \& Roberts, C. (1999). Kinship and friendship: Attitudes and behaviour in Britain, 1986-1995. In S. McRae (Ed.), Changing Britain: Families and households in the 1990s (pp. 141-155). New York, NY: Oxford University Press.

McKenna, K., Green, A., \& Gleason, M. (2002). Relationship formation on the Internet: What's the big attraction? Journal of Social Issues, 58(1), 9-31.

McNaughton, D. (2000). A synthesis of qualitative home visiting research. Public Health Nursing, 17(6), 405-414. 
McNeil, L. (2003). Teaching an old genre new tricks: The diary on the internet. Biography, 26(1), 24-47.

Milgrom, J., \& Beatrice, G. (2003). Coping with the stress of motherhood: Cognitive and defense style of women with postnatal depression. Stress and Health, 19, 281287.

Miller, J. (1976). Toward a new psychology of women. Boston, MA: Beacon Press.

Miller, J. (1984). The development of women's sense of self (Work in Progress No. 12). Wellesley, MA: Stone Center Working Papers Series.

Mitchell, W., \& Green, E. (2002). "I don't know what I'd do without our Mam": Motherhood, identity and support networks. Sociological Review, 50(1), 1-22.

Mulvaney, C., \& Kendrick, D. (2005). Depressive symptoms in mothers of pre-school children. Social Psychiatry and Psychiatric Epidemiology, 40(3), 202-208.

Murray, S. L., \& Holmes, J. G. (1999). The (mental) ties that bind: Cognitive structures that predict relationship resilience. Journal of Personality and Social Psychology, 77(6), 1228-1244.

National Women's Health Resource Center. (2003). National women's health report. (2003). Red Bank, NJ: Author.

Nelson, S. K., Kushlev, K., \& Lyubomirsky, S. (2014). The pains and pleasures of parenting: When, why, and how is parenthood associated with more or less wellbeing? Psychological Bulletin, 140(3), 846-895.

Noor, N. (2003). Work-and family-related variables, work-family conflict and women's well-being: Some observations. Community, Work \& Family, 6(3), 297-319.

Nordenmark, M. (2004). Balancing work and family demands: Do increasing demands increase strain? A longitudinal study. Scandinavian Journal of Public Health, 32, 450-455.

Oakley, A. (1979). Becoming a mother. Oxford, UK: Martin Robertson.

Oakley, A. (1992). Social support and motherhood. Oxford, UK: Blackwell.

Oberman, Y., \& Josselson, R. (1996). Matrix of tensions: A model of mothering. Psychology of Women Quarterly, 20, 341-359. 
O’Connor, H., \& Madge, C. (2004). “My mum's thirty years out of date.” The role of the Internet in the transition to motherhood. Community, Work and Family, 7(3), 351-369.

Offer, S., \& Schneider, B. (2011). Revisiting the gender gap in time-use patterns multitasking and well-being among mothers and fathers in dual-earner families. American Sociological Review, 76(6), 809-833.

Olpin, M., \& Hesson, M. (2007). Stress management for life: A research-based experiential approach. Pacific Grove, CA: Brooks Cole.

Östberg, M. (1998). Parental stress, psychosocial problems and responsiveness in helpseeking parents with small (2-45 months old) children. Acta Paediatrica, 87(1), 69-76.

Pedersen, C., \& Boccia, M. (2002). Oxytocin links mothering received, mothering bestowed and adult stress responses. Stress, 5, 249-257.

Pedersen, D., \& Higber, K. (1969). Personality correlates of self-disclosure. Journal of Social Psychology, 78, 81-89.

Pennebaker, J. W. (1990). Opening up: The healing power of confiding in others. New York, NY: Morrow.

Pennebaker, J. W. (1997). Writing about emotional experiences as a therapeutic process. Psychological science, 8(3), 162-166.

Pennebaker, J. W. (2012). Opening up: The healing power of expressing emotions. New York, NY: Guilford Press.

Pennebaker, J. W., \& Segal, J. D. (1999). Forming a story: The health benefits of narrative. Journal of Clinical Psychology, 55, 1243-1254.

Perrin, A. (2015, October). Social media usage: 2005-2015 (Pew Research Center). Retrieved from http://www.pewinternet.org/2015/10/08/social-networking-usage2005-2015/

Perrin, A., \& Duggan, M. (2015, June). Americans' Internet access: 2000-2015 (Pew Research Center). Retrieved from http://www.pewinternet.org/2015/06/26/ americans-internet-access-2000-2015/

Pettigrew, S., Archer, C., \& Harrigan, P. (2015, December 10). A thematic analysis of mothers' motivations for blogging. Maternal and Child Health Journal, 1-7. 
Porter, C., \& Hsu, H. (2003). First-time mothers' perceptions of efficacy during the transition to motherhood: Links to infant temperament. Journal of Family Psychology, 17(1), 54-64.

Radloff, L. S. (1977). The CES-D Scale: A self-report depression scale for research in the general population. Applied Psychological Measurement, 1, 385-401. doi:10.1177/014662167700100306

Rainie, L. (2005). The state of blogging. Washington, DC: Pew Internet and American Life Project. Retrieved from http://www.pewinternet.org/pdfs/PIP_blogging_data.pdf

Raley, S., Bianchi, S. M., \& Wang, W. (2012). When do fathers care? Mothers' economic contribution and fathers' involvement in child care. American Journal of Sociology, 117(5), 1422-1459.

Rapoport, R., Bailyn, L., Fletcher, J., \& Pruitt, B. (2002). Beyond work-family balance: Advancing gender equity and workplace performance. San Francisco, CA: Jossey-Bass.

Rogers, C. (1980). A way of being. New York, NY: Houghton Mifflin Harcourt.

Rollins, J., Saris, R., \& Johnston-Robledo, I. (2001). Low-income women speak out about housing: A high-stakes game of musical chairs. Journal of Social Issues, 57, 277-298.

Rosal, M., King, J., Ma, Y., \& Reed, G. (2004). Stress, social support, and cortisol: Inverse associations? Behavioral Medicine, 30, 11-21.

Rowe, J., Barnes, M., \& Sutherns, S. (2013). Supporting maternal transition: Continuity, coaching, and control. The Journal of Perinatal Education, 22(3), 145.

Ruble, D., Fleming, A., Hackel, L., \& Stangor, C. (1988). Changes in the marital relationship during the transition to first time motherhood: Effects of violated expectations concerning division of household labor. Journal of Personality and Social Psychology, 55(1), 78-87.

Salmela-Aro, K., Nurmi, J., Saisto, T., \& Halmesmaki, E. (2001). Goal reconstruction and depressive symptoms during the transition to motherhood: Evidence from two cross-lagged longitudinal studies. Journal of Personality and Social Psychology, $81(6), 385-431$.

Saris, R., \& Johnston-Robledo, I. (2000). Poor women are still shut out of mainstream psychology. Psychology of Women Quarterly, 24, 233-235. 
Schmidt, J. (2007). Blogging practices: An analytical framework. Journal of ComputerMediated Communication, 12(4), 1409-1427.

Schoppe-Sullivan, S. J., \& Mangelsdorf, S. C. (2013). Parent characteristics and early coparenting behavior at the transition to parenthood. Social Development, 22(2), 363-383.

Schoutrop, M., Lange, A., Hanewald, G., Duurland, C., \& Bermond, B. (1997). The effects of structured writing assignments on overcoming major stressful events: An uncontrolled study. Clinical Psychology and Psychotherapy, 4(3), 179-185.

Schwarz, B., Trommsdorff, G., Albert, I., \& Mayer, B. (2005). Adult parent-child relationships: Relationship quality, support, and reciprocity. Applied Psychology: An International Review, 54(3), 396-417.

Sepa, A., Frodi, A., \& Ludvigsson, J. (2004). Psychosocial correlates of parenting stress, lack of support and lack of confidence/security. Scandinavian Journal of Psychology, 45(2), 169-179.

Sharp, C., Kim, S., Herman, L., Pane, H., Reuter, T., \& Strathearn, L. (2014). Major depression in mothers predicts reduced ventral striatum activation in adolescent female offspring with and without depression. Journal of Abnormal Psychology, 123(2), 298-309.

Sharp, H., \& Bramwell, R. (2004). An empirical evaluation of a psychoanalytic theory of mothering orientation: Implications for the antenatal prediction of postnatal depression. Journal of Reproductive and Infant Psychology, 22(2), 71-89.

Shields, M., \& Wooden, M. (2003, February). Marriage, children and subjective wellbeing. Paper presented at the Eighth Australian Institute of Family Studies Conference, Melbourne, Australia.

Short, S., Goldscheider, F., \& Torr, B. (2006). Less help for mother: The decline in coresidential female support for the mothers of young children, 1880-2000. Demography, 43(4), 617-629.

Silver, E., Heneghan, A., Bauman, L., \& Stein, R. (2006). The relationship of depressive symptoms to parenting competence and social support in inner-city mothers of young children. Maternal and Child Health Journal, 10(1), 105-112.

Simonds, S. (2001). Depression and women: An integrative treatment approach. New York, NY: Springer.

Simpson, P., \& Stroh, L. (2004). Gender differences: Emotional expression and feelings of inauthenticity. Journal of Applied Psychology, 89(4), 715-721. 
Slootjes, H., McKinstry, C., \& Kenny, A. (2015). Maternal role transition: Why new mothers need occupational therapists. Australian Occupational Therapy Journal, 63(2), 130-133 doi:10.1111/1440-1630.12225

Sockol, L. E., Epperson, C. N., \& Barber, J. P. (2014). The relationship between maternal attitudes and symptoms of depression and anxiety among pregnant and postpartum first-time mothers. Archives of Women's Mental Health, 17(3), 199-212.

Sorapure, M. (2003). Screening moment, scrolling lives: Diary writing on the Web. Biography, 26(1), 1-24.

Spinelli, M., Poehlmann, J., \& Bolt, D. (2013). Predictors of parenting stress trajectories in premature infant-mother dyads. Journal of Family Psychology, 27(6), 873-883.

Spitzmueller, C., Wang, Z., Zhang, J., Thomas, C. L., Fisher, G. G., Matthews, R. A., \& Strathearn, L. (2015, Nov 4). Got milk? Workplace factors related to breastfeeding among working mothers. Journal of Organizational Behavior. doi:10.1002/job.2061

Steinbeis, N., Engert, V., Linz, R., \& Singer, T. (2015). The effects of stress and affiliation on social decision-making: Investigating the tend-and-befriend pattern. Psychoneuroendocrinology, 62, 138-148.

Stevens, D., Kiger, G., \& Riley, P. (2001). Working hard and hardly working: Domestic labor and marital satisfaction among dual-earner couples. Journal of Marriage and Family, 63, 514-526.

Strazdins, L., Galligan, R., \& Scannell, E. (1997). Gender and depressive symptoms: Parents' sharing of instrumental and expressive tasks when their children are young. Journal of Family Psychology, 11(2), 222-233.

Surrey, J. (1983). The relational self in women: Clinical implications. Work in Progress No. 82-02. Wellesley, MA: Stone Center Working Paper Series.

Surrey, J. (1985). Self-in-relation. A theory of women's development. Work in Progress No. 13. Wellesley, MA: Stone Center Working Papers Series.

Taylor, S., \& Klein, L. (2000). Biobehavioral responses to stress in females. Tend-andbefriend, not fight-or-flight. Psychological Review, 107(3), 411-429.

Troll, L. (1987). Gender differences in cross-generation networks. Sex Roles, 17(11/12), 751-766. 
Turner, H. (2006). Stress, social resources, and depression among never-married and divorced rural mothers. Rural Sociology, 71(3), 479-504.

Umberson, D. (1989). Relationships with children: Explaining parents' psychological well-being. Journal of Marriage and Family, 51, 999-1012.

Vandewater, E., Ostrove, J., \& Stewart, A. (1997). Predicting women's well-being in midlife: The importance of personality development and social role involvements. Journal of Personality and Social Psychology, 72(5), 1147-1160.

Velaga, N. R., Beecroft, M., Nelson, J. D., Corsar, D., \& Edwards, P. (2012). Transport poverty meets the digital divide: Accessibility and connectivity in rural communities. Journal of Transport Geography, 21, 102-112.

Weis, K. L., \& Ryan, T. W. (2012). Mentors offering maternal support: A support intervention for military mothers. Journal of Obstetric, Gynecologic, and Neonatal Nursing, 41(2), 303-314.

Whitney, R. V., \& Smith, G. (2015). Emotional disclosure through journal writing: Telehealth intervention for maternal stress and mother-child relationships. Journal of Autism and Developmental Disorders, 45(11), 3735-3745.

Williams, J., \& Cooper, H. (2004). The public policy of motherhood. Journal of Social Issues, 60(4), 849-865.

Winkler, A., Dörsing, B., Rief, W., Shen, Y., \& Glombiewski, J. A. (2013). Treatment of Internet addiction: A meta-analysis. Clinical Psychology Review, 33(2), 317-329.

Wolf, N. (2003). Misconceptions: Truth, lies, and the unexpected on the journey to motherhood. New York, NY: Anchor.

Wolfson, A., Lacks, P., \& Futterman, A. (1992). Effects of parent training on infant sleeping patterns, parent's stress, and perceived parental competence. Journal of Consulting and Clinical Psychology, 60(1), 41-48.

Yavorsky, J. E., Kamp Dush, C. M., \& Schoppe-Sullivan, S. J. (2015). The production of inequality: The gender division of labor across the transition to parenthood. Journal of Marriage and Family, 77(3), 662-679.

Yazdanfar, M., Manshaee, G., Herris, M. A., Alipour, A., \& Noorbala, A. A. (2015). The effectiveness of written emotional disclosure training on psychological well-being and quality of life in psychosomatic disorders. Journal of Nervous and Mental Disease, 193(6), 425-426. 
Young, M., Wallace, J. E., \& Polachek, A. J. (2013). Gender differences in perceived domestic task equity: A study of professionals. Journal of Family Issues, 36(13), 1751-1781.

Zimet, G. D., Dahlem, N. W., Zimet, S. G., \& Farley, G. K. (1988). The multidimensional scale of perceived social support. Journal of Personality Assessment, 52, 30-41.

Zimet, G. D., Powell, S. S., Farley, G. K., Werkman, S., \& Berkoff, K. A. (1990). Psychometric characteristics of the multidimensional scale of perceived social support. Journal of Personality Assessment, 55, 610-617.

Zimmer, K., \& Minkovitz, C. (2003). Maternal depression: An old problem that merits increased recognition by child healthcare practitioners. Current Opinion in Pediatrics, 15, 536-540. 
Appendix A

Introduction Letter 
Dear

My name is Bobbie Sue Arias and I am a blogger, a mother of three young children and a Ph.D. student at Portland State University. I am currently completing my dissertation under the supervision of Dr. Eileen Brennan in the Social Work and Social Research program.

Because I am a mother, I have a particular interest in studying those things that make motherhood easier. The growing number of "Mommy Bloggers" has piqued my curiosity and I am interested in researching the benefits of blogging for parents of young children. Your blog is very popular and visited frequently by many mothers and I would like to ask for your help in recruiting participants for my research. Your help with this research would facilitate the participation of many parents, who likely have important things to say about what blogging may or may not provide for them as parents.

Your help would be greatly appreciated and go a long way toward increasing the knowledge of the ways in which blogging can be meaningful for people like mothers. If you should decide to be part of this research, you would receive a prepared statement informing potential participants about the study and directing them to an outside website by way of a hyperlink. You would be asked to post the information to your blog for the duration of one weekday. The hyperlink to the research website would not be used for any other purpose than to collect anonymous data from the participants and to fulfill the requirements for my dissertation. And, although I am a blogger, my personal blog would not be connected in any way to the research website.

Would you be interested in helping me in this research? Do you feel amenable to directing your readers to participate in this research?

I look forward to your response. Should you have any questions, concerns or suggestions, please do not hesitate to contact me.

Sincerely,

Bobbie Sue Arias, ABD, MSW

509-526-5603 
Appendix B

Informed Consent 


\section{Dear Blogger:}

My name is Bobbie Sue Arias, and I am a Ph.D. student at Portland State University. I am beginning a study on blogging among parents of young children, and I would like to invite you to participate.

You are being asked to take part because you are a blogger and a parent of young child[ren]. As part of the study, I am interested in your opinions about blogging and how it may or may not impact you as a parent. I am also interested in your experience as a parent in terms of whether or not you feel stress or depression in your daily life It is my hope that the information I collect will help us to better understand the ways in which blogging may benefit parents of young children. If you decide to participate, you will be +asked to complete a survey, which involves answering questions about blogging, stress, depression and parenting. It should take approximately 25 minutes to complete.

As a result of the study, you may feel uncomfortable or experience a sense of guilt in identifying your personal levels of stress, depression or uncertainty about parenting. However, I assure you that any information you provide will be anonymous. You may not receive any direct benefit from taking part in this study, but the study may help to increase knowledge that may help others in the future. Any information that is obtained in connection with this study and that can be linked to you or identify you will be kept confidential. Subject identities will be anonymous, as no subject identifiers will be connected to the survey.

Participation is entirely voluntary. Your decision to participate or not will not affect your relationship with the person who referred you, or with the researcher. If you decide to take part in the study, you may choose to withdraw at any time without penalty. Please keep a copy of this letter for your records.

If you have concerns or problems about your participation in this study or your rights as a research subject, please contact the Human subjects Research Review Committee, Office of Research and Sponsored Projects, 111 Cramer Hall, Portland State University, (503) 725-4288. If you have questions about the study itself, contact Bobbie Sue Arias at (509) 526-5603.

Sincerely,

Bobbie Sue Arias, ABD, MSW Graduate School of Social Work Portland State University 
Appendix C

Blog Relationships Survey 
Graduate School of Social Work

Portland State University

\section{Blog Relationships Survey}

Thank you for agreeing to participate in this research. There are several questions to follow. We are mindful of the fact that you have a busy and full life and have put effort into making these questions as brief as possible and easy to answer. This survey will take you approximately 25 minutes to complete. If you are interrupted and should need to stop taking this survey, you can click a "Get Code" button and you will be provided a code to input on your return visit so that you can start again where you left off. You may click the "Get Code" button at any time during the survey.

1. I agree to participate

Y Yes

No

Each new section of the survey will provide brief instructions to help guide you through. Please read each set of instructions carefully. Thank you for taking our survey!

\section{Section I: Participant \& Household}

First, we would like to ask a few questions about you and your household.

2. What is your gender?

Female

Male

3. What is your age?

4. What country are you from?

United States

Canada

England

Australia

Other 
5. How would you describe your primary race/ethnicity (Check all that apply)? African American American Indian/Native American Asian American/Pacific Islander Caucasian Latino/a American Other

6. Describe where you live. Suburban Urban Rural

7. How long have you lived in your current residence:

_months

-years

8. How many people are living at your residence?

9. How many children under age 18 live with you 4 days/wk or more?

10. How many preschool (5 and under) children live with you 4 days/wk or more?

If none: "Thank you for your time in taking this survey"

11. Please describe the preschool children living with you:

a. Child 1: i. Age:

ii. Is this child:

_Biological

Adopted

Stepchild

_Foster child

_Grandchild

b. Child 2: etc.

-Other

If any child is over 5 years old: "Thank you for your time in taking this survey" 
12. How long has (have) your preschool child(ren) been living with you? (Please choose the one answer that most closely matches your situation.)

a. Child 1:

Since their birth

Less than 6 months

6-11 months

1 year

2 years

3 years

4 years

5 years

$6+$ years

b. Child 2:

Since their birth

Less than 6 months

6-11 months

1 year

2 years

3 years

4 years

5 years

$6+$ years

c. Child 3: (etc.)

13. How many adults live at your place of residence 4 days/wk or more?

14. What percentage of the total childcare duties is your responsibility?

$\begin{array}{lllllllllll}0 & 10 & 20 & 30 & 40 & 50 & 60 & 70 & 80 & 90 & 100\end{array}$

15. What percentage of the total household duties/chores is your responsibility?

$\begin{array}{lllllllllll}0 & 10 & 20 & 30 & 40 & 50 & 60 & 70 & 80 & 90 & 100\end{array}$ 


\section{Section II: General Blogging \& Intensity}

Next, we would like to ask you some questions about blogging.

16. About how long have you been blogging?

_.Six months or less

_One year

2-3 years

4 years

5 years

-6+ years

17. How many blogs do you currently author (or co-author)?

_ One
_ Two
_ Three or more
_ Don't know

For the next few questions, please think only about your MAIN blog, the one you spend the most time on.

18. Are you the only author on that blog, or are there multiple authors?

_Only author

_Multiple authors

Don't know

19. Do you blog under your own name, or do you use a pseudonym or made-up name?

_Blog under own name

_Use pseudonym/made-up name

Don't know

20. How often do you typically post new material on your blog?

_Several times a day

About once a day

3-5 days a week

1-2 days a week

Once every few weeks

Less often

Don't know 
21. In a typical week, approximately how many hours do you spend working on your main blog?

Don't know

a. If you have other blogs, how many additional hours do you spend blogging in a typical week?

Does not apply to me

22. Where do you USUALLY blog from - home, work, or someplace else?

Home

Work

Someplace else

Both home and work equally

Don't know

[If "home" or "both home and work equally:"]

a. How does the computer you use at HOME connect to the Internet?

__Dial-up telephone line

_High-speed

__DSL-enabled phone line

Cable modem

_Wireless connection (either land-based or satellite)

Other

_T-1 fiber optic connection

Don't know

23. Does your blog include a list of links to other blogs, like a blog roll?

- Yes

No

Don't know

(If Yes)

a. Approximately how many links are on your blog roll or list?

_ Fewer than 10

10-49

50 or more

Don't know 
24. In a typical week, approximately how many hours do you spend reading other people's blogs?

\author{
Don’t know
}

25. How frequently do you read other people's blogs?

Several times a day

_About once a day

3-5 days a week

1-2 days a week

_Once every few weeks

Less often

Don't know

26. Who reads your blog?

_.Most people I personally know

Mostly people I have never met

Both equally

Don't know

27. Overall, would you say you blog...?

Mostly for yourself

Mostly for your audience

Both equally

Neither

Don't know

28. Do you allow comments on your blog?

Yes

-No

Don't know 


\section{Section III: Blog Motivation}

29. Which of the following three statements BEST describes what your blog means to you...?

-My blog is very important to me and it's a big part of my life

-My blog is like a hobby for me, and I enjoy working on it when I can

My blog is something I do, but not something I spend a lot of time on

None of theses

Don't know

30. Below are some reasons a person might blog. Please indicate how important each reason is to you PERSONALLY.

For each statement, use the following:

Not at all important to me $=0$

Slightly important to me $=1$

Somewhat important to me $=2$

Very important to me $=3$

Extremely important to me $=4$

a. To express yourself creatively
$-0$
$-$
$-2$
$-3$
$-4$

b. To influence the way other people think

$\begin{array}{lllll}-0 & -1 & -2 & -3 & -4\end{array}$

c. To motivate other people to action

$\begin{array}{lllll}-0 & -1 & -2 & -3 & -4\end{array}$

d. To document your personal experiences and share them with others
$-0$
1
$-2$
$-3$
$-4$

e. To share practical knowledge or skills with others
$-0$
$-1$
$-2$
$-3$
$-4$

f. To network or to meet new people
$-0$

1

$-2$

$-3$

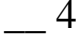

g. To entertain people

$\begin{array}{lllll}0 & -1 & -2 & -{ }^{3} & -{ }^{4}\end{array}$


h. To stay in touch with friends and family

$\begin{array}{lllll}-0 & -1 & -2 & -3 & -{ }^{4}\end{array}$

i. To make money
$-0$
$-1$
$-2$
$-3$
$-4$

j. To store resources or information that is important to you
$-0$
$-1$
$-2$
$-3$
$-4$

k. To connect with people who are similar to you

$\begin{array}{lllll}-0 & -1 & -2 & -3 & -{ }^{4}\end{array}$

1. To gain knowledge about parenting
$-0$
1
$-2$
$-3$
$-4$

$\mathrm{m}$. To learn more about parenting tasks (potting training, how to treat chickenpox, etc.)
$-0$
$-1$
$-2$
$-3$
$-4$

n. To feel understood

$\begin{array}{lllll}-0 & -1 & -2 & -{ }^{3} & -4\end{array}$

o. To vent frustrations about parenting
$-0$
1
$-2$
$-3$
$-4$

p. To feel more confident as a parent
$-0$
1
$-2$
$-3$
$-4$

q. To see how others feel about parenting

$\begin{array}{lll}0 & 1\end{array}$

$-2$

$-3$

$-4$

r. To see how others handle the stress of parenting
$-0$
1
$-2$
$-3$
$-4$

s. To see how others express their joy of parenting
$-0$
$-2$
$-3$
$-4$

t. To document your life in order to pass it on to your children
$-0$
1
$-2$
$-3$
$-4$

u. In your own words, please describe why you blog. 
31. Are you able to blog as much as you want to?

-Yes

No

Don't know

(If answered "No")

a. If you could spend more time blogging, would you?

Yes

No

Don't know

32. If you had to say, do you think you'll still be blogging a year from now?

Yes

No

Have already stopped

Don't know

a. Over the past 6 months, would you say that the total amount of time you spend blogging has:

_increased
_ decreased
_ stayed the same
_don't know

\section{(If answered "increased" or "decreased")}

b. Why would you say your blogging has increased/decreased? 


\section{Section IV: Competency}

33. Please answer the following questions using the following scale:

$\overline{\text { (strongly disagree) }}^{2} \quad-^{3} \quad-^{4} \quad \leftarrow^{5} \underset{\text { (strongly agree) }}{-6}$

a. The problems of taking care of a child are easy to solve once you know how your actions affect your child, an understanding I have acquired.
$-1$
$-2$
$-3$
4
$-5 \quad-6$

b. Even though being a parent could be rewarding, I am frustrated now while my child is at his/her present age.
$-1$
$-2$
3
$-^{4}-\square^{5} \quad-^{6}$

c. I go to bed the same way I wake up in the morning, feeling I have not accomplished a whole lot.
$-1$
$-2$
$-3$
$-4$
$-5-6$

d. I don not know why it is, but sometimes when I'm supposed to be in control, I feel more like the one being manipulated.

$\begin{array}{lllllll}-1 & -2 & -3 & -4 & -^{5} & -6\end{array}$

e. My mother/father was better prepared to be a good mother/father than I am.

$\begin{array}{lllllll}-1 & -2 & -3 & -4 & -5 & -6\end{array}$

f. I would make a fine model for a new mother/father to follow in order to learn what she/he would need to know in order to be a good parent.
$-1$
$-$
$-^{3}$
$-$
$-5-6$

g. Being a parent is manageable, and any problems are easily solved.
$-1$
$-2$
3
$-4$
$-5 \quad-6$

h. A difficult problem in being a parent is not knowing whether you're doing a good job or a bad one.
$-1$
$-2$
$-3$
$-4$
$-5$
$-6$

i. Sometimes I feel like I'm not getting anything done.
$-1$
$-2$
$-3$
$-4$
$-5 \quad-6$

j. I meet my own personal expectations for expertise in caring for my child.

$\begin{array}{lllllll}-1 & -2 & -3 & -4 & -5 & -6\end{array}$


k. If anyone can find the answer to what is troubling my child, I am the one.

$\begin{array}{llllll}-1 & -2 & -3 & -4 & { }^{5} & -6\end{array}$

1. My talents and interests are in other areas, not in being a parent.

$\begin{array}{lllllll}-1 & -2 & -3 & -4 & { }^{3} & -6\end{array}$

$\mathrm{m}$. Considering how long I've been a mother/father, I feel thoroughly familiar with this role.
$-1$
$-$
$-3$
$-4 \quad-5 \quad-6$

n. If being a mother/father of a child were only more interesting, I would be motivated to do better job as a parent.
$-1$
$-2$
$-3$
$-$
$-5 \quad-6$

o. I honestly believe I have all the skills necessary to be a good mother/father to my child.
$-1$
$-2$
$-3$
4
$-5 \quad-6$

p. Being a parent makes me tense and anxious.

$\begin{array}{lllllll}-1 & -2 & -3 & -4 & -5 & -6\end{array}$

q. Being a good mother/father is a reward in itself.

$\begin{array}{lllllll}-1 & -2 & -3 & -4 & { }^{5} & -6\end{array}$




\section{Section V: Stress}

34. The next set of questions asks you about your feelings and thoughts during the last month. In each case, please indicate how often you felt or thought a certain way.

a. In the last month, how often have you been upset because of something that happened unexpectedly? _never ___almost never___sometimes ___fairly often __ very often

b. In the last month, how often have you felt that you were unable to control the important things in your life? never___almost never ___ sometimes__fairly often __ very often

c. In the last month, how often have you felt nervous and "stressed"?

__never__almost never___sometimes__fairly often __ very often

d. In the last month, how often have you felt confident about your ability to handle your personal problems?

_ never __almost never ___ sometimes __ fairly often __ very often

e. In the last month, how often have you felt that things were going your way? never__almost never __ sometimes__fairly often __ very often

f. In the last month, how often have you found that you could not cope with all the things that you had to do? never__almost never___sometimes __ fairly often __ very often

g. In the last month, how often have you been able to control irritations in your life? _never__almost never ___sometimes __ fairly often __ very often

h. In the last month, how often have you felt that you were on top of things? __ never __almost never___sometimes__fairly often __ very often

i. In the last month, how often have you been angered because of things that were outside of your control?

_ never __almost never ___ sometimes __ fairly often __ very often

j. In the last month, how often have you felt difficulties were piling up so high that you could not overcome them? never__almost never __ sometimes__fairly often __ very often 


\section{Section VI: Depression}

The next set of questions will ask you about your general mood and feelings. Please indicate the number which best describes how often you felt or behaved in this wayDURING THE PAST WEEK.

\begin{tabular}{|c|c|c|c|c|}
\hline 35. During the past week: & $\begin{array}{l}\text { Rarely or } \\
\text { none of the } \\
\text { time (less } \\
\text { than } 1 \text { day) } \\
\Downarrow\end{array}$ & $\begin{array}{l}\text { Some or } \\
\text { little of } \\
\text { the time } \\
(1-2 \\
\text { days) } \\
\\
\Downarrow\end{array}$ & $\begin{array}{l}\text { Occasionally } \\
\text { or a moderate } \\
\text { amount of } \\
\text { time (3-4 } \\
\text { days) } \\
\Downarrow\end{array}$ & $\begin{array}{l}\text { Most or all } \\
\text { of the time } \\
\text { (5-7 days) } \\
\\
\Downarrow\end{array}$ \\
\hline $\begin{array}{l}\text { a. I was bothered by things } \\
\text { that usually don't bother me. }\end{array}$ & 1 & 2 & 3 & 4 \\
\hline $\begin{array}{l}\text { b. I did not feel like eating; } \\
\text { my appetite was poor }\end{array}$ & & & & \\
\hline $\begin{array}{l}\text { c. I felt that I could not shake } \\
\text { off the blues even with help } \\
\text { from my family or friends }\end{array}$ & & & & \\
\hline $\begin{array}{l}\text { d. I felt that I was just as good } \\
\text { as other people }\end{array}$ & & & & \\
\hline $\begin{array}{l}\text { e. I had trouble keeping my } \\
\text { mind on what I was doing }\end{array}$ & & & & \\
\hline f. I felt depressed & & & & \\
\hline $\begin{array}{l}\text { g. I felt that everything I did } \\
\text { was an effort }\end{array}$ & & & & \\
\hline $\begin{array}{l}\text { h. I felt hopeful about the } \\
\text { future }\end{array}$ & & & & \\
\hline $\begin{array}{l}\text { i. I thought my life had been a } \\
\text { failure }\end{array}$ & & & & \\
\hline j. I felt fearful & & & & \\
\hline
\end{tabular}




\begin{tabular}{|l|l|l|l|l|}
\hline k. My sleep was restless & & & & \\
\hline I. I was happy & & & & \\
\hline m. I talked less than usual & & & & \\
\hline n. I felt lonely & & & & \\
\hline o. People were unfriendly & & & & \\
\hline p. I enjoyed life & & & & \\
\hline q. I had crying spells & & & & \\
\hline r. I felt sad & & & & \\
\hline s. I felt that people disliked me & & & & \\
\hline t. I could not get going & & & & \\
\hline
\end{tabular}




\section{Section VII: Social Support}

We are interested in how you feel about the following statements. Read each statement carefully.

36. Indicate how you feel about each statement, with:

"1" if you Very Strongly Disagree
"2" if you Strongly Disagree
"3" if you Mildly Disagree
"4" if you are Neutral
"5" if you Mildly Agree
"6" if you Strongly Agree
"7" if you Very Strongly Agree

a. There is a special person who is around when I am in need.

$\begin{array}{lllllll}1 & 2 & 3 & 4 & 5 & 6 & 7\end{array}$

b. There is a special person with whom I can share my joys and sorrows.

$\begin{array}{lllllll}1 & 2 & 3 & 4 & 5 & 6 & 7\end{array}$

c. My family really tries to help me.

$\begin{array}{lllllll}1 & 2 & 3 & 4 & 5 & 6 & 7\end{array}$

d. I get the emotional help and support I need from my family.

$\begin{array}{lllllll}1 & 2 & 3 & 4 & 5 & 6 & 7\end{array}$

e. I have a special person who is a real source of comfort to me.

$\begin{array}{lllllll}1 & 2 & 3 & 4 & 5 & 6 & 7\end{array}$

f. My friends really try to help me.

$\begin{array}{lllllll}1 & 2 & 3 & 4 & 5 & 6 & 7\end{array}$

g. I can count on my friends when things go wrong.

$\begin{array}{lllllll}1 & 2 & 3 & 4 & 5 & 6 & 7\end{array}$

h. I can talk about my problems with my family.

$\begin{array}{lllllll}1 & 2 & 3 & 4 & 5 & 6 & 7\end{array}$

i. I have friends with whom I can share my joys and sorrows.

$\begin{array}{lllllll}1 & 2 & 3 & 4 & 5 & 6 & 7\end{array}$


j. There is a special person in my life who cares about my feelings.

$$
\begin{array}{lllllll}
1 & 2 & 3 & 4 & 5 & 6 & 7
\end{array}
$$

k. My family is willing to help me make decisions.

$\begin{array}{lllllll}1 & 2 & 3 & 4 & 5 & 6 & 7\end{array}$

1. I can talk about my problems with my friends.

$\begin{array}{lllllll}1 & 2 & 3 & 4 & 5 & 6 & 7\end{array}$

m. My blog-friends really try to help me out.

$\begin{array}{lllllll}1 & 2 & 3 & 4 & 5 & 6 & 7\end{array}$

n. I can count on my blog-friends when things go wrong.

$\begin{array}{lllllll}1 & 2 & 3 & 4 & 5 & 6 & 7\end{array}$

o. I have blog-friends with whom I can share my joys and sorrows.

$\begin{array}{lllllll}1 & 2 & 3 & 4 & 5 & 6 & 7\end{array}$

\section{Peer, Mentor \& Community Support}

\section{PEER}

The next set of questions will ask you about your relationship with fellow bloggers.

37. For each statement, please indicate the number that best applies to your relationship with a close blog friend.

$$
1=\text { Never } ; \quad 2=\text { Seldom } ; \quad 3=\text { Sometimes } ; \quad 4=\text { Often } ; \quad 5=\text { Always }
$$

a. Even when I have difficult things to share, I can be honest and real with my friend.

b. After a conversation with my friend, I feel uplifted.

c. The more time I spend with my friend, the closer I feel to him/her.

d. I feel understood by my friend.

e. It is important to us to make our friendship grow.

f. I can talk to my friend about our disagreements without feeling judged.

g. My friendship inspires me to seek other friendships like this one.

h. I am uncomfortable sharing my deepest feelings and thoughts with my friend. ®

i. I have a greater sense self-worth through my relationship with my friend.

j. I feel positively changed by my friend.

k. I can tell my friend when he/she has hurt my feelings.

1. My friendship causes me to grow in important ways. 
36x. Is there a fellow blogger you consider to be an important mentor?

-Yes

No

(Pop-up box with re-direct: If "yes" proceed to Mentor Index, if "no" proceed to Community Index)

\section{MENTOR:}

38. For each statement below, please indicate the number that best applies to your relationship with your most important blog mentor.

$1=$ Never $; \quad 2=$ Seldom $; \quad 3=$ Sometimes $; \quad 4=$ Often $; \quad 5=$ Always

a. I can be genuinely myself with my mentor.

b. I believe my mentor values me as a whole person (e.g., professionally/academically and personally).

c. My mentor's commitment to and involvement in our relationship exceeds that required by his/her social/professional role.

d. My mentor shares stories about his/her own experiences with me in a way that enhances my life.

e. I feel as though I know myself better because of my mentor.

f. My mentor gives me emotional support and encouragement.

g. I try to emulate the values of my mentor (such as social, academic, religious, physical/athletic).

h. I feel uplifted and energized by interactions with my mentor.

i. My mentor tries hard to understand my feeling and goals (academic, personal, or whatever is relevant).

j. My relationship with my mentor inspires me to seek other relationships like this one.

k. I feel comfortable expressing my deepest concerns to my mentor.

1. Do you know the age of this mentor?

-Yes

_No

m. (If yes) How old are they? 


\section{COMMUNITY:}

39. For each statement below, please indicate the number that best applies to your relationship with or involvement in your blogging community.

$$
1=\text { Never } ; \quad 2=\text { Seldom } ; \quad 3=\text { Sometimes } ; \quad 4=\text { Often } ; \quad 5=\text { Always }
$$

a. I feel a sense of belonging to this community.

b. I feel better about myself after my interactions with this community.

c. If members of this community know something is bothering me, they ask me about it.

d. Members of this community are not free to just be themselves. ®

e. I feel understood by members of this community

f. I feel mobilized to personal action after meetings with this community.

g. There are parts of myself I feel I must hide from the community. ${ }^{\circledR}$

$\mathrm{h}$. It seems as if people in this community really like me as a person.

i. There is a lot of backbiting and gossiping in this community. $(\mathbb{}$

j. Members of this community are very competitive with each other. ${ }^{\circledR}$

k. I have a greater sense of self-worth through my connection with this community.

1. My connections with this community are so inspiring that they motivate me to pursue relationships with other people outside this community.

$\mathrm{m}$. This community has shaped my identity in many ways.

n. This community provides me with emotional support. 
40. For each statement below, please indicate the number that best applies to your relationship with your mother.

$$
1 \text { = Never; } 2 \text { =Seldom; } 3 \text { = Sometimes; } 4 \text { = Often; } 5 \text { = Always }
$$

1. I can be genuinely myself with my mother.

m. I believe my mother values me as a whole person (e.g., professionally/academically and personally).

n. My mother's commitment to and involvement in our relationship exceeds that required by his/her social/professional role.

o. My mother shares stories about his/her own experiences with me in a way that enhances my life.

p. I feel as though I know myself better because of my mother.

q. My mother gives me emotional support and encouragement.

r. I try to emulate the values of my mother (such as social, academic, religious, physical/athletic).

s. I feel uplifted and energized by interactions with my mother.

t. My mother tries hard to understand my feeling and goals (academic, personal, or whatever is relevant).

u. My relationship with my mother inspires me to seek other relationships like this one.

v. I feel comfortable expressing my deepest concerns to my mother.

\section{Section VIII: Demographics}

Please answer these last few questions about yourself:

41. Are you a single parent?

Yes

42. What is your marital status?

Now married

Unmarried, Living together

Widowed

Divorced

Separated

Never Married 
43. Describe your education.

Some high school

High school graduate

Some college

College graduate

Graduate school

44. Which of the following best describes your current main daily activities and/or responsibilities? (Please check all that apply to you.)

Working full time

Working part-time

Unemployed or laid off

Looking for work

Keeping house or raising children full-time

Retired

45. What is your annual household income from all contributing members?

Less than $\$ 5,000$

$\$ 5,000$ through $\$ 11,999$

$\$ 12,000$ through $\$ 15,999$

$\$ 16,000$ through $\$ 24,999$

$\$ 25,000$ through $\$ 34,999$

$\$ 35,000$ through $\$ 49,999$

$\$ 50,000$ through $\$ 74,999$

$\$ 75,000$ through $\$ 99,999$

$\$ 100,000$ and greater

Don't know

No response

Thank you very much for your participation in this research. We sincerely appreciate your willingness to tell us about yourself by answering our questions. Your participation has been very valuable.

Thanks again! 